\title{
Shrub and tree expansion in Siberian Low Arctic ecotones since the 1960s
}

\author{
Gerald Verner Frost, Jr. \\ East Point, Georgia
}

Bachelor of Science, Biological Sciences, University of Alaska Fairbanks, 1999

A Dissertation presented to the Graduate Faculty of the University of Virginia in Candidacy for the Degree of Doctor of Philosophy

\section{Department of Environmental Sciences}

\section{University of Virginia}

July 2013

Dr. Howard E. Epstein

Dr. Joseph C. Zieman

Dr. Herman H. Shugart

Dr. Jennie L. Moody

Dr. Laura F. Galloway

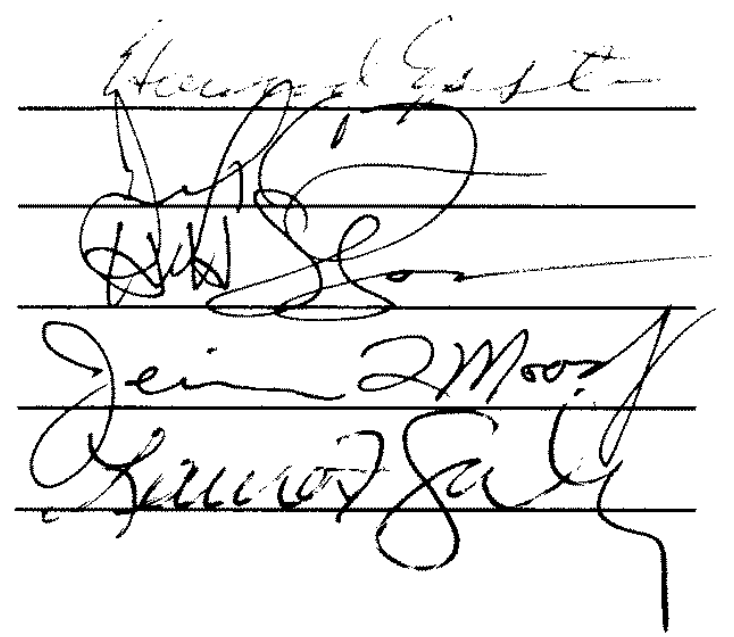




\section{ABSTRACT}

Patterns of tree and tall shrub occurrence form conspicuous and dynamic ecological boundaries at the interface of the Arctic tundra and boreal forest biomes. Reports from the North American and European Arctic indicate that climatic warming over the last century is promoting circumpolar tree and tall shrub increase in tundra ecotones, but little evidence exists for northern Siberia, despite its immense geographic extent. Here I address this knowledge gap, by examining recent changes in ecotonal landscapes spanning the Siberian Low Arctic utilizing three approaches: (1) spatially-explicit comparisons of high-resolution satellite imagery from the mid-1960s, and recent years for eleven Siberian tundra ecotones; (2) field studies of landscape-scale mechanisms that facilitate shrub proliferation in permafrost patterned-ground ecosystems; and (3) spatiotemporal analyses of Landsat-observed trends in tundra vegetation productivity and shrub-driven land-cover change in northwest Siberia since 1984. Tree and tall shrub abundance increased in nine of eleven Siberian ecotones since the 1960s; however, most land-cover changes were driven by the proliferation of tall shrubs, particularly alder (Alnus), rather than trees. Alder increase was greatest in the northwest Siberian region, and was largely linked to permafrost disturbance processes that facilitate shrub recruitment within widespread mosaics of small, disturbed microsites in patterned-ground landscapes. Landsat time-series of the normalized difference vegetation index (NDVI), a spectral metric of vegetation biomass, indicate increasing tundra productivity in most of northwest Siberia since 1984, but there was high regional variability linked to differences in landscape physiography, soil properties, and permafrost geomorphology. Increases in 
shrubland productivity were ubiquitous, however, indicating that shrubland expansion is occurring throughout the region. The primary conclusions I reached are that (1) recent tree and shrub expansion is virtually ubiquitous in Siberian ecotones, with rapid changes evident in moister, shrub-dominated regions; (2) disturbed landforms in general, and patterned-ground landscapes in particular, are highly susceptible to shrub expansion; and (3) at least in the near-term, increasing shrub abundance within the present-day tundra biome is likely to be a dominant form of high-latitude environmental change, rather than shifts in the spatial extent of the Arctic tundra and boreal forest biomes per se. 
"The power and enchantment of the taiga lie not in giant trees or the silence of the graveyard, but in the fact that only birds of passage know where it ends."

- Anton Chekhov, The Island: A Journey to Sakhalin (1890) 
TABLE OF CONTENTS

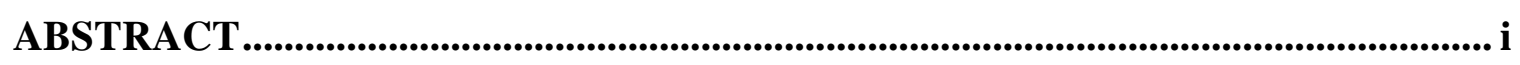

TABLE OF CONTENTS ................................................................................................................ v

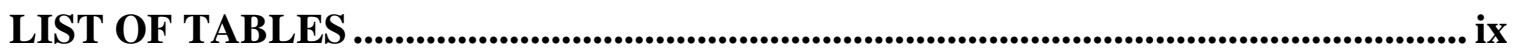

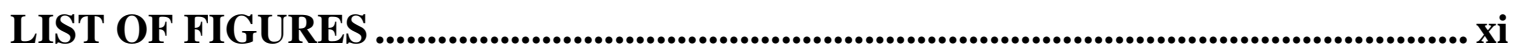

ACKNOWLEDGEMENTS ........................................................................................ xiv

CHAPTER 1 - GENERAL INTRODUCTION ...................................................... 1

CHAPTER 2 - TALL SHRUB AND TREE EXPANSION IN SIBERIAN TUNDRA ECOTONES SINCE THE 1960'S ............................................................................ 13

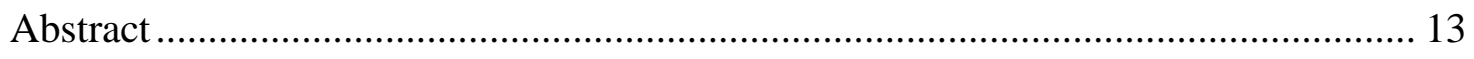

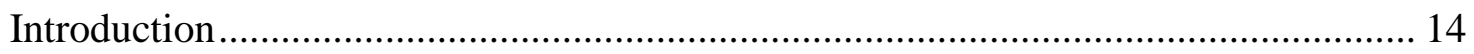

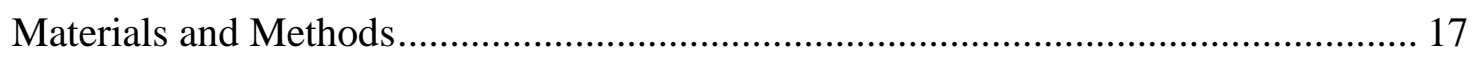

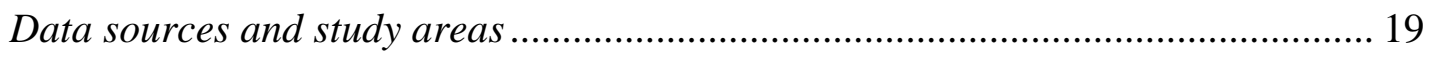

Retrospective analysis of VHR imagery ........................................................... 25

Physiographic stratification of landscapes......................................................... 26

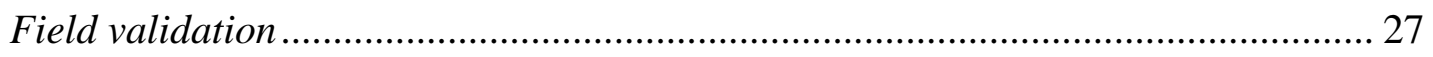

Climate effects on ecotonal vegetation dynamics .................................................... 27

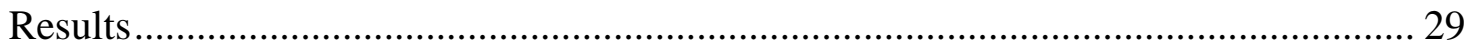

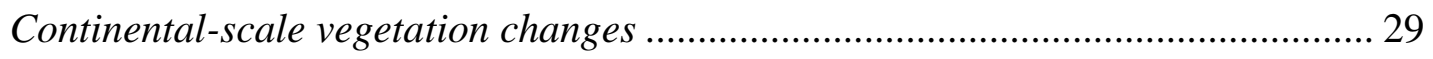


Landscape heterogeneity of ecotonal vegetation change ....................................... 32

Climate effects on ecotonal vegetation dynamics ................................................ 33

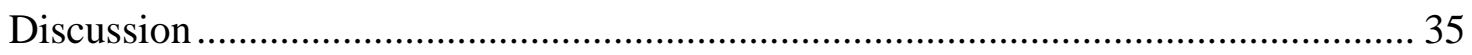

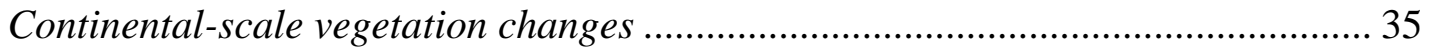

Landscape heterogeneity of ecotonal vegetation change ...................................... 37

Climate effects on ecotonal vegetation dynamics .............................................. 41

Landscape susceptibility to advance of boreal vegetation .................................... 43

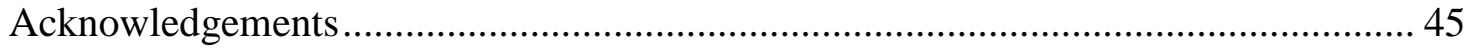

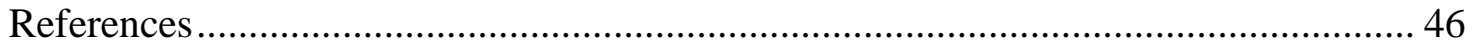

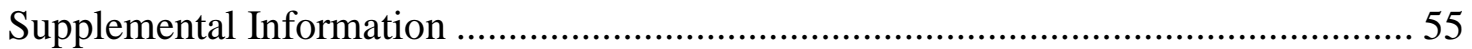

\section{CHAPTER 3 - PATTERNED-GROUND FACILITATES SHRUB EXPANSION IN}

LOW ARCTIC TUNDRA .......................................................................66

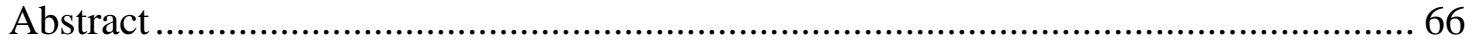

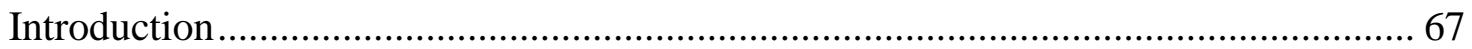

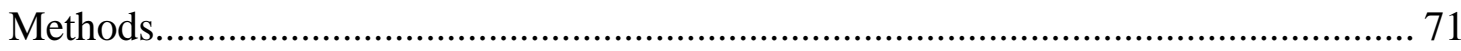

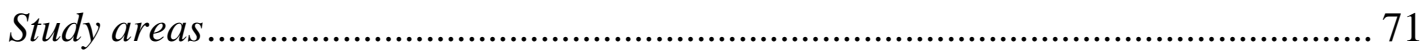

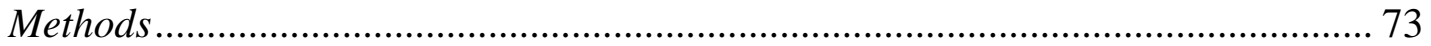

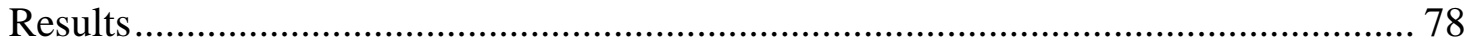

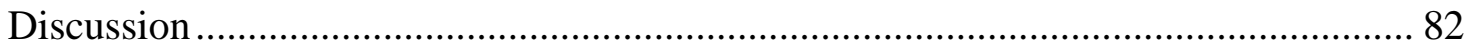




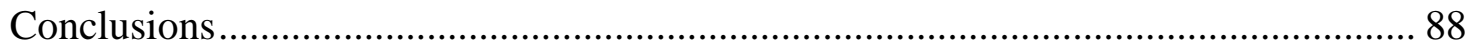

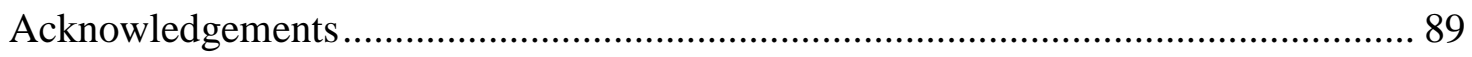

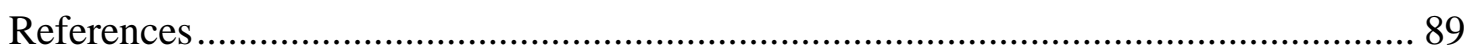

\section{CHAPTER 4 - LANDSCAPE AND REGIONAL-SCALE VARIABILITY OF} VEGETATION DYNAMICS AND SHRUB PROLIFERATION IN NORTHWEST SIBERIAN ARCTIC TUNDRA ......................................... 99

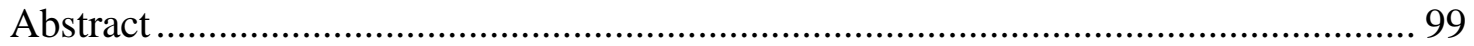

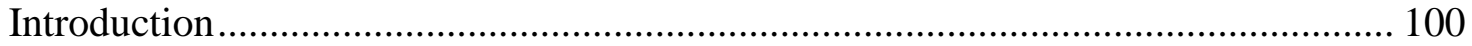

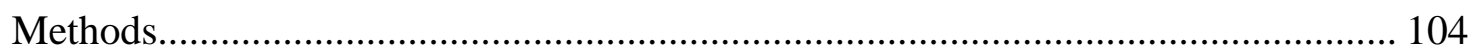

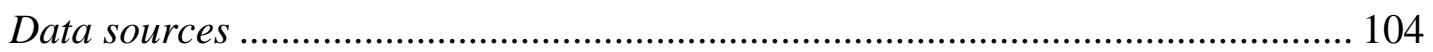

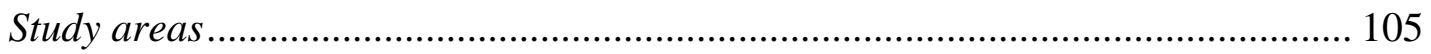

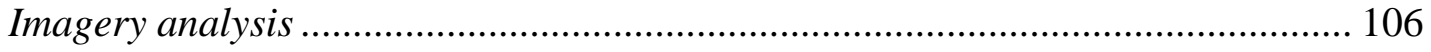

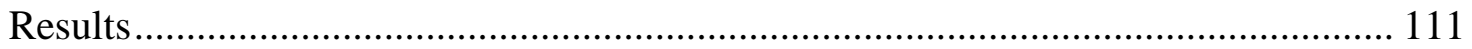

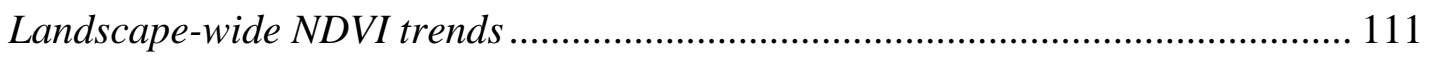

Shrubland spectral trends ....................................................................... 112

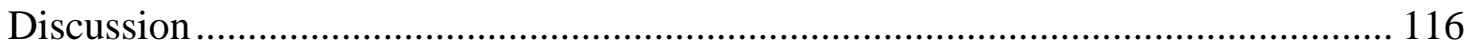

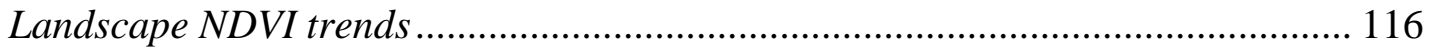

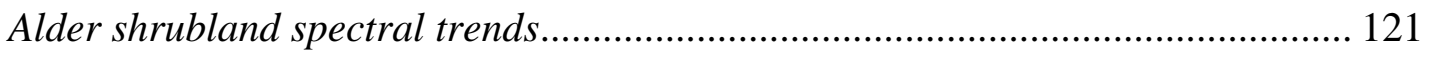

Agreement with other NDVI time-series ...................................................... 123 
Acknowledgements

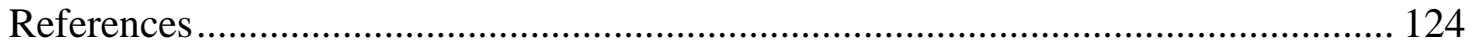

CHAPTER 5 - SYNTHESIS AND CONCLUSIONS .............................................. 131

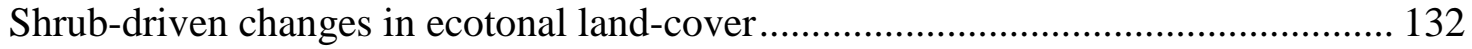

Quaternary perspectives on recent vegetation changes .................................... 132

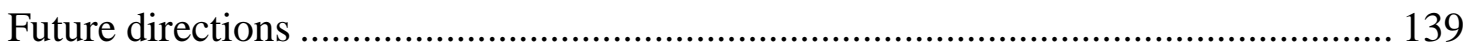

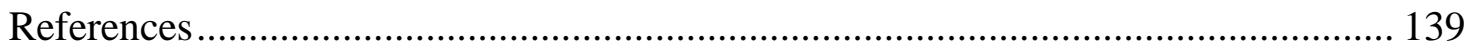




\section{LIST OF TABLES}

1.1 Summary of dissertation research components, questions, and approaches........8

2.1 Summary of study landscape location, elevation, area, and means of annual temperature, June-July-August temperature, December-January-February temperature, and annual precipitation..................................18

2.2 Period-of-record, acquisition dates, and sources of historical VHR satellite imagery used to compare tall shrub and tree cover at the study landscapes.......23

2.3 Descriptions of physiographic units used to stratify the vegetation sampling-

points.

2.4 Summary of areal and percent change in tall shrub and tree cover at eleven Siberian ecotones, and the total area of the ecotones excluding waterbodies......30

2.5 Summary of normalized canopy expansion rates $\left(\%\right.$ decade $\left.^{-1}\right)$ for tall shrubs (NSER) and trees (NTER) by landscape and physiographic unit.

3.1 Total alder cover in 1968 and 2010, and areal and relative changes in alder cover (1968-2010), at Kharp and Obskaya study sites .78

3.2 Median values of soil organic depth, mineral soil thickness, and sample sizes measured along transects and at adjacent alders at Kharp....................79

3.3 Relative abundance of shrub age classes, by shrub stand-age, at Kharp..........80

4.1 Summary of locations, historical and modern VHR imagery attributes, and Landsat period-of-record for the eleven study landscapes..................107

4.2 Physiographic units used to stratify the study landscapes...................110 
4.3 Summary of Landsat NDVI trends at the study landscapes for alder shrublands

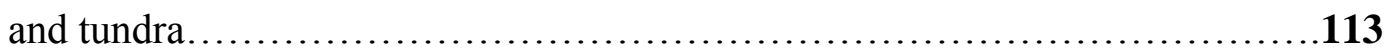

4.4 Decadal rate of change in alder shrubland extent estimated from Landsat NDVI trends for all landscapes, and observed from comparisons of VHR imagery from the 1960s and recent years for the five intensive study landscapes............116 


\section{LIST OF FIGURES}

1.1 The geographic extent of the Arctic tundra biome, portrayed in the Circumpolar Arctic Vegetation Map (CAVM Team, 2003) ................................

1.2 Global trends of mean annual temperature for 1962-2010, the approximate observational period applied in this dissertation, derived from reanalysis of global instrumental datasets.......................................................

1.3 Time-series of anomalies of Arctic sea-ice extent in the month of September

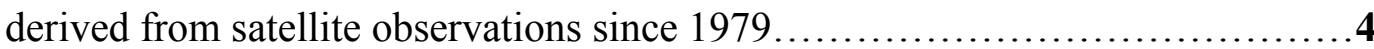

1.4 Examples of forest-tundra ectones. Clockwise from upper left: (1) abrupt, elevational treeline; (2) diffuse treeline zone with patches of tundra in a matrix of forest; (3) diffuse treeline zone with patches of forest in a matrix of tundra; and (4) isolated riparian tall alder shrubs in tundra.

.5

1.5 Forest-tundra near King Salmon, southwest Alaska in 1918 (left) and 2005 (right); birch shrubs have become much more widespread in this ecotone................

2.1 Map of northern Siberia showing locations of the study areas..................18

2.2 Comparison of 1966 (Gambit; left) and 2009 (GeoEye-1; right) imagery showing alder shrubland expansion on hilltops at Dudinka study landscape.

2.3 Comparison of 1966 (Gambit; left) and 2009 (WorldView-1; right) imagery showing larches on rims of ice-wedge polygons at Hatanga study landscape, eastern Taymyr region 
2.4 Summary of net changes in tall shrub (white boxes) and larch (black boxes) cover at eleven tundra ecotones in northern Siberia.

2.5 Normalized expansion rate of tall shrubs and trees in four physiographic units, and percent of the total modern shrub and tree cover that occurred in each physiographic unit, by study landscape..............................32

2.6 Linear regression of normalized expansion rate of tall shrubs and trees against (a) JJA temperature trend; and (b) mean annual precipitation...................34

3.1 Aerial view of alder shrubland or "savanna" in which alders are regularly spaced, Selawik River area, northwest Alaska..................................69

3.2 Patterned-ground with young alders growing on circles, Obskaya site...........70

3.3 Map of southern Yamal Peninsula region, Russia, showing locations of Kharp and Obskaya study sites and other places mentioned in the text...................72

3.4 Comparison of 1968 (Corona) and 2003 (QuickBird) satellite images showing representative area of recent shrub expansion at Kharp site...................74

3.5 Soil characteristics in alder stands of varying age, shown as frequency distributions of organic thickness and total mineral horizon thickness along transects and at alders in three shrubland successional stages.................80

3.6 Maps of circle distribution and alder density for three 4 x 20 m transects........81

3.7 Mid-summer $5 \mathrm{~cm}$ soil temperatures taken at Kharp at circles and inter-circles, by

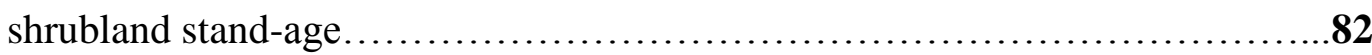


3.8 Time-series of mean June-July-August temperature for Kharp and Obskaya for

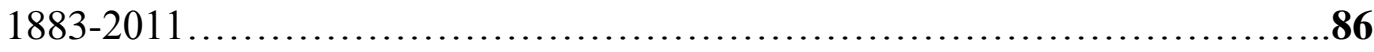

4.1 Ground photo of recently-established alders in Kharp study landscape..........103

4.2 Map of northwest Siberian Low Arctic showing locations of the study landscapes. Intensive landscapes are outlined in red, regional landscapes in black..........107

4.3 Proportion of Landsat pixel stacks with significant NDVI trends by physiographic unit, and the proportion of each landscape comprised by each unit.

4.4 Corona (left) and QuickBird (center) images of shrub-tundra at the Kharp landscape. Landsat data for 1985-2010 (right) show disproportionately high greening in shrublands

4.5 NDVI response curves for Landsat pixel stacks in pre-existing and newlyestablished shrublands 115

4.6 Upland and lowland terrain at Gydan landscape (left), and overlay of significant

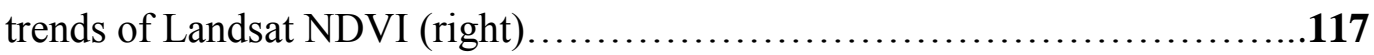

4.7 (a) Cryogenic landslide at Taz landscape shown in 2002 and 2010, and significant trends of Landsat NDVI; (b) Patterned-ground area at Laborovaya; widespread greening occurred in patterned-ground and especially in alder shrublands.....120

4.8 Scatterplot of mean NDVI, versus mean NDVI trend for pre-existing and expanding alder shrublands at Kharp study landscape 


\section{ACKNOWLEDGEMENTS}

This research would not have been possible without a lot of help from many special people. Foremost, I thank Howie Epstein for his support, encouragement, and scientific insight, both as a mentor and friend. I also owe a special debt of gratitude to Jay Zieman, who provided crucial financial support that allowed me to attend the University of Virginia. I also thank my other committee members, Hank Shugart, Jennie Moodie, and Laura Galloway, for their counsel along the way. Skip Walker, at the University of Alaska, provided invaluable insights and feedback, and helped to support field studies at Kharp. I also thank my Russian colleagues Marina Leibman, Ksusha Ermokhina, Pasha Orekhov, and Roma Ivanov at the Earth Cryosphere Institute, and Gosha Matyshak at Moscow State University, who made essential logistical arrangements and scientific contributions during field expeditions in Siberia. I will never forget these experiences; “большое спасибо, мои друзья!” Over the years, I received a lot of help from undergraduate Research Assistants at UVa, including Shalane Carlson, Bert Richards, Kate Boles, Dana Lillard, John Tran, Carolyn Relton, Brandon Groves, Abby Credicott, Sarah Medley, Nicole Koren, Emma Siegfried, Wes Andrews, Alfred Hubbard, Emily Kangas, and Kelcy Kent. I graciously thank my funding sources at the Department of Environmental Sciences, the Alaska Geobotany Center, the NASA Land-Cover Land-Use Change Initiative, the Virginia Space Grant Consortium, and the U.S. Permafrost Association. I thank the entire EVSC community for making my time in Charlottesville so fun and engaging. Finally, I thank my parents, Marge and Jerry Frost, and my wife, Shalane Frost, for their love, friendship, and support. 


\section{CHAPTER 1 - GENERAL INTRODUCTION}

The Arctic tundra biome constitutes the world's northernmost terrestrial biome, bound by the Arctic Ocean to the north and by the northern "treeline" of the boreal forest biome to the south. At the circumpolar scale, the southern latitudinal limit of Arctic tundra varies considerably, but is everywhere characterized by proximity to Arctic coastlines and associated strong gradients in summer temperature that exist from landward regions to the ocean (Alexandrova, 1974). The Arctic tundra biome extends as far south as $\sim 55^{\circ} \mathrm{N}$ in Canada among the largely ice-covered inlets and straits separating the islands of the Canadian Arctic Archipelago, but is only found above $\sim 70^{\circ} \mathrm{N}$ in central Siberian regions with a highly continental climate regime (Figure 1.1). Tundra vegetation also occurs at high elevation at temperate latitudes of the northern and southern hemispheres; these tundras are termed "alpine tundra," and share many of the attributes of Arctic tundra. The tundra biome is unique among the world's biomes, in that its geographic extent is driven by temperature alone and is not appreciably linked to gradients of precipitation. Climatic warming observed globally over the last $\sim 150$ years has been most pronounced at high latitudes (Figure 1.2), bringing widespread attention to Arctic tundra ecosystems as bellwethers of global environmental change.

The Arctic tundra biome is characterized by low-growing, treeless vegetation, but there is considerable latitudinal zonation within the biome (Alexandrova, 1974; Walker et al., 2005). The stature and biomass of tundra vegetation progressively decreases from landward to seaward, and there is a shift in the relative abundance of plant functional 


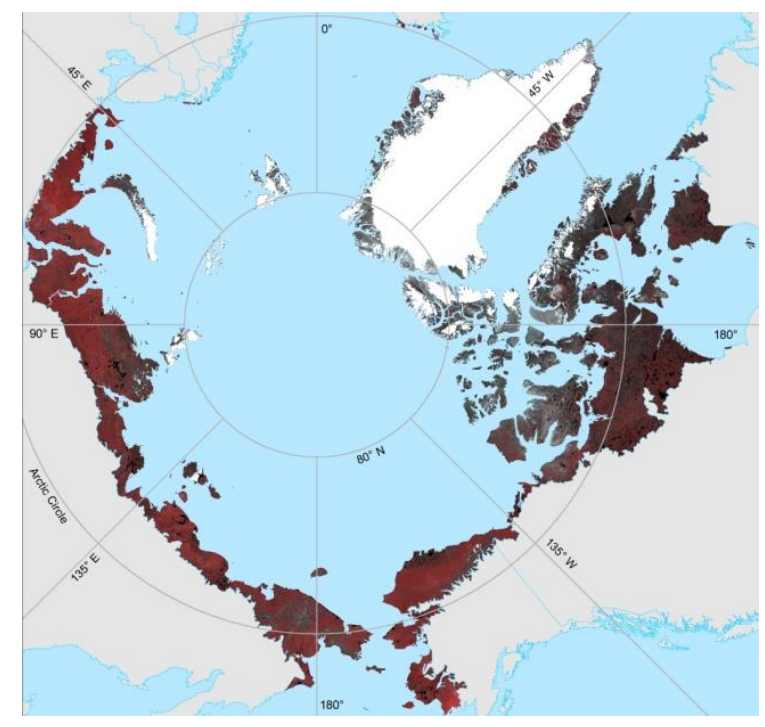

Figure 1.1. The geographic extent of the Arctic tundra biome (shaded area), portrayed in the Circumpolar Arctic Vegetation Map (CAVM Team, 2003).

types. In the warmer, southernmost parts of the biome, often referred to as the "Low Arctic," woody shrubs are a dominant component of the vegetation and often form an erect canopy of $\sim 1 \mathrm{~m}$ or more in height. "High Arctic" tundra describes tundras in the coldest parts of the biome, where woody shrubs have a prostrate growth form or are absent altogether. High Arctic tundra is closely linked to areas in which offshore sea-ice is most persistent (Walker et al., 2005); however, dramatic declines in the seasonal duration and extent of Arctic sea-ice have amplified recent increases in regional and global temperature (Serreze and Barry, 2011) (Figure 1.3), with increases in the productivity of vegetation evident virtually throughout the Arctic tundra biome (Bhatt et al., 2010). Given that Arctic tundra biome extent is strongly dependent on temperature, these observations have prompted hypotheses regarding the poleward displacement of Arctic tundra, and its replacement in southern areas by boreal forest. 


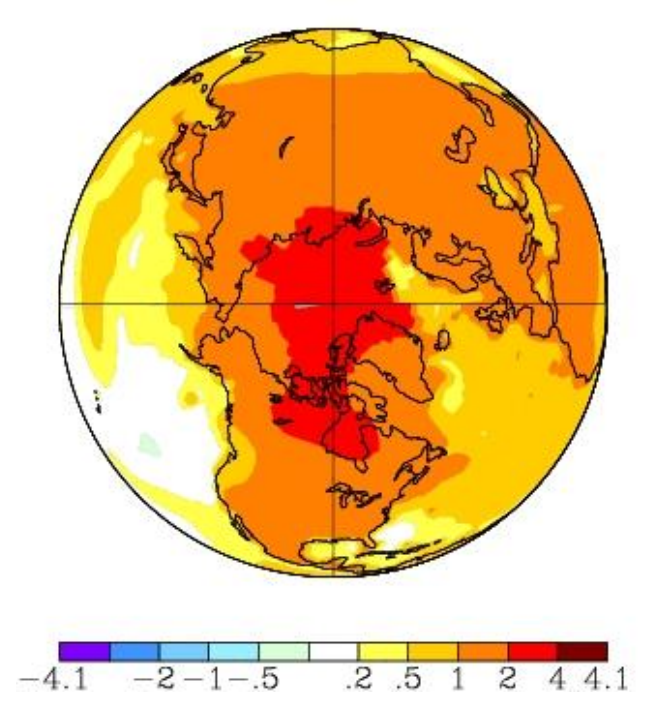

Figure 1.2. Global trends of mean annual temperature for 1962-2012, the approximate observational period of satellite-based remote-sensing applied in this dissertation, derived from reanalysis of global instrumental datasets. The colored scale is in units of ${ }^{\circ} \mathrm{C}$. Figure courtesy of NASA Goddard Institute for Space Studies.

The boreal forest biome is one of the most extensive biomes globally, encompassing broad swaths of northern Eurasia and North America. The northern limit of the boreal forest coincides fairly closely with the $10^{\circ} \mathrm{C}$ July isotherm (Holtmeier, 2003). Circumpolar-scale maps of the world's biomes portray Arctic tundra and boreal forest as more or less contiguous circumpolar belts separated by a latitudinal "treeline," but the forest-tundra transition is almost never characterized by abrupt shifts from treed to treeless vegetation. Rather, the Arctic-boreal transition encompasses a broad ecotone of "forest-tundra" vegetation, in which the relative abundance of trees diminishes from south to north (Figure 4). This gradual spatial transition is frequently termed a "diffuse" 


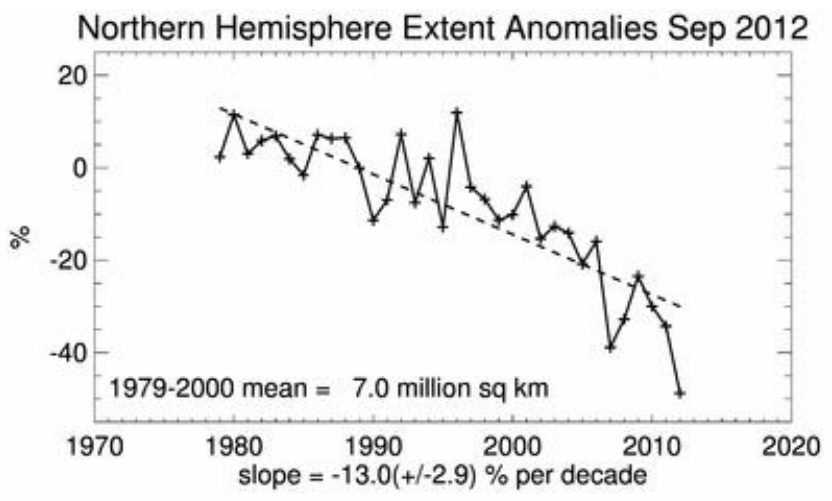

Figure 1.3. Time-series of anomalies of Arctic sea-ice extent in the month of September derived from satellite observations since 1979, indicating dramatic decreases in the persistence of sea-ice cover. Figure courtesy of the National Snow and Ice Data Center (NSIDC).

treeline, in contrast to the "abrupt" treelines frequently observed in montane regions (Figure 1.4).

The encroachment of tall shrubs and trees into tundra-dominated areas has a broad range of implications at local, regional, and potentially global scales. Increased shrubland and forest canopy cover promotes local and regional climatic warming by altering the exchange of radiant and energy between the land and the atmosphere, particularly in late winter and in spring, when solar insolation is high and there are strong contrasts in the absorptive properties of snow cover and exposed vegetation (Bonan et al., 1992; Chapin et al., 2005; Loranty et al., 2011). Widespread tree and shrub expansion within the present-day tundra biome also has the potential to influence global climate by altering atmospheric circulation (Bonan, 2008; Bonan et al., 1992; Chapin et al., 2002). Tree and shrub proliferation in tundra can also affect a wide range of biophysical system-properties 

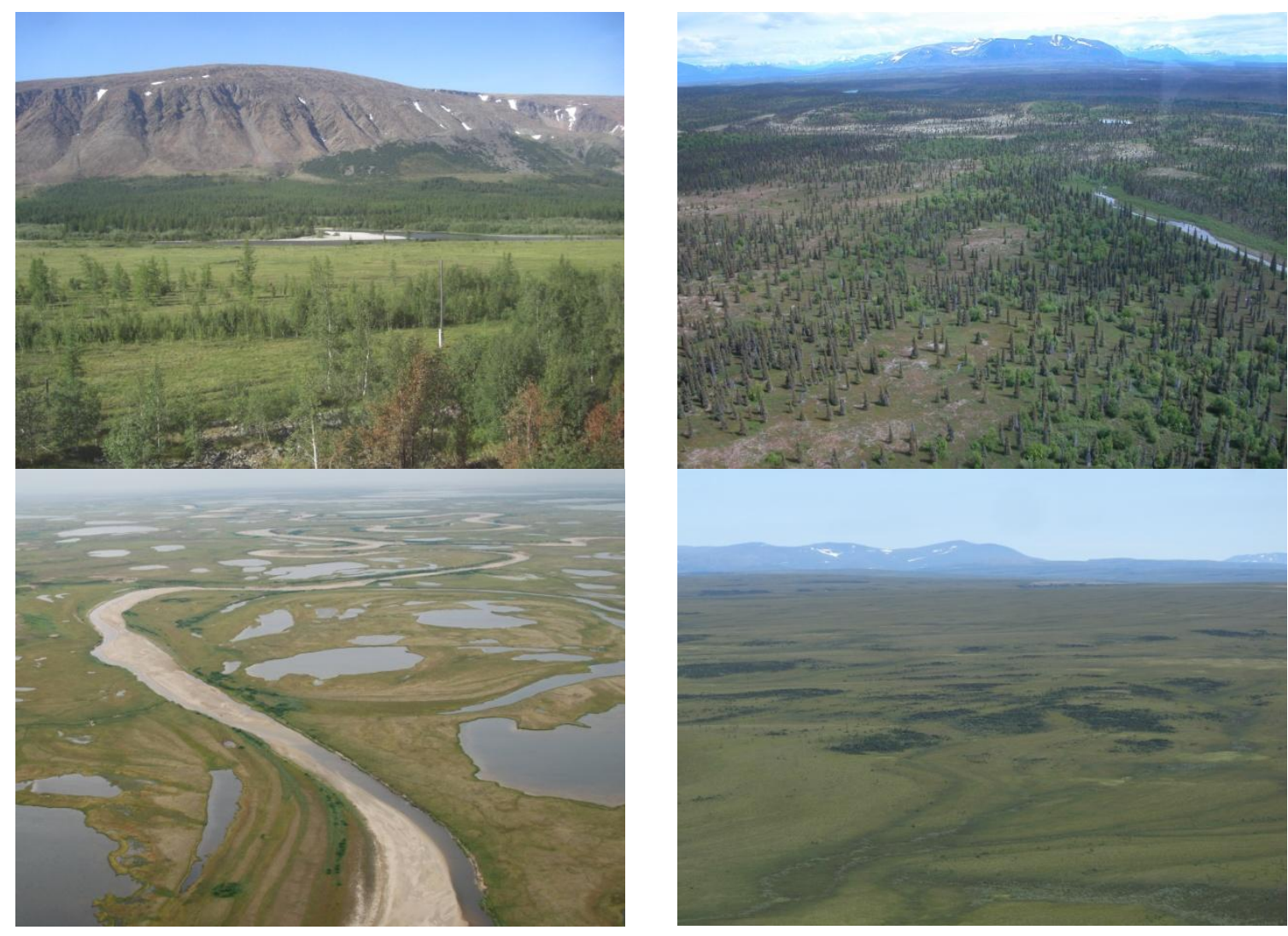

Figure 1.4. Examples of forest-tundra ecotones. Clockwise from upper left: (1) abrupt, elevational treeline, Polar Ural Mountains, Russia; (2) diffuse treeline zone with patches of tundra in a matrix of forest, western Alaska; (3) diffuse treeline zone with patches of forest in a matrix of tundra, southern Yamal Peninsula, Russia; and (4) isolated riparian tall alder shrubs (dark patches) in tundra, central Yamal Peninsula, Russia.

of Arctic landscapes, including hydrological processes (Sturm et al., 2005), permafrost temperature (Blok et al., 2010), and nutrient cycling (Kaarlejärvi et al., 2012); these alterations also have potentially significant, indirect impacts on the global climate system, because large pools of carbon are stored in live vegetation, and permafrost soils which underlie virtually all of the Arctic tundra domain (Oechel et al., 2000; Ping et al., 2008). Changes in tall shrub and tree abundance also fundamentally alter wildlife habitat 
characteristics (e.g., Ehrich et al., 2012) and can impact traditional human activities (Forbes et al., 2009).

Current lines of evidence regarding recent shifts in the extent of Arctic tundra and boreal forest come from field-based studies (Esper and Schweingruber, 2004; Lloyd et al., 2002; Suarez et al., 1999) and observations from earth-observing satellites (e.g., Beck et al., 2011; Kharuk et al., 2006; McManus et al., 2012), as well as projections derived from processed-based simulation models (e.g., Kaplan and New, 2006; Shuman et al., 2011). Other lines of evidence regarding environmental change in Pan-Arctic terrestrial ecosystems, however, have highlighted the role of tall (> $2 \mathrm{~m}$ height), canopy-forming shrubs in driving structural changes both in forest-tundra, and within the matrix of present-day Low Arctic tundra (e.g., Sturm et al., 2001; Tape et al., 2006) (Figure 1.5). Tall shrubs are widespread in the boreal forest biome, and also in Low Arctic tundra; perhaps for this reason, changes in shrubland extent have not been viewed in the context of biome shifts until relatively recently (Myers-Smith et al., 2011). Observational evidence of changes in the abundance of trees, and especially tall shrubs in Arctic tundra overwhelmingly comes from North America and Fennoscandia. Inferences regarding circumpolar changes in tree and tall shrub abundance on the basis of observations in these regions are frequently encountered in the literature, but little direct evidence exists for the Siberian Low Arctic, a geographically immense region that has traditionally posed considerable political and logistical obstacles for scientific research. Although the Siberian boreal forest and tundra domains are similar in many ways to those of the North American and European Pan-Arctic, there are significant differences pertaining to 

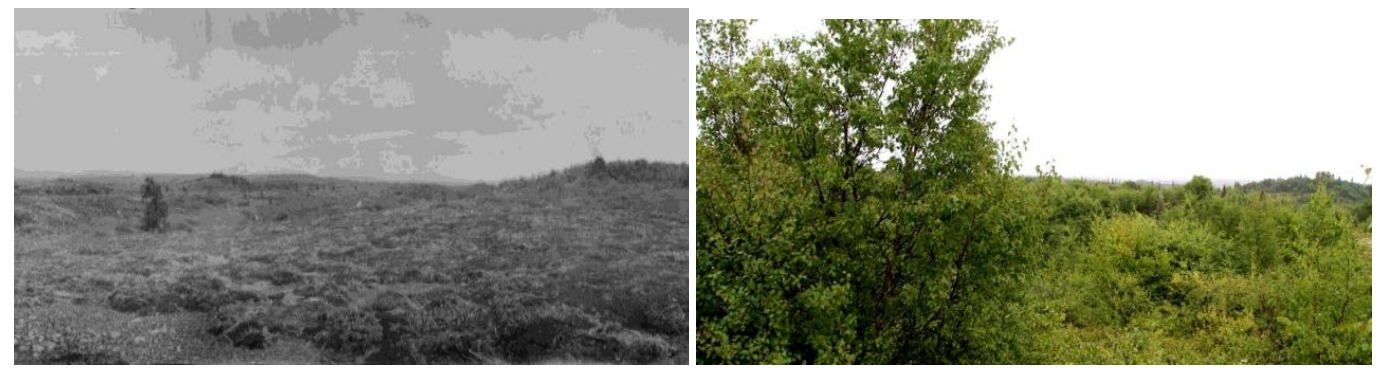

Figure 1.5. Forest-tundra near King Salmon, southwest Alaska in 1918 (left) and 2005 (right). Birch (Betula) shrubs have become much more widespread within this ecotone. 1918 photo by P. Hagelbarger, courtesy of National Geographic Society; 2005 photo by G. Frost.

landscape history and biogeography that are highly relevant to discussions of recent and future vegetation dynamics. For example, in contrast to much of northern North America and Europe, most of the northern Siberian region remained unglaciated during the Pleistocene, and so the development of modern treelines has occurred over a relatively long period of time across most of the region. In light of the Siberian region's geographic extent, the lack of direct, observational evidence of recent vegetation dynamics and landcover change in the region represents a large gap in global change studies.

The primary motivation for my dissertation is to shed light on recent vegetation dynamics and land-cover change in northern Siberia (Table 1). In this dissertation, I applied three general approaches to examine recent changes in ecotonal landscapes spanning the Siberian Low Arctic: (1) spatially-explicit comparisons of high-resolution satellite imagery from the mid-1960s, and recent years for eleven Siberian tundra ecotones; (2) field studies of landscape-scale mechanisms that facilitate shrub proliferation in permafrost patterned-ground ecosystems; and (3) spatio-temporal 
Table 1.1. Summary of dissertation research components, questions, and approaches.

\begin{tabular}{|c|c|c|}
\hline Component & Major questions & Approaches \\
\hline \multirow[t]{3}{*}{$\begin{array}{l}\text { I. Changes in } \\
\text { ecotonal shrub and } \\
\text { tree cover }\end{array}$} & $\begin{array}{l}\text { 1. Is recent shrub and tree } \\
\text { expansion a ubiquitous } \\
\text { phenomenon in the Siberian } \\
\text { Low Arctic? }\end{array}$ & $\begin{array}{l}\text { Quantify changes in shrub and tree cover over } \\
\text { the last } \sim 45 \text { years at widely-distributed Siberian } \\
\text { ecotones through visual interpretation of } 1960 \text { s } \\
\text { and modern satellite photography }\end{array}$ \\
\hline & $\begin{array}{l}\text { 2. What parts of ecotonal } \\
\text { landscapes are most } \\
\text { susceptible to shrub and tree } \\
\text { expansion? }\end{array}$ & $\begin{array}{l}\text { Stratify each study area by physiographic units } \\
\text { in a GIS, and assess changes in shrub and tree } \\
\text { cover by stratum }\end{array}$ \\
\hline & $\begin{array}{l}\text { 3. To what extent can changes } \\
\text { in shrub and tree cover be } \\
\text { explained by temporal } \\
\text { anomalies of seasonal } \\
\text { temperature and precipitation? }\end{array}$ & $\begin{array}{l}\text { Generate time-series of mean summer } \\
\text { temperature, mean winter temperature, and } \\
\text { annual precipitation from instrumental records } \\
\text { and correlate the magnitude of vegetation } \\
\text { change with climatic trends }\end{array}$ \\
\hline \multirow[t]{2}{*}{$\begin{array}{l}\text { II. Role of } \\
\text { permafrost } \\
\text { processes in } \\
\text { ecotonal vegetation } \\
\text { dynamics }\end{array}$} & $\begin{array}{l}\text { 4. Is shrub expansion } \\
\text { facilitated by disturbance } \\
\text { processes in permafrost } \\
\text { patterned-ground? }\end{array}$ & $\begin{array}{l}\text { Measure soil stratigraphic attributes in } \\
\text { expanding, and stable alder shrublands, and map } \\
\text { the locations of alders in relation to periglacial } \\
\text { landforms }\end{array}$ \\
\hline & $\begin{array}{l}\text { 5. What is the role of } \\
\text { disturbance in driving recent } \\
\text { vegetation dynamics? }\end{array}$ & $\begin{array}{l}\text { Evaluate the disturbance history for two } \\
\text { northwest Siberian sites, and evaluate spatial } \\
\text { relationships between shrub expansion areas, } \\
\text { and footprints of disturbance }\end{array}$ \\
\hline \multirow{2}{*}{$\begin{array}{l}\text { III. Contribution of } \\
\text { shrub expansion to } \\
\text { "greening" } \\
\text { observed in NDVI } \\
\text { time-series }\end{array}$} & $\begin{array}{l}\text { 6. To what extent do recent } \\
\text { changes in shrub and tree } \\
\text { cover explain NDVI } \\
\text { anomalies at the sites? }\end{array}$ & $\begin{array}{l}\text { Generate NDVI time-series using Landsat data } \\
\text { for northwest Siberian ecotones and isolate } \\
\text { NDVI trends for newly-established, and pre- } \\
\text { existing alder shrublands }\end{array}$ \\
\hline & $\begin{array}{l}\text { 7. Is the shrub increase } \\
\text { observed in ecotones with } \\
\text { 1960s imagery representative } \\
\text { of changes occurring across } \\
\text { the northwest Siberian Arctic? }\end{array}$ & $\begin{array}{l}\text { Using findings from Component I, generate } \\
\text { empirical functions that predict the spatial extent } \\
\text { of newly-established shrublands across large } \\
\text { areas, based on the magnitude of Landsat NDVI } \\
\text { trends observed in shrublands since } 1984\end{array}$ \\
\hline
\end{tabular}

analyses of Landsat-observed trends in tundra vegetation productivity and shrub-driven

land-cover change in northwest Siberia since 1984. 


\section{References}

Alexandrova, V. D. 1974. The Arctic and Antarctic: Their Division into Geobotanical Areas. Cambridge University Press, Cambridge, UK.

Beck, P. S. A., Juday, G. P., Alix, C., Barber, V. A., Winslow, S. E., Sousa, E. E., Heiser, P., Herriges, J. D., and Goetz, S. J., 2011. Changes in forest productivity across Alaska consistent with biome shift. Ecology Letters, 14, 373-379.

Bhatt, U. S., Walker, D. A., Raynolds, M. K., Comiso, J. C., Epstein, H. E., Jia, G., Gens, R., Pinzon, J. E., Tucker, C. J., Tweedie, C. E., and Webber, P. J., 2010. Circumpolar Arctic tundra vegetation change is linked to sea ice decline. Earth Interactions, 14, 1-20.

Blok, D., Heijmans, M. M. P. D., Schaepman-Strub, G., Kononov, A. V., Maximov, T. C., and Berendse, F. 2010. Shrub expansion may reduce summer permafrost thaw in Siberian tundra. Global Change Biology, 16, 1296-1305.

Bonan, G.B. 2008. Forests and climate change: forcings, feedbacks, and the climate benefits of forests. Science, 320, 1444-1449.

Bonan, G. B., Pollard, D., and Thompson, S. L. 1992. Effects of boreal vegetation on global climate. Nature, 359, 716-718.

CAVM Team. 2003. Circumpolar Arctic Vegetation Map (1:7,500,000 scale). Conservation of Arctic Flora and Fauna (CAFF) Map No. 1. U. S. Fish and Wildlife Service, Anchorage, AK. 
Chapin, F. S., McGuire, A. D., Randerson, J., Pielke, R., Baldocchi, D., Hobbie, S. E., et al. 2002. Arctic and boreal ecosystems of western North America as components of the climate system. Global Change Biology, 6, 211-223.

Chapin, F. S., Sturm, M., Serreze, M. C., McFadden, J. P., Key, J. R., Lloyd, A. H., et al. 2005. Role of land-surface changes in Arctic summer warming. Science, 310, $657-660$.

Ehrich, D., Henden, J. A., Ims, R. A., Doronina, L. O., Killengren, S. T., Lecomte, N., et al. 2012. The importance of willow thickets for ptarmigan and hares in shrub tundra: the more the better? Oecologia, 168, 141-151.

Esper, J., and Schweingruber, F. H. 2004. Large-scale treeline changes recorded in Siberia. Geophysical Research Letters, 31, L06202.

Forbes, B. C., Stammler, F., Kumpula, T., Meschtyb, N., Pajunen, A., and Kaarlejärvi, E. 2009. High resilience in the Yamal-Nenets social-ecological system, West Siberian Arctic, Russia. Proceedings of the National Academy of Sciences, 106, 22041-22048.

Holtmeier, F.-K., 2003. Mountain Timberlines: Ecology, Patchiness, and Dynamics. Kluwer Academic Publishers, Dordrecht, Netherlands.

Kaarlejärvi, E., Baxter, R., Hofgaard, A., Hytteborn, H., Khitun, O., Molau, U., Sjögersten, S., Wookey, P., and Olofsson, J. 2012. Effects of warming on shrub abundance and chemistry drive ecosystem-level changes in a forest-tundra ecotone. Ecosystems, 15, 1219-1233. 
Kaplan, J. O., and New, M., 2006. Arctic climate change with a $2^{\circ} \mathrm{C}$ global warming: timing, climate patterns and vegetation change. Climatic Change, 79, 213-241.

Kharuk, V. I., Ranson, K. J., Im, S. T., and Naurzbaev, M. M. 2006. Forest-tundra larch forests and climatic trends. Russian Journal of Ecology, 37, 291-298.

Lloyd, A. H., Rupp, T. S., Fastie, C. L., and Starfield, A. M. 2002. Patterns and dynamics of treeline advance on the Seward Peninsula, Alaska. Journal of Geophysical Research, 108, D28161.

Loranty, M. M., Goetz, S. J., and Beck, P. S. A. 2011. Tundra vegetation effects on panArctic albedo. Environmental Research Letters, 6, 029601.

McManus, K. M., Morton, D. C., Masek, J. G., Wang, D., Sexton, J. O., Nagol, J. R., Ropars, P., and Boudreau, S. 2012. Satellite-based evidence for shrub and graminoid tundra expansion in northern Quebec from 1986 to 2010. Global Change Biology, 18, 2313-2323.

Myers-Smith, I. H., Forbes, B. C., Wilmking, M., Hallinger, M., Lantz, T., Blok, D., et al. 2011. Shrub expansion in tundra ecosystems: dynamics, impacts and research priorities. Environmental Research Letters, 6, 045509.

Oechel, W. C., Vourlitis, G. L., Hastings, S. J., Zulueta, R. C., Hinzman, L., and Kane, D. 2000. Acclimation of ecosystem $\mathrm{CO}_{2}$ exchange in the Alaskan Arctic in response to decadal climate warming. Nature, 406, 978-981.

Ping, C.-L., Michaelson, G. J., Jorgenson, M. T., Kimble, J. M., Epstein, H., Romanovsky, V. E., and Walker, D. A. 2008. High stocks of soil organic carbon in the North American Arctic region. Nature Geoscience, 1, 615-619. 
Serreze, M. C., and Barry, R.G. 2011. Processes and impacts of Arctic amplification: a research synthesis. Global and Planetary Change, 77, 85-96.

Shuman, J. K., Shugart, H. H., and O'Halloran, T. L. 2011. Sensitivity of Siberian larch forests to climate change. Global Change Biology, 17, 2370-2384.

Sturm, M., Douglas, T., Racine, C., and Liston, G.E. 2005. Changing snow and shrub conditions affect albedo with global implications. Journal of Geophysical Research, 110, G01004.

Sturm, M., Tape, K., and Racine, C. 2001. Climate change: increasing shrub abundance in the Arctic. Nature, 411, 546-547.

Suarez, F., Binkley, D., Kaye, M.W., and Stottlemyer, R. 1999. Expansion of forest stands into tundra in the Noatak National Preserve, northwest Alaska. Ecoscience, 6, $465-470$.

Tape, K., Sturm, M., and Racine, C. 2006. The evidence for shrub expansion in Northern Alaska and the Pan-Arctic. Global Change Biology, 12, 686-702.

Walker, D. A., Raynolds, M. K., Daniëls, F. J. A., Einarsson, E., Elvebakk, A., Gould, W. A., Katenin, A. E., Kholod, S. S., Markon, C. J., Melnikov, E. S., et al. 2005. The circumpolar Arctic vegetation map. Journal of Vegetation Science, 16, 267-282. 


\title{
CHAPTER 2 - TALL SHRUB AND TREE EXPANSION IN SIBERIAN TUNDRA ECOTONES SINCE THE 1960's ${ }^{1}$
}

\begin{abstract}
Circumpolar expansion of tall shrubs and trees into Arctic tundra is widely thought to be occurring as a result of recent climate warming, but little quantitative evidence exists for northern Siberia, which encompasses the world's largest forest-tundra ecotonal belt. We quantified changes in tall shrub and tree canopy cover in eleven, widely-distributed Siberian ecotonal landscapes by comparing very-high-resolution photography from the Cold War-era "Gambit" and "Corona" satellite surveillance systems (1965-1969) with modern imagery. We also analyzed within-landscape patterns of vegetation change to evaluate the susceptibility of different landscape components to tall shrub and tree increase. The total cover of tall shrubs and trees increased in nine of eleven ecotones. In northwest Siberia, alder (Alnus) shrubland cover increased 5.3-25.9\% in five ecotones. In Taymyr and Yakutia, larch (Larix) cover increased 3.0 - 6.7\% within three ecotones, but declined $16.8 \%$ at a fourth ecotone due to thaw of ice-rich permafrost. In Chukotka, the total cover of alder and dwarf pine (Pinus) increased $6.1 \%$ within one ecotone and was little-changed at a second ecotone. Within most landscapes, shrub and tree increase was linked to specific geomorphic settings, especially those with active disturbance regimes such as permafrost patterned-ground, floodplains, and colluvial hillslopes. Mean summer temperatures increased at most ecotones since the mid-1960s, but rates of shrub and tree canopy cover expansion were not strongly correlated with temperature trends

${ }^{1}$ Frost, G. V. and Epstein, H. E. In review, Global Change Biology.
\end{abstract}


and were better correlated with mean annual precipitation. We conclude that shrub and tree cover is increasing in tundra ecotones across most of northern Siberia, but rates of increase vary widely regionally and at the landscape-scale. Our results indicate that extensive changes can occur within decades in moist, shrub-dominated ecotones, as in northwest Siberia, while changes are likely to occur much more slowly in the highly continental, larch-dominated ecotones of central and eastern Siberia.

\section{Introduction}

Patterns of boreal tree and tall shrub occurrence form conspicuous and dynamic ecological boundaries along the southern margin of the Arctic tundra biome. The distribution of trees and tall shrubs in forest-tundra ecotones can change within multidecadal timescales in response to climatic changes, geomorphic processes, and many forms of natural and anthropogenic disturbance (Holtmeier \& Broll, 2005; Myers-Smith et al., 2011). Climatic warming is widely expected to promote the northward and upslope expansion of trees and tall shrubs into tundra-dominated areas in the coming decades. These predictions are largely based on observations of warming-induced increases in the secondary growth and reproduction of boreal trees and shrubs (Esper \& Schweingruber, 2004; Kullman, 2007; Danby \& Hik, 2007b; Devi et al., 2008; Forbes et al., 2010), and space-based observations that indicate widespread increases in the productivity of foresttundra and Low Arctic tundra since the 1980s (Bhatt et al., 2010; Beck et al., 2011; Lloyd et al., 2011; McManus et al., 2012). The most direct and spatially-explicit observational evidence of tree and tall shrub increase comes from comparative 
assessments of tree and shrub canopy cover in vertical and oblique aerial photography over multi-decadal timescales. Such assessments primarily come from plot- to regionalscale studies in Alaska (Sturm et al., 2001; Tape et al., 2006; Naito \& Cairns, 2011) and Canada (Danby \& Hik, 2007a; Tremblay et al., 2012; Ropars \& Boudreau, 2012; Lantz et al., 2012). The Siberian Low Arctic, however, encompasses the longest contiguous belt of forest-tundra vegetation globally $(>5,000 \mathrm{~km})$, but nonetheless remains greatly understudied. Here we address this knowledge gap, by quantifying changes in the cover of tall shrubs and trees since the 1960s across a network of ecotonal landscapes spanning the Siberian Low Arctic.

Changes in tree and tall shrub abundance are a critical component of high-latitude environmental change, because changes in the areal cover of erect plant canopies strongly modify system properties of tundra-dominated lands that feed back to the climate system (Foley et al., 1994; Levis et al., 2000). There is therefore a pressing need to characterize the susceptibility of Low Arctic ecosystems to tall shrub and tree advance, and to better constrain the rates at which changes in erect canopy cover are likely to occur in coming decades. Recent model-based simulations of circumpolar vegetation are largely driven by temperature, and project changes in potential vegetation that do not account for constraints on seedling recruitment and species migration rates (ACIA, 2005; Kaplan \& New, 2006; Tchebakova et al., 2009); these projections therefore appear to greatly overestimate the potential for large-scale vegetation changes in the present-day Arctic tundra biome. Although most recent studies in Pan-Arctic ecotones have reported increases in tree and especially tall shrub abundance, and there are virtually no reports of 
decline (Harsch et al., 2009; Myers-Smith et al., 2011), a high degree of heterogeneity exists in the magnitude of vegetation change observed regionally and within landscapes. A range of abiotic and biotic factors can create strong contrasts in the local responses of vegetation to a shared climatic forcing, such as differences in geomorphology (Gamache \& Payette, 2005; Frost et al., 2013) and disturbance history (Lantz et al., 2009, 2012). Elucidation of the relative importance of, and the dynamic linkages among, large-scale climatic forcing, landscape-scale processes, and the resilience of existing tundra vegetation is therefore necessary in order to more accurately predict the susceptibility of the Low Arctic to boreal vegetation advance in space and time.

Observational studies of shrub and tree dynamics are challenging in the PanArctic in general, and northern Siberia in particular, because of the large size and inaccessibility of these regions, and the multi-decadal time periods required for observable changes in vegetation structure to become manifest in cold ecosystems that are dominated by long-lived species. Dendrochronological studies provide strong evidence for increased secondary growth rates of Siberian trees (Briffa et al., 1995; Kharuk et al., 2006) and tundra shrubs (Forbes et al., 2010) that are contemporaneous with climate warming over the last century. Dendroecological techniques have also been used to document recent tree expansion in elevational ecotones of the Polar Ural Mountains (Shiyatov et al., 2005; Devi et al., 2008) and Putorana Mountains (Kirdyanov et al., 2012), and recent increases in tree recruitment have been recorded in northwest Siberian forest-tundra since the mid-20 ${ }^{\text {th }}$ century (Esper \& Schweingruber (2004). It is difficult, however, to extrapolate areal changes in tree and tall shrub cover over large 
areas based on in situ measurements of individuals. Additionally, climate-induced increases in the productivity and fecundity of mature trees may not be accompanied by areal expansion of tree cover, because suitable sites for seedling recruitment may be lacking (Walker et al., 2012b). Retrospective studies of ecotonal vegetation using highresolution image pairs offer a straightforward means to assess areal changes in tree and tall shrub canopy cover, and to distinguish the magnitude of vegetation changes in landscape components that are stratified by geomorphic and topographic attributes of interest.

Our objectives in this study were threefold: (1) to quantify changes in the cover of tall shrubs and trees since the mid-1960s in eleven ecotonal landscapes distributed across the Siberian Low Arctic; (2) to assess and compare the landscape-scale heterogeneity of vegetation changes within the eleven ecotonal landscapes; and (3) to assess the extent to which variability in rates of change of tall shrub and tree canopy-cover between landscapes can be explained by climatic variables associated with summer temperature, winter temperature, and annual precipitation.

\section{Materials and Methods}

We quantified changes in tall shrub and tree cover within eleven ecotones spanning the Siberian Low Arctic, by comparing very-high-resolution (VHR; $\leq 2 \mathrm{~m}$ spatial resolution) satellite photographs from the 1960s with VHR imagery from recent years (Table 2.1, Fig. 2.1). We also applied ancillary remote-sensing datasets to delineate geomorphic and physiographic properties of the study landscapes, and compare the 
Table 2.1. Summary of study landscape location, elevation, area, mean annual temperature (MAT), mean June-July-August temperature (JJA), mean DecemberJanuary-February temperature (DJF), and mean annual precipitation (MAP) for 19652010.

\begin{tabular}{lcccccccc}
\hline Landscape & $\begin{array}{c}\text { Latitude } \\
\left({ }^{\circ} \mathrm{N}\right)\end{array}$ & $\begin{array}{c}\text { Longitude } \\
\left({ }^{\circ} \mathrm{E}\right)\end{array}$ & $\begin{array}{c}\text { Elevation } \\
(\mathrm{m})\end{array}$ & $\begin{array}{c}\text { Area } \\
\left(\mathrm{km}^{2}\right)\end{array}$ & $\begin{array}{c}\text { MAT } \\
\left({ }^{\circ} \mathrm{C}\right)\end{array}$ & $\begin{array}{c}\text { JJA } \\
\left({ }^{\circ} \mathrm{C}\right)\end{array}$ & $\begin{array}{c}\text { DJF } \\
\left({ }^{\circ} \mathrm{C}\right)\end{array}$ & $\begin{array}{c}\text { MAP } \\
(\mathrm{mm})\end{array}$ \\
\hline Kharp & $66.84^{\circ}$ & $65.99^{\circ}$ & 225 & 64 & -7.5 & 10.1 & -23.4 & 450 \\
Obskaya & $66.92^{\circ}$ & $66.59^{\circ}$ & 210 & 59 & -7.4 & 10.2 & -23.3 & 450 \\
Tanlova & $67.53^{\circ}$ & $69.67^{\circ}$ & 20 & 50 & -7.2 & 10.2 & -23.4 & 404 \\
Taz & $67.23^{\circ}$ & $74.04^{\circ}$ & 30 & 72 & -7.7 & 9.9 & -23.4 & 371 \\
Dudinka & $69.61^{\circ}$ & $86.53^{\circ}$ & 50 & 58 & -9.8 & 10.5 & -27.1 & 515 \\
Hatanga & $72.16^{\circ}$ & $102.68^{\circ}$ & 15 & 34 & -12.6 & 9.7 & -31.3 & 275 \\
Lukunsky & $72.48^{\circ}$ & $105.20^{\circ}$ & 30 & 34 & -12.6 & 9.7 & -31.3 & 275 \\
Uyandi & $69.45^{\circ}$ & $141.65^{\circ}$ & 300 & 54 & -14.2 & 10.5 & -36.5 & 268 \\
Kolyma & $68.93^{\circ}$ & $161.36^{\circ}$ & 10 & 45 & -11.2 & 10.9 & -32.0 & 198 \\
Pekulney & $65.39^{\circ}$ & $174.20^{\circ}$ & 150 & 73 & -8.6 & 9.8 & -24.0 & 325 \\
Velikaya & $63.73^{\circ}$ & $175.10^{\circ}$ & 50 & 78 & -7.7 & 10.9 & -23.5 & 378 \\
\hline
\end{tabular}

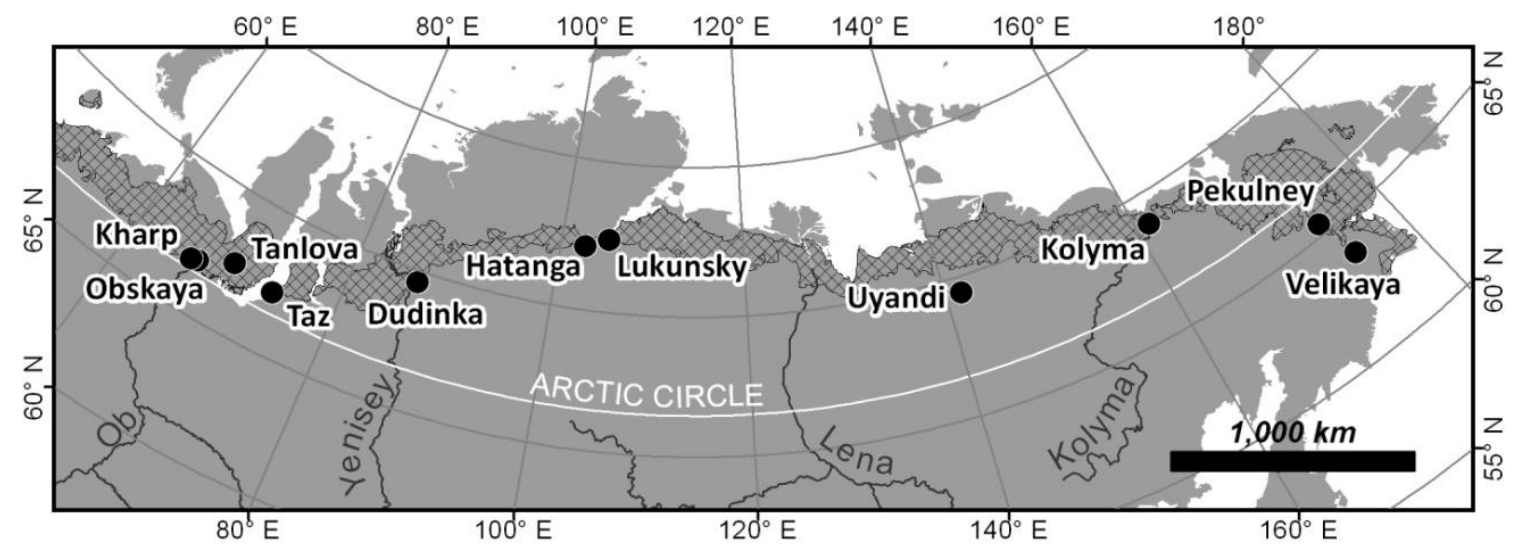

Fig. 2.1. Map of northern Siberia showing locations of the study areas. The hatched area shows the extent of the warmest, southern bioclimate subzone of the Arctic tundra biome (CAVM Team 2003). 
susceptibilities of different landscape components to tall shrub and tree increase. Finally, we evaluated the influence of summer and winter temperatures, and annual precipitation on ecotonal vegetation dynamics using ground-based meteorological records.

\section{Data sources and study areas}

Spatially-explicit, retrospective studies of ecotonal vegetation changes require baseline data sources that possess both the spatial resolution necessary to distinguish vegetation canopies, and a period-of-record adequate to detect directional changes in vegetation. Aerial photographs have been successfully used to quantify multi-decadal vegetation changes in forest-tundra and Low Arctic tundra in North America (Tape et al., 2006; Danby \& Hik, 2007a; Dial et al., 2007; Naito \& Cairns, 2011; Tremblay et al., 2012; Ropars \& Boudreau, 2012; Lantz et al., 2012), but virtually no readily-accessible sources of aerial photography exist for Russian ecotones. We exploited a heretofore littleused archive of 1960s imagery from two declassified, Cold War-era satellite surveillance systems, KH-7 “Gambit” and KH-4B "Corona." Gambit (1963-1967) marked the beginning of space-based VHR remote-sensing, acquiring panchromatic photography at a spatial resolution of $\sim 75 \mathrm{~cm}$ (U.S. Department of the Air Force, 1967); no publiclyavailable satellite imagery achieved comparable resolution until the launch of the IKONOS commercial satellite in 1999. Gambit was replaced by the KH-4B Corona system (1967-1972), which acquired panchromatic photography of much larger swathwidths, at lower spatial resolution $(\sim 2 \mathrm{~m})$. When paired with modern VHR imagery, Gambit and Corona offer a readily-available source of baseline data for landcover-change 
studies with a period-of-record of almost fifty years. Gambit and Corona have yet to be widely applied in landcover-change studies in northern ecosystems, although a case study concluded that it had high potential (Rees et al., 2002). Imagery from KH-4A, an earlier variant of Corona ( $\sim 3-7 \mathrm{~m}$ spatial resolution), has been used to study forest-tundra dynamics on the Taymyr Peninsula (Kharuk et al., 2006), coastal tundra in Chukotka (Lin et al., 2012), and industrial impacts to boreal forest in European Russia (Rigina, 2003).

Gambit and Corona are well-suited for landcover change studies in tundra ecotones, because tall shrubs and trees form abrupt transitions in vegetation structure that create unambiguous, readily-interpreted photo-signatures. These photo-signatures result from the shadowing projected by the canopies of tall shrubs and trees, which greatly overtop tundra vegetation and create areas of high contrast in panchromatic imagery. For example, Siberian alder (Alnus viridis ssp. fruticosa), a common tall shrub in tundra ecotones, tends to form dense thickets that are readily distinguished (Fig. 2.2). Boreal conifers such as larch (Larix spp.) tend to form columnar canopies with areal footprints that are too small to distinguish in Corona imagery, but are readily detected in Gambit imagery-particularly because the high angle-of-incidence of sunlight at high latitudes produces long canopy shadows (Fig. 2.3). We therefore only applied Corona imagery to track changes in shrub cover, and relied on Gambit imagery for ecotones in which larch was abundant.

Prospective study areas were greatly constrained by the availability of historical imagery with appropriate seasonal timing and lack of cloud cover. We restricted our imagery search to the warmer, southernmost parts of the Arctic tundra biome (Bioclimate 


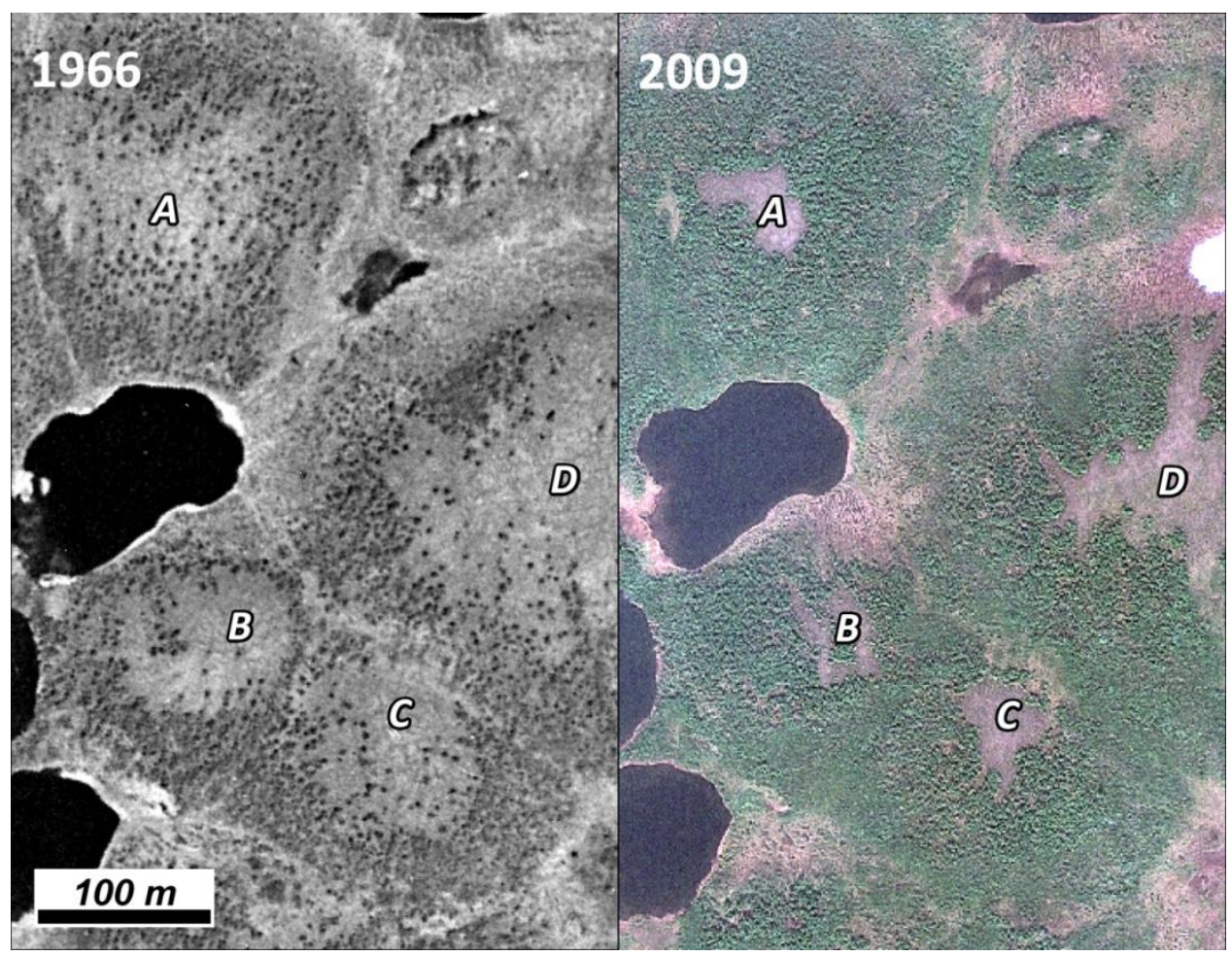

Fig. 2.2. Comparison of 1966 (Gambit; left) and 2009 (GeoEye-1; right) imagery showing alder shrubland expansion on hilltops at Dudinka study landscape, northwest Siberia; alder abundance increased 25.9\%. GeoEye-1 image (C) Digital Globe, Inc.

Subzone E of the Circumpolar Arctic Vegetation Map [(CAVM Team, 2003), but in an attempt to maximize longitudinal coverage in Yakutia, we also evaluated one elevational ecotone (Uyandi) that is $\sim 100 \mathrm{~km}$ south of Bioclimate Subzone E. A series of Corona satellites acquired extensive cloud-free, mid-summer photography in northwest Siberia in August 1968, and for Chukotka in July 1969 (Table 2.2). The spatial extent of Gambit photography is much more limited, but useful images exist for the Taymyr Peninsula and Yakutia, mainly along major rivers. Prospective study areas were further constrained by the availability of co-incident modern imagery; we therefore made opportunistic use of 


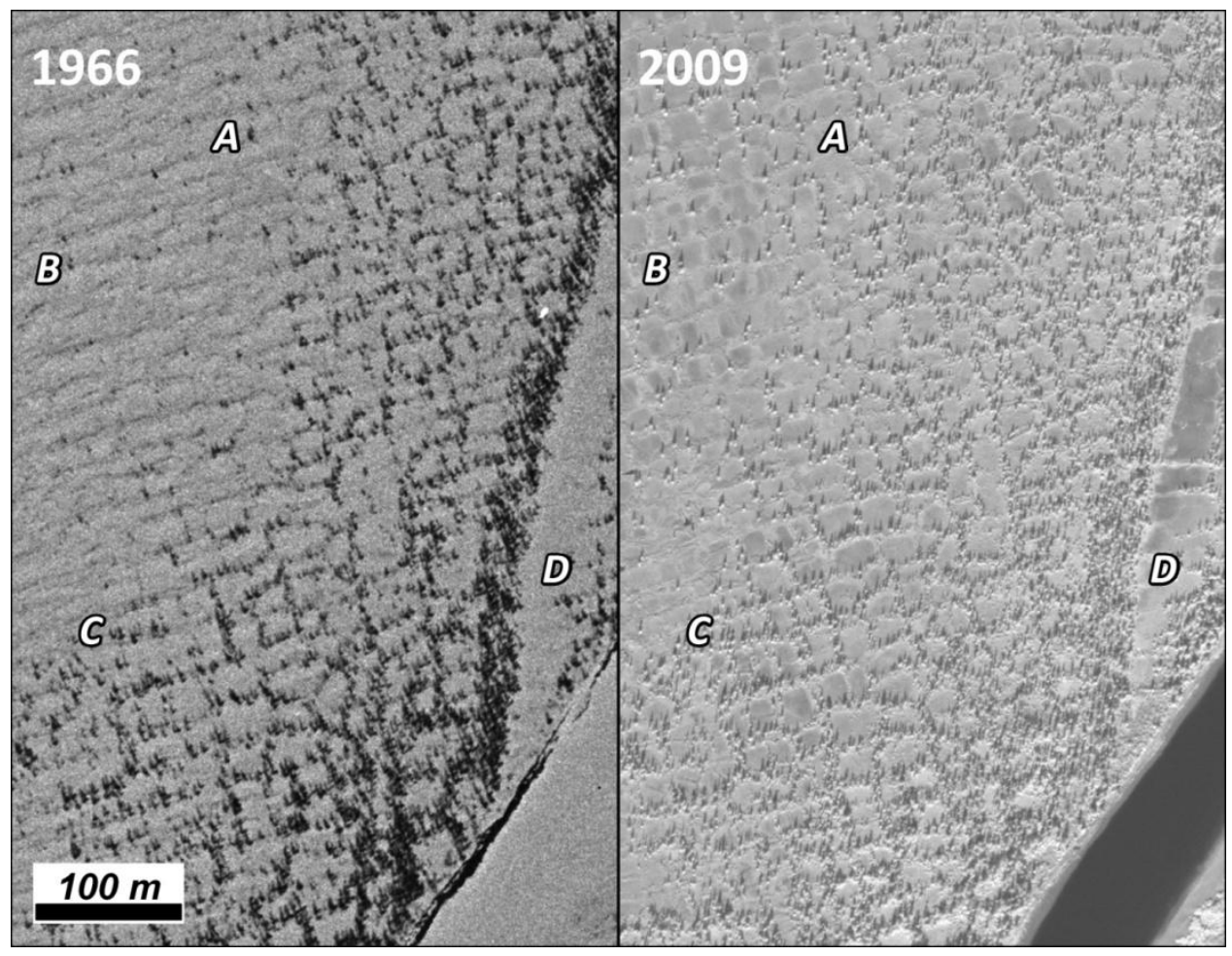

Fig. 2.3. Comparison of 1966 (Gambit; left) and 2009 (WorldView-1; right) imagery showing larches on rims of ice-wedge polygons at Hatanga study landscape, eastern Taymyr region. Tree shadows produce strong contrast against snow in the 1966 image. Tree abundance increased 5.0\% at the Hatanga landscape. WorldView-1 image @ Digital Globe, Inc.

archives from four commercial multi-spectral sensors-IKONOS, QuickBird, GeoEye-1, and WorldView-2 - and one panchromatic sensor, WorldView-1. All five of these sensors have a panchromatic band with spatial resolution comparable to each other (50$80 \mathrm{~cm})$ and to Gambit $(\sim 75 \mathrm{~cm})$; the four multi-spectral sensors collect data with spatial resolution comparable to Corona $(\sim 2 \mathrm{~m})$. 
Table 2.2. Period-of-record, acquisition dates, and sources of historical and modern VHR satellite imagery used to compare tall shrub and tree canopy cover at the study landscapes.

\begin{tabular}{lcccc}
\hline Landscape & $\begin{array}{c}\text { Area } \\
\left(\mathrm{km}^{2}\right)\end{array}$ & $\begin{array}{c}\text { Study } \\
\text { period } \\
(\mathrm{yrs})\end{array}$ & Historical imagery & Modern imagery $^{1}$ \\
\hline Kharp & 64 & 42 & 19 Aug 1968 (KH-4B) & 24Jul2003 (QB), 21Jun2010 (WV-1) \\
Obskaya & 59 & 43 & 19 Aug 1968 (KH-4B) & 29 Jul 2004 (IK), 3 Jun 2011 (WV-2) \\
Tanlova & 50 & 43 & 21 Aug 1968 (KH-4B) & 22 Jul 2011 (WV-2) \\
Taz & 72 & 42 & 21 Aug 1968 (KH-4B) & 9Aug2002 (IK), 20Aug2010 (WV-1) \\
Dudinka & 58 & 43 & 15 Jul 1966 (KH-7) & 9 Jul 2009 (GE-1) \\
Hatanga & 34 & 43 & 04 Jun 1966, 13 Jul 1966 (KH-7) & 29 Jul 2009 (WV-1) \\
Lukunsky & 34 & 44 & 13 Mar 1965 (KH-7) & 11 Jul 2009 (GE-1) \\
Uyandi & 54 & 44 & 13 Jul 1966(KH-7) & 28 May 2010 (GE-1) \\
Kolyma & 45 & 45 & 1 Jun 1965, 1 Oct 1965 (KH-7) & 16Sep2003 (QB), 7Jul2010 (WV-1) \\
Pekulney & 73 & 41 & 25 Jul 1969 (KH-4B) & 29 Jul 2010 (GE-1) \\
Velikaya & 78 & 40 & 25 Jul 1969 (KH-4B) & 22 Jun 2009 (GE-1) \\
\hline
\end{tabular}

${ }^{1} \mathrm{IK}=\mathrm{IKONOS}$, GE-1 = GeoEye-1, QB = QuickBird, WV-1 = WorldView-1, WV-2 = WorldView-2

After we identified overlapping historical and modern imagery, we delineated study landscapes in which some boreal vegetation was already present in the 1960s. Siberian alder tends to be the dominant tall shrub in ecotonal communities of the southern Yamal (Khitun, 1995), western Taymyr (Kozhevnikov, 1996), and Chukotka regions (Belikovich, 2001; Lozhkin et al., 2006), whereas two larch species are dominant in the drier, highly continental climate regime of the eastern Taymyr Peninsula (L. gmellini) and Yakutia (L. cajanderi) (Vargina, 1976; Abaimov, 2010). Siberian dwarf pine (Pinus pumila) is also present in Yakutia and is common in Chukotka (Belikovich, 2001); we treat it as a tall shrub because of its multi-stemmed, thicket-forming growth habit. For alder-dominated ecotones, imagery had to come from the growing season $(\sim$ June to August). For larch-dominated ecotones, we also used imagery from other seasons, because shadows cast by the trees contrast strongly with snow. We did not attempt to 
quantify changes in larch cover in six ecotones for which no Gambit imagery was available, but modern imagery indicates that larch is absent from four of these ecotones, and is much less abundant than alder in the Kharp and Obskaya ecotones. Additionally, we did not record changes in tall shrub cover at one ecotone (Lukunsky), because baseline Gambit imagery came from the winter.

Once we identified ecotonal areas with useful imagery, we delineated study landscapes $\sim 60 \mathrm{~km}^{2}$ in size that maximized coverage of ecotonal vegetation; however, some study landscapes were smaller due to limited overlap between historical and modern imagery. All study landscapes are at least $10 \mathrm{~km}$ (and usually much farther) from populated areas; direct human disturbance is absent or limited to off-road vehicle trails. We scrutinized 1960s imagery with intent to analyze recent fire scars in treeless tundra areas, because fire is known to promote tall shrub recruitment in Low Arctic tundra (Racine et al., 2004; Lantz et al., 2012), but we found no suitable imagery. We recognized that older wildfires that occurred well before the remote-sensing period-ofrecord could confound analyses of ecotonal vegetation change and their cause, particularly in larch-dominated ecotones in central and eastern Siberia. Fire frequency is much lower, however, at the forest-tundra boundary in these regions compared to the interior of the boreal forest biome (Furyaev et al., 2001; Soja et al., 2004); published estimates of fire return intervals exceed 300 years in the vicinity of our sites on the eastern Taymyr ((Kharuk et al., 2012) and near the Kolyma River ((Berner et al., 2012). We reasoned that ecotones showing dramatic and/or highly patchy changes to vegetation (particularly in tree cover) were likely to have experienced recent fire. 
Retrospective analysis of VHR imagery

We used a point-intercept sampling approach to compare the cover of tall shrubs and trees between historical and modern imagery. We first ortho-rectified modern imagery using digital elevation models (DEMs) from the European Space Agency Data User Element Permafrost Project, that had been derived from Russian topographic maps; these DEMs have a nominal horizontal resolution of $\sim 70 \mathrm{~m}$. We then co-registered the historical photos to the modern ortho-images, by establishing control points on persistent landscape features, such as the intersections of ice-wedge polygons, individual trees, and rock outcrops. We co-registered baseline photographs to the modern ortho-images using a spline transformation with GIS software (ArcMap v. 10.0; Environmental Systems Research Institute, Redlands, USA). Although it is not possible to compute registration errors for spline transformations, the high spatial resolution of the imagery allowed us to rigorously assess co-registration across a multitude of landscape features, and insert additional control points as needed. High-resolution DEMs and ground control points would have been desirable, but these data do not exist for northern Eurasia. We stress, however, that a point-intercept sampling approach is well-suited for comparative purposes under these conditions.

After image co-registration, we generated a grid of uniformly-spaced samplingpoints for each study landscape. We spaced sampling-points at intervals of either $30 \mathrm{~m}$ or $50 \mathrm{~m}$; we sampled alder-dominated landscapes at higher resolution to support a separate study using $30 \mathrm{~m}$ resolution Landsat satellite data. We then visually assessed the sampling-points and recorded the presence/absence of tall shrub and larch cover; we took 
care to distinguish vegetation canopies from their projected shadows. From the pointintercept data, we calculated the areal cover of tall shrubs and trees in baseline and modern imagery for each ecotone. We then calculated the net change in shrub/tree cover on an area basis, and a percent basis. Finally, because the period-of-record was not the same for all landscapes, we normalized the percent change values into normalized shrub expansion rates (NSER; \% decade ${ }^{-1}$ ) and tree expansion rates (NTER; \% decade ${ }^{-1}$ ). NSER and NTER express the decadal rate of canopy cover change, as a percentage of the total canopy cover present at the beginning of the study period for each landscape.

\section{Physiographic stratification of landscapes}

At each landscape, we stratified the vegetation sampling-points into five physiographic units: upland, lowland, inactive floodplain, active floodplain, and waterbody (Table 2.3). The physiographic units integrate multiple state-factors related to soils, moisture regime, permafrost, and disturbance regime, yet are simple enough to be applied across widely-distributed study areas. We digitized physiographic units through visual photo-interpretation of modern imagery for each site; we also referred to historical imagery to delineate active floodplains. We utilized DEMs to assist in distinguishing lowland and upland physiographic units, such that only areas with slope angles $\leq 2^{\circ}$ could be assigned to the lowland unit. We then calculated NSER and NTER for each physiographic unit, within each landscape. 
Table 2.3. Descriptions of physiographic units used to stratify the vegetation samplingpoints.

\begin{tabular}{ll}
\hline Physiographic unit & Description \\
\hline Upland & $\begin{array}{l}\text { Slopes }\left(\geq 2^{\circ}\right) \text { and plateaus with high position in local topography } \\
\text { Non-floodplain areas occupying low position in local topography, flat or with } \\
\text { low relief }\left(<2^{\circ} \text { slope }\right)\end{array}$ \\
Active floodplain & $\begin{array}{l}\text { Riverine landforms and channels in which active deposition and erosion } \\
\text { occurred during the study period }\end{array}$ \\
Inactive floodplain & $\begin{array}{l}\text { Floodplains and riverine terraces lacking direct fluvial disturbance during the } \\
\text { study period }\end{array}$ \\
Waterbody & Perennial ponds, lakes, and river channels \\
\hline
\end{tabular}

\section{Field validation}

We accessed two ecotones in the southern Yamal Peninsula region on the ground (Kharp and Obskaya), and undertook an aerial reconnaissance of a third ecotone (Tanlova). We utilized these field visits to validate our photo-interpretation of vegetation and physiographic units in modern imagery. Additionally, we made general observations of soil stratigraphy and permafrost features to characterize the recent disturbance history of the Kharp and Obskaya ecotones; detailed descriptions of these landscapes can be found in (Frost et al., 2013).

\section{Climate effects on ecotonal vegetation dynamics}

We compiled mean monthly temperature and precipitation data from meteorological stations to assess the degree to which inter-landscape variability in NSER and NTER can be explained by differences in trends of growing-season temperature (June-August; hereafter, "JJA temperature”), winter temperature (November-March), and mean annual precipitation. We focused on these three climatic variables, because 
although the growth of trees and tall shrubs in tundra ecotones is largely limited by summer temperature (Alexandrova, 1974), treeline dynamics are often more strongly linked to winter temperature trends (Harsch et al., 2009), and moisture regime is known to strongly affect temporal dynamics of tree productivity and recruitment in forest-tundra (Lloyd \& Fastie, 2002; Devi et al., 2008; Beck et al., 2011; Lloyd et al., 2011).

We acquired station data from the National Climatic Data Center at $\langle$ http://www.ncdc.noaa.gov/land-based-station-data $>$ and calculated annual values of JJA temperature, winter temperature, and precipitation for the remote-sensing period-ofrecord for each ecotone; we also included three preceding years, to account for short-term lags in seed production and seed viability arising from climatic conditions in previous years. We converted the temperature and precipitation values to anomalies with respect to a 1981-2010 base period, and conducted least-squares linear regression to determine the magnitude and significance of temporal trends. We then conducted least-squares regression between NSER and NTER, and climatic variables for which significant trends were found. Additionally, because the study landscapes span a wide gradient in mean annual precipitation (MAP) $\left(198-515 \mathrm{~mm} \mathrm{year}^{-1}\right.$; Table 2.1), we conducted regressions between NSER and NTER, and MAP. Five of the ten ecotones are located within $45 \mathrm{~km}$ of a meteorological station, and all are within $200 \mathrm{~km}$ of one or more stations; when possible, we averaged anomalies from two stations within $250 \mathrm{~km}$ for ecotones that lacked a nearby ( $<45 \mathrm{~km})$ station (Fig. S1 in Supplementary Information). 


\section{Results}

\section{Continental-scale vegetation changes}

Across the network of eleven ecotonal landscapes, the total cover of tall shrubs and larch (if present) increased in nine landscapes $(+3.0-+25.9 \%$; median $+8.4 \%)$, declined in one landscape $(-5.9 \%)$, and remained about the same in one landscape ($0.8 \%$ ) (Table 2.4). Tall shrub cover increased in nine landscapes $(+5.3-+25.9 \%$; median $+11.4 \%$ ), and there was little net change in one landscape (-0.8\%) (Fig. 2.4); we did not assess changes in shrub cover in one landscape (Lukunsky) due to the seasonal timing of 1960s imagery. Larches occurred in seven of the eleven landscapes; larch cover increased in four landscapes $(+3.0 \%-+18.2 \%$; median $+5.9 \%)$ and declined in one landscape ($16.8 \%)$. We did not quantify changes in larch cover in two additional landscapes that had trees (Kharp and Obskaya), because higher-resolution Gambit imagery was not available.

The most extensive landcover changes, on both a percent and especially an area basis, occurred in shrub-dominated ecotones. At Velikaya, the one ecotone in which total shrub cover stayed about the same, there was a net loss of riparian shrublands, but tall shrub cover increased slightly in other parts of the landscape. Among the four larchdominated ecotones, modest increases in larch cover occurred at Hatanga, Lukunsky, and Uyandi, while larch cover declined markedly at Kolyma due to thaw of ice-rich permafrost and subsequent ponding. The largest percent increases in larch cover occurred at Dudinka; however, larch is not common in this ecotone, and the great majority of landcover change at this site was the result of tall shrub increase. In the four ecotones in which we assessed changes in both tall shrub and larch cover, percent increases in shrub 
Table 2.4. Summary of areal and percent change in tall shrub and tree canopy cover at eleven Siberian ecotones, and the total area of the ecotones excluding waterbodies. Negative values are shown in parentheses. We did not analyze changes in tall shrub cover at Lukunsky, and we did not analyze changes in larch cover for the six landscapes that lacked Gambit historical imagery; modern shrub and tree cover values are given for these landscapes.

\begin{tabular}{|c|c|c|c|c|c|c|c|c|c|}
\hline \multirow[b]{2}{*}{ Site } & \multicolumn{4}{|c|}{ Tall shrub cover (ha) } & \multicolumn{4}{|c|}{ Tree cover (ha) } & \multirow{2}{*}{$\begin{array}{l}\text { Total } \\
\text { land } \\
\text { (ha) }\end{array}$} \\
\hline & $1960 \mathrm{~s}$ & $2000 \mathrm{~s}$ & $\Delta$ & $\% \Delta$ & $1960 \mathrm{~s}$ & $2000 \mathrm{~s}$ & $\Delta$ & $\% \Delta$ & \\
\hline Kharp & 713 & 771 & 58 & 8.4 & - & 59 & - & - & 6,198 \\
\hline Obskaya & 484 & 585 & 102 & 21.0 & - & 43 & - & - & 5,887 \\
\hline Tanlova & 331 & 395 & 65 & 19.5 & - & 0 & - & - & 4,274 \\
\hline Taz & 1,213 & 1,277 & 64 & 5.3 & - & 0 & - & - & 6,894 \\
\hline Dudinka & 1,284 & 1,617 & 333 & 25.9 & 6 & 7 & 1 & 18.2 & 5,130 \\
\hline Hatanga & 153 & 161 & 8 & 5.4 & 136 & 142 & 7 & 5.0 & 2,778 \\
\hline Lukunsky & - & 18 & - & - & 245 & 262 & 17 & 6.7 & 2,910 \\
\hline Uyandi & 2 & 2 & $<1$ & 14.3 & 550 & 566 & 17 & 3.0 & 5,356 \\
\hline Kolyma & 236 & 263 & 27 & 11.4 & 378 & 315 & (62) & $(16.5)$ & 3,494 \\
\hline Pekulney & 1,230 & 1,305 & 75 & 6.1 & - & 0 & - & - & 7,287 \\
\hline Velikaya & 1,607 & 1,594 & (13) & $(0.8)$ & - & 0 & - & - & 7,190 \\
\hline
\end{tabular}

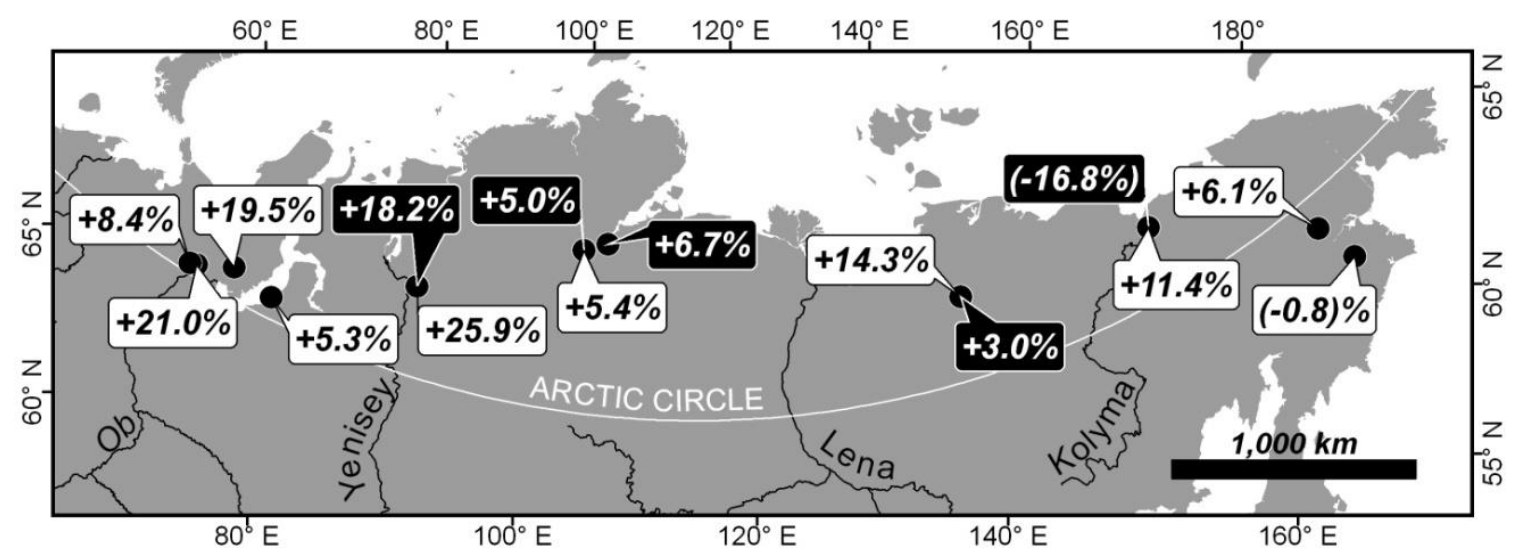

Fig. 2.4. Summary of net changes in tall shrub (white boxes) and larch (black boxes) cover at eleven tundra ecotones in northern Siberia. Negative values are given in parentheses. 
cover were uniformly greater than for larches. Across all ecotones, we recorded virtually no die-back of pre-existing tall shrub and tree cover, except on active floodplains and in areas affected by thaw of ice-rich permafrost.

The largest increases in tall shrub cover occurred at ecotones in the northwest Siberian region. Photo-interpretation, corroborated by field observations at three of the ecotones and floristic descriptions in the vicinity of two others (Khitun, 1995; Kozhevnikov, 1996), indicate that tall shrublands in these five ecotones are strongly dominated by alder. Alder shrubland extent increased $>5 \%$ in all five northwest Siberian ecotones, and by $\geq 19.5 \%$ in three of them. The $6.1 \%$ increase in tall shrubland cover observed at one Chukotkan landscape (Pekulney), where alder is also the dominant tall shrub, fell within the range recorded in northwest Siberian landscapes. At Velikaya, cover of riparian alder and willow (Salix) shrublands declined, but there was a modest increase of dwarf pine on long-abandoned river terraces, and in uplands. Dwarf pine abundance also increased at Uyandi, although its distribution is extremely limited there. We could not distinguish between tall shrub species at Hatanga and Kolyma because modern multi-spectral imagery was lacking; however, floristic descriptions indicate that tall shrublands in these areas are primarily composed of willow and alder (Vargina, 1976; Petrovsky \& Koroleva, 1979). Tall shrub cover increased in both landscapes; at Kolyma, shrub cover increased even as tree cover decreased. 
Landscape heterogeneity of ecotonal vegetation change

We observed substantial contrasts in rates of shrub and tree canopy expansion, with respect to physiographic units. Shrub and tree canopy cover increased in uplands at all nine landscapes in which uplands were present, and increases in upland shrub and tree cover accounted for most of the total increases within eight of these landscapes (Fig. 2.5). In lowlands, tall shrub canopy cover increased in seven landscapes and was unchanged in two landscapes, while lowland tree cover increased in two landscapes, remained the same in one landscape, and declined in one landscape (Table 2.5). Rates of shrub and tree canopy expansion were higher in uplands than in lowlands across all nine landscapes in

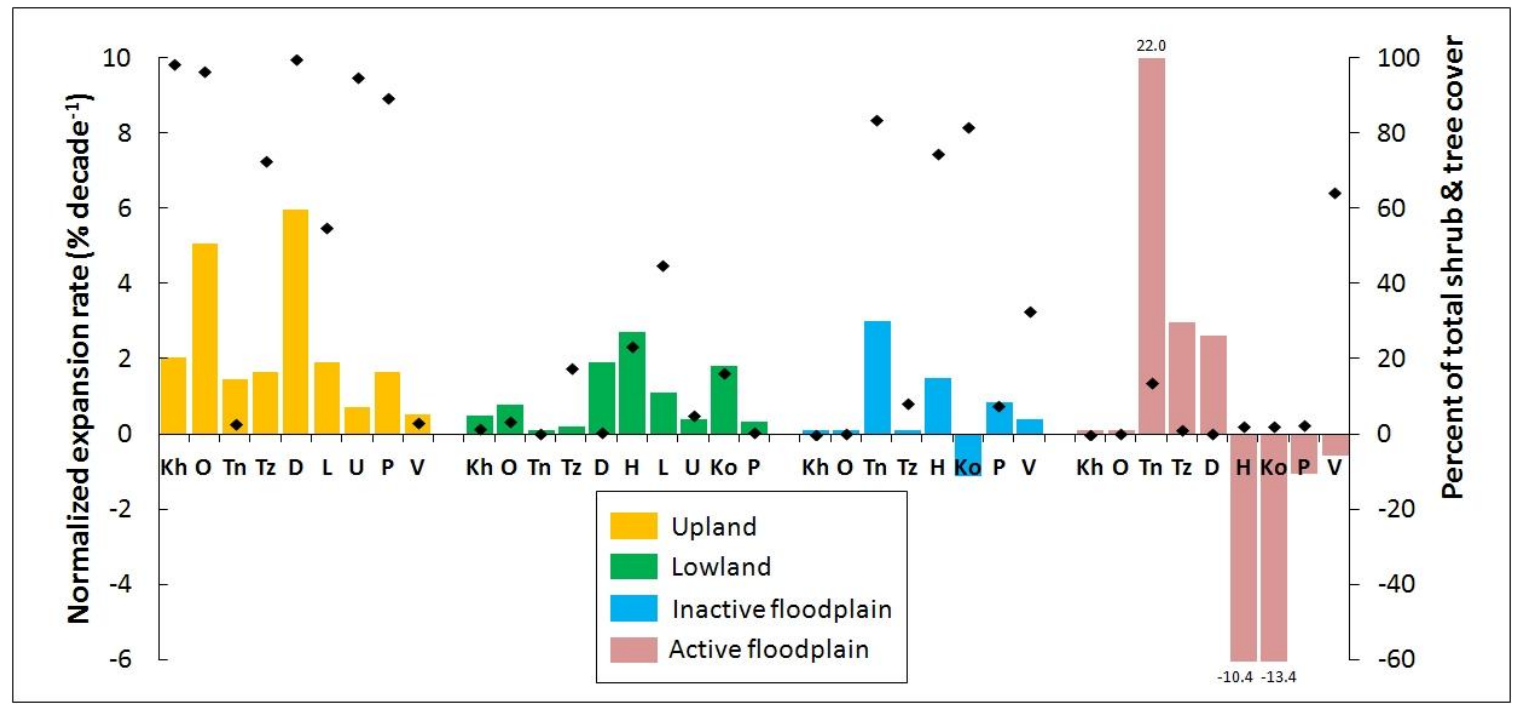

Fig. 2.5. Normalized expansion rate of tall shrubs and trees in four physiographic units (colored bars plotted on left vertical axis), and percent of the total modern shrub and tree cover that occurred in each physiographic unit, by study landscape (black markers plotted on right vertical axis). Expansion rates for shrubs and trees are consolidated as a single value. 
Table 2.5. Summary of normalized canopy expansion rates $\left(\%\right.$ decade $\left.^{-1}\right)$ for tall shrubs (NSER) and trees (NTER) by landscape and physiographic unit. Negative rates (i.e., dieback) are shown in parentheses.

\begin{tabular}{|c|c|c|c|c|c|c|c|c|c|c|}
\hline \multirow[b]{2}{*}{ Ecotone } & \multicolumn{2}{|c|}{ Total } & \multicolumn{2}{|c|}{ Upland } & \multicolumn{2}{|c|}{ Lowland } & \multicolumn{2}{|c|}{$\begin{array}{c}\text { Inactive } \\
\text { floodplain }\end{array}$} & \multicolumn{2}{|c|}{$\begin{array}{c}\text { Active } \\
\text { floodplain }\end{array}$} \\
\hline & NTER & NSER & NTER & NSER & NTER & NSER & NTER & NSER & NTER & NSER \\
\hline Kharp & - & 2.0 & - & 2.0 & - & 0.5 & - & 0 & - & 0 \\
\hline Obskaya & - & 4.9 & - & 5.1 & - & 0.8 & - & 0 & - & 0 \\
\hline Tanlova & - & 4.5 & - & 1.4 & - & 0 & - & 3.0 & - & 22.0 \\
\hline Taz & - & 1.3 & - & 1.7 & - & 0.2 & - & 0 & - & 3.0 \\
\hline Dudinka & 4.2 & 6.0 & 4.2 & 6.0 & - & 1.9 & - & 0 & - & 10.0 \\
\hline Hatanga & 1.2 & 1.3 & - & - & 0 & 2.8 & 1.1 & 2.0 & 0 & $(11.1)$ \\
\hline Lukunsky & 1.5 & - & 1.9 & - & 1.1 & - & - & & - & - \\
\hline Uyandi & 0.7 & 3.2 & 0.7 & 3.2 & 0.4 & 0 & - & 0 & - & - \\
\hline Kolyma & (3.7) & 2.5 & - & - & $(12.6)$ & 5.9 & (2.6) & 2.3 & $(21.4)$ & (7.9) \\
\hline Pekulney & - & 1.5 & - & 1.6 & - & 0.3 & - & 0.8 & - & (1.0) \\
\hline Velikaya & - & $(0.2)$ & - & 0.5 & - & - & - & 0.4 & - & $(0.6)$ \\
\hline
\end{tabular}

which both physiographic units were present. On inactive floodplains, tall shrub cover increased in five landscapes and was unchanged in five landscapes; tree cover increased on inactive floodplains at two landscapes, was unchanged in one landscape, and declined in one landscape. Changes in canopy cover were most variable on active floodplains; across the network of ecotones, we observed examples of dramatic increase, dramatic decrease, and little or no change in shrub canopy cover. Tree canopy cover on active floodplains either declined, or was unchanged.

Climate effects on ecotonal vegetation dynamics

Significant, linear increases in JJA temperature occurred over the study period for all landscapes $(\mathrm{p}<0.05)$, except Hatanga $(\mathrm{p}=0.15)$, Lukunsky $(\mathrm{p}=0.13)$, and Uyandi ( $\mathrm{p}$ $=0.06$ ). (Fig. S2 in Supplemental Information). The magnitude of increase ranged from 
$0.28-0.49^{\circ} \mathrm{C}$ decade $^{-1}$. Mean JJA temperatures were relatively cool at all ecotones in the early- to mid-1960s - the beginning of the remote-sensing period-of-record examined here. Significant changes in winter temperature occurred at only one landscape (Kolyma), and significant changes in annual precipitation occurred at only two landscapes (Taz and Uyandi).

We observed a positive, but non-significant $(\mathrm{p}=0.15)$ linear relationship between canopy expansion rates and rates of JJA temperature increase (Fig. 2.6a). However, there was a significant linear relationship between canopy expansion rates and MAP $(p=0.03)$ (Fig. 2.6b). In both of these regressions, we excluded increases in canopy cover that were associated with primary succession on floodplains and recently-drained lake basins, and losses in canopy cover that were directly attributable to physical disturbance, such as
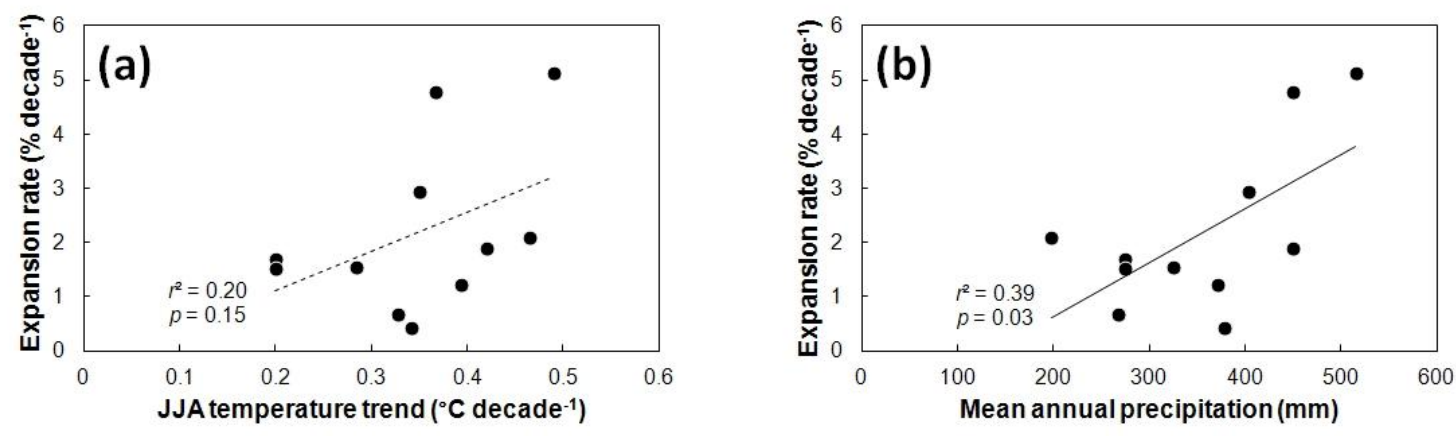

Fig. 2.6. Linear regression of normalized expansion rate $\left(\%\right.$ decade $\left.^{-1}\right)$ of tall shrubs and trees against (a) JJA temperature trend $\left({ }^{\circ} \mathrm{C}\right.$ decade $\left.{ }^{-1}\right)$; and (b) mean annual precipitation (mm). Shrub and tree expansion rates are consolidated into a single value. Expansion rates exclude canopy cover increases related to primary succession, and canopy cover decreases related to fluvial disturbance and thermokarst. 
cutbank erosion and thermokarst.

\section{Discussion}

Continental-scale vegetation changes

The direct, spatially-explicit assessments of multi-decadal changes in tall shrub and tree cover presented here are the first reported to date for most of the Siberian Low Arctic. We observed an overall pattern of increasing tall shrub and tree abundance at the continental-scale, but we did observe disturbance-induced declines in two ecotones. The most rapid and extensive landcover changes were associated with expansion of tall shrublands. The rate and extent of future land-cover changes in Siberian ecotones are therefore likely to vary regionally, with respect to the relative abundance of tall shrubs in ecotonal communities.

Previous studies of tundra shrub dynamics in Siberia are few, and have primarily addressed trends and relationships between shrub secondary growth and climate (Forbes et al., 2010; Blok et al., 2011). Spatially-explicit, quantitative assessments of changes in shrub cover-which include not only changes in the size of pre-existing shrubs, but also the recruitment of new individuals — are almost entirely lacking. Such assessments have, however, been conducted at landscape- to regional scales in North America that found tall shrub increase of similar magnitude to what we observed in Siberian ecotones. In northern Alaska, Tape et al. (2006) found that alder abundance increased in $\sim 87 \%$ of repeated, oblique aerial photo-pairs over a $\sim 50$ year period, while Naito \& Cairns (2011) reported alder cover increases of $\sim 0-46 \%$ in five vertical photo-pairs spanning 35 years. 
In northwest Canada, Lantz et al. (2012) reported a $~ 38 \%$ increase in alder shrubland extent over a 32-year period. Retrospective studies in northern Quebec reveal tall shrub increase of similar magnitude over 40-50 years (Tremblay et al., 2012; Ropars \& Boudreau, 2012), although these increases primarily involve American dwarf birch (Betula glandulosa), a Nearctic species that does not occur in Siberia. Considered together with these studies, as well as observations indicating shrub increase in European tundra (Hallinger et al., 2010), our results from northern Siberia leave little question that tall shrub increase in tundra is a circumpolar phenomenon, resulting within decades in conspicuous land-cover changes across tundra landscapes with divergent climate histories, physiographic characteristics, biogeography, and glacial histories.

Temporal dynamics of larch growth in northern Siberia have been comparatively well-studied, although few studies have quantitatively assessed changes in larch abundance. Local- to continental-scale increases in larch canopy cover have been inferred in Siberian forest-tundra primarily on the basis of demographic studies of present-day larch stands, and temporal trends in remotely-sensed proxies of tree density and vegetation productivity. (Esper \& Schweingruber, 2004) concluded that episodes of increased larch recruitment occurred during the mid- and late- $20^{\text {th }}$ century in foresttundra in northwest Siberia and the southern Taymyr. Other dendroecological studies reached similar conclusions for Siberian larch (L. sibirica) in elevational ecotones of the Polar Ural Mountains (Shiyatov et al., 2005; Mazepa, 2005; Devi et al., 2008), near our study landscape at Kharp. In the eastern Taymyr region near Hatanga, (Kharuk et al., 2006) concluded that larch density increased in forest-tundra since 1965 , based on 
analyses of relatively coarse-resolution $\mathrm{KH}-4 \mathrm{~A}$ Corona and Landsat data. In a regionalscale study in Yakutia, (Lloyd et al., 2011) found that temporal trends in NDVI were almost uniformly positive near the forest-tundra transition, a pattern also observed in Alaskan forest-tundra (Beck et al., 2011). Our quantitative assessments of larch canopy cover within diffuse treeline zones in northwest Siberia, Taymyr, and Yakutia generally support inferences of increasing larch abundance in these regions. However, while numerous lines of evidence indicate large-scale increases in larch abundance in Siberian forest-tundra, our assessments indicate that increases in larch cover are generally small compared to changes in shrub cover. Although conspicuous increases in larch abundance have been documented over a 35 year period in abrupt, elevational ecotones of the Polar Ural Mountains (Moiseev \& Shiyatov, 2003), our results indicate that the latitudinal expansion of larch is likely to require centuries. In the near term, tall shrubs appear far more likely to drive land-cover changes within the present-day Low Arctic.

\section{Landscape heterogeneity of ecotonal vegetation change}

In most landscapes, tall shrub and tree increases were concentrated on specific geomorphic features and were frequently linked to permafrost processes (Frost et al., 2013), indicating that the susceptibility of tundra landscapes to shrub and tree advance is highly dependent on local attributes of soils, permafrost, and disturbance regime. Net changes in ecotonal tall shrub and tree cover were uniformly positive in upland areas, and the rate and spatial extent of increase - particularly of shrubs - tended to be greatest in uplands. These findings are somewhat at odds with landscape-scale patterns of shrub 
expansion observed in North America. Several retrospective studies reported shrub increase primarily on floodplains, fluvial terraces and adjacent valley slopes, with relatively little change in upland tundra in northern Alaska (Tape et al., 2006; Naito \& Cairns, 2011) and northern Quebec (Ropars \& Boudreau, 2012). In northwest Canada, however, (Lantz et al., 2012) observed rapid shrub expansion in upland tundra following wildfire. Although some of these apparent inconsistencies may arise from differences in the way landscape components were categorized, contrasts in intra-landscape patterns of ecotonal vegetation change appear likely given the variability of soils, permafrost attributes, disturbance history, and other state-factors at the circumpolar scale.

Most of the shrub increase we observed in northwest Siberian landscapes was closely linked to disturbance processes in upland permafrost. Ground-based observations at Kharp and Obskaya indicated that virtually all shrub increase occurred in areas with abundant fine-scale patterned-ground features, and that the recruitment of individual shrubs occurred almost entirely on the mineral-rich centers of sorted- and non-sorted circles (Frost et al., 2013). Widespread patterned-ground features, similar to those found at Kharp and Obskaya, are apparent in modern VHR imagery within newly-established shrublands at the Dudinka ecotone, where we observed the highest rates of shrub increase of any site; we infer that shrub expansion here was similarly facilitated by widespread cryogenic disturbance processes in patterned-ground landscapes. Rates of shrub expansion were comparatively modest at Taz, but many pre-existing shrub patches increased in size on and adjacent to active-layer detachments (Lewkowicz, 1992), a form of cryogenic landslide that is common on marine sedimentary deposits of the Yamal and 
Tazovskiy Peninsulas (Leibman, 1995; Ermokhina \& Myalo, 2012; Walker et al., 2012a). These observations are consistent with findings from northwest Canada, where alder shrublands are closely linked to retrogressive thaw slumps (Lantz et al., 2009), a form of cryogenic landslide that also exposes mineral substrates. Shrub expansion was also concentrated in uplands at the Pekulney landscape in Chukotka. Here, upland shrub increase was not linked to permafrost geomorphology, and was instead associated with sparsely vegetated areas, such as colluvial hillslopes and rock outcrops. This correspondence is similar to reports from northern Alaska (Tape et al., 2012), and is broadly consistent with observations elsewhere of alder increase on sparsely vegetated, mineral-rich microsites.

We observed increases in shrub and tree cover in the lowland physiographic unit in most landscapes, but shrubs and trees tended to be sparsely distributed in lowland areas (see Fig. 5) and several landscapes exhibited "inverted treelines," such that shrub and tree occurrence was restricted to areas with high position in local topography. In permafrost regions, this distribution pattern is indicative of paludified, wet soils and a shallow active-layer in low-lying areas. Field measurements at one such landscapeKharp-indicated dramatically shallower active-layer depth and soil temperature in lowland shrublands relative to upland stands (Frost et al., 2012). Although we did not make systematic measurements at other landscapes, feedbacks among soil moisture, organic matter content, and active layer depth are well-documented in lowland permafrost across the Arctic (Washburn, 1980), and we suggest that the susceptibility of lowland areas to shrub and tree increase is generally low because the cold, organic- 
dominated, wet soils are unfavorable for seedling development. We did, however, observe extensive increases in lowland shrub cover at two sites, Hatanga and Kolyma. Thaw lakes are widespread in these landscapes, and virtually all lowland shrub increase was concentrated in lake basins that had drained during the study period; recently-drained lake basins typically support highly productive plant communities, due to the high availability of nutrients in lacustrine sediments (Billings and Peterson, 1980). We also observed modest increases in lowland tree cover at Hatanga, where larches are closely linked to mesic microsites on the elevated rims of low-centered ice-wedge polygons (Fig. 3). Extensive larch die-back occurred in similar geomorphic environments at Kolyma, however, due to thaw of ground-ice underlying the polygons. Widespread loss of forest cover after permafrost thaw has also been documented in interior Alaska (Jorgenson et al., 2001); these observations indicate that losses of present-day tree and shrub cover are likely, where their occurrence is dependent on ice-rich permafrost.

Changes in shrub and tree canopy cover were highly variable on floodplains, with dramatic increase, dramatic decrease, and no change all observed at the landscape-scale. The magnitude of vegetation change on floodplains varied largely with respect to channel morphology. We observed little or no change in shrub and tree cover on the narrow floodplains of small, incised streams. Three ecotones encompassed floodplains of meandering rivers; shrub establishment greatly exceeded mortality of 1960s-era shrublands elsewhere on meandering floodplains at two ecotones, while small net losses occurred at a third. One ecotone (Velikaya) encompassed a large, braided floodplain; here, a large proportion of 1960s-era riparian shrub cover suffered mortality due to channel 
migration and flooding, and establishment of successional shrublands elsewhere on the floodplain did not fully compensate for these losses. Large rivers also occurred at the Hatanga and Kolyma ecotones; these rivers are well-channelized, but cut-bank erosion of ice-rich polygonal ground resulted in substantial mortality of larch woodlands, and these losses were not compensated by larch development on young fluvial deposits. Given the dynamic geomorphic and successional processes associated with floodplains and riparian vegetation, our observations on floodplains are somewhat equivocal in the context of directional changes in ecotonal vegetation. An imbalance between the establishment and mortality of riparian vegetation over time may be indicative of directional changes, and increases in high-biomass shrubs and trees may promote greater river channelization, as has been reported in Alaska (Tape et al., 2006; Naito \& Cairns, 2011). The wide range of floodplain vegetation changes that we observed, however, indicates that responses of riparian landcover to future environmental changes will be highly variable.

\section{Climate effects on ecotonal vegetation dynamics}

In most landscapes, tall shrub and tree increases were clearly linked to specific geomorphic features, emphasizing the importance of local-scale mechanisms that create or maintain favorable substrates for seedling recruitment. The near-ubiquity of tall shrub and tree increase reported from widely divergent landscapes spanning the circumpolar region, however, leaves little doubt that ecotonal vegetation is responding to large-scale climate dynamics. The 1960s-era imagery applied in this study was acquired during a relatively cool period across much of the Arctic, particularly in northwest Siberia and 
Chukotka. The 40-45 year period investigated here therefore offers an opportunity to assess rates of shrub and tree expansion during a period of relatively rapid warming. In order to assess the short-term, biotic response of ecotonal vegetation to climate across the network of ecotones, we derived canopy expansion rates for tall shrubs and trees that exclude primary successional processes (e.g., colonization of young fluvial deposits and drained-lake basins), and disturbance-induced mortality. Although our analyses are based on only eleven landscapes, canopy expansion rates were derived from spatially continuous sampling across a wide range of geomorphic features distributed across permafrost-dominated, latitudinal tundra ecotones. Our findings suggest a positive relationship between landscape-scale canopy expansion rates and local temperature trends, but results are not significant $(\mathrm{p}=0.15)$ (Fig. 6a). Expansion rates are correlated, however, with mean annual precipitation $(p=0.03)$ (Fig. 6b). This result suggests that the capacity for vegetation to respond to warming is relatively low in dry, highly continental regions of central and eastern Siberia, compared to moister regions in northwest Siberia and Chukotka. Such a relationship is consistent with regional-scale dendroecological measurements of white spruce (Picea glauca) in Alaska, which indicated an negative response of tree growth to warming at all but the wettest ecotones (Lloyd \& Fastie, 2002). Based on our observations at eleven widely-separated ecotones which share similar JJA temperatures and JJA temperature trends, but span a wide precipitation gradient $(\sim 200-$ $515 \mathrm{~mm} \mathrm{yr}^{-1}$ ), we conclude that within multi-decadal timescales, widespread increases in ecotonal shrub and tree cover are only likely to occur in moist regions. We suggest, however, that the full effects of post-1960s climate trends on plant growth and 
reproduction - particularly of larches, which require decades to mature even on favorable sites—will likely require several additional decades to become fully manifest.

Landscape susceptibility to advance of boreal vegetation

At most of the study landscapes, ecotonal vegetation changes - particularly in the cover of tall shrubs - were linked to disturbance features, with little change evident in well-vegetated areas. Disturbance mechanisms varied within and among landscapes, ranging from mosaics of cryoturbated microsites in patterned-ground, to patch-based disturbances created by cryogenic landslides, and larger-scale floodplain processes. Our observations of shrub increase in disturbed areas are consistent with reports from northwest Canada, where growth and reproduction of alder are enhanced on retrogressive thaw slumps (Lantz et al., 2009) and after wildfire (Lantz et al., 2012). All of the disturbance mechanisms described here expose or maintain mineral-rich soils, which tend to be more favorable for shrub growth, seed production, and seedling recruitment than undisturbed tundra with a continuous cover of competing vegetation and thick accumulations of organic matter. One limitation brought about by the continental-scale domain of our study, was the impracticality of obtaining ground data concerning soils and disturbance history for all landscapes. Wildfire is known to play a key role in ecotonal vegetation dynamics (e.g., (Payette \& Gagnon, 1985; Higuera et al., 2008; Lantz et al., 2012), and there are indications that tundra fire frequency is increasing (e.g., Hu et al., 2010), which raises the question of what influence historical wildfire may have had in the ecotonal vegetation dynamics we observed. We recognized that although fire is 
infrequent in the areas studied, large-scale disturbance due to historical fire offers a potential explanation for observations of dramatic increases in shrub and tree cover. Field studies indicated that extensive increases in shrub cover at two sites (Kharp and Obskaya) were not related to recent wildfire (see Frost et al., 2013) and were instead linked to shrub recruitment in patterned-ground. Spatial patterns of shrub increase at Dudinka, where landcover changes were most extensive, indicate a similar mechanism for shrub expansion there. We cannot rule out legacy effects of historical fire at other landscapes, but the frequent correspondence between vegetation changes and other, geomorphic disturbance processes indicate against widespread fire effects. Fire was most likely to have occurred in the larch-dominated ecotones, but the relatively small observed rates of tree canopy cover increase indicate that our observations do not represent secondary succession after fire.

Given the frequent correspondence between shrub expansion and disturbance features, much of the landscape heterogeneity of shrub expansion reported here and elsewhere may best be explained by local disturbance agents, their intensities, and the spatio-temporal scales at which they operate, rather than multi-decadal climate trends. The most extensive land-cover changes that we observed were found in northwest Siberian landscapes with abundant, small-scale patterned-ground features, in which frostheave occurs annually within extensive mosaics of meter-scale microsites. At another northwest Siberian landscape (Taz), patterned-ground was virtually absent, and shrub increase primarily occurred on cryogenic landslides; however, these features were relatively small and landscape-wide changes in shrub cover were not extensive. All of 
these northwest Siberian landscapes share similar multi-decadal climate trends, so contrasts in the rate and extent of tall shrub increase are best explained by differences in the spatio-temporal dynamics of local disturbance processes. We conclude that the landscape-scale heterogeneity of observed changes in forest-tundra ecotonal vegetation, with respect to landscape physiography, permafrost attributes, and disturbance regime, indicates that tall shrub and tree increase is a circumpolar phenomenon that is strongly governed by both regional and local rules related to climate regime, biogeography, and landscape history.

\section{Acknowledgements}

This work was funded by the Department of Environmental Sciences at the University of Virginia, and the National Aeronautics and Space Administration (NASA) Land-Cover and Land-Use Change initiative, grants NNG6GE00A and NNX09AK56G. We thank the National Geospatial-Intelligence Agency (NGA) Commercial Imagery Program for permitting scientists access to NGA satellite imagery archives; we are greatly indebted to Jaime Nickeson at NASA, and Paul Morin at the University of Minnesota for coordinating NGA data requests. We also thank Annett Bartsch and the DUE Permafrost project for providing DEMs for northern Siberia. This manuscript benefited greatly from comments by Donald "Skip" Walker, University of Alaska, Marina Leibman at the Earth Cryosphere Institute, and Gosha Matyshak at Moscow State University. 


\section{References}

Abaimov, A. P. 2010. Geographical distribution and genetics of Siberian larch species. Pp. 41-58 in: Osawa, A., Zyryanova, O. A., Matsuura, Y., Kajimoto, T. and Wein, R. W. (eds.) Permafrost Ecosystems: Siberian Larch Forests. Springer, Dordrecht, Netherlands.

ACIA. 2005. Arctic Climate Impact Assessment. Cambridge University Press, New York, NY.

Alexandrova, V. D. 1974. The Arctic and Antarctic: Their Division into Geobotanical Areas. Cambridge University Press, Cambridge, UK.

Beck, P. S. A., Juday, G. P., Alix, C., et al. 2011. Changes in forest productivity across Alaska consistent with biome shift. Ecology Letters, 14, 373-379.

Belikovich, A. V. 2001. Vegetation of the Northern Koryak Highlands. Dal'nauka, Vladivostok, Russia.

Berner, L. T., Beck, P. S. A., Loranty, M. M., Alexander, H. D., Mack, M. C., and Goetz, S. J. 2012. Cajander larch (Larix cajanderi) biomass distribution, fire regime and post-fire recovery in northeastern Siberia. Biogeosciences, 9, 3943-3959.

Bhatt U. S., Walker, D. A., Raynolds, M. K., Comiso, J. C., Epstein, H. E., Jia, G., Gens, R., Pinzon, J. E., Tucker, C. J., Tweedie, C. E., and Webber, P. J. 2010. Circumpolar Arctic tundra vegetation change is linked to sea ice decline. Earth Interactions, 14, 1-20. 
Blok, D., Sass-Klaassen, U., Schaepman-Strub, G., Heijmans, M. M. P. D., Sauren, P., and Berendse, F. 2011. What are the main climate drivers for shrub growth in Northeastern Siberian tundra? Biogeosciences, 8, 1169-1179.

Briffa, K. R., Jones, P. D., Schweingruber, F. H., Shiyatov, S. G., and Cook, E. R. 1995. Unusual twentieth-century summer warmth in a 1,000-year temperature record from Siberia. Nature, 376, 156-159.

CAVM Team. 2003. Circumpolar Arctic Vegetation Map (1:7,500,000 scale). Conservation of Arctic Flora and Fauna (CAFF) Map No. 1. U. S. Fish and Wildlife Service, Anchorage, AK.

Danby, R. K., and Hik, D. S. 2007a. Responses of white spruce (Picea glauca) to experimental warming at a subarctic alpine treeline. Global Change Biology, 13, 437-451.

Danby, R. K., and Hik, D. S. 2007b. Evidence of recent treeline dynamics in southwest Yukon from aerial photographs. Arctic, 60, 411-420.

Devi, N., Hagedorn, F., Moiseev, P., Bugmann, H., Shiyatov, S., Mazepa, V., and Rigling, A. 2008. Expanding forests and changing growth forms of Siberian larch at the Polar Urals treeline during the 20th century. Global Change Biology, 14, 15811591.

Dial, R. J., Berg, E. E., Timm, K., McMahon, A., and Geck, J. 2007. Changes in the alpine forest-tundra ecotone commensurate with recent warming in southcentral Alaska: Evidence from orthophotos and field plots. Journal of Geophysical Research, 112, G04015. 
Ermokhina, K. A., and Myalo, E. G. 2012. Phytoindicators of landslide disturbances in the central Yamal. Proceedings of the Tenth International Conference on Permafrost, 2, 531-536.

Esper, J., and Schweingruber, F. H. 2004 Large-scale treeline changes recorded in Siberia. Geophysical Research Letters, 31, L06202.

Foley, J. A., Kutzbach, J. E., Coe, M. T., and Levis, S. 1994. Feedbacks between climate and boreal forests during the Holocene epoch. Nature, 371, 52-54.

Forbes, B. C., Macias-Fauria, M. M., and Zetterberg, P. 2010. Russian Arctic warming and "greening" are closely tracked by tundra shrub willows. Global Change Biology, 16, 1542-1554.

Frost, G. V., Epstein, H. E., Walker, D. A., Matyshak, G., and Ermokhina, K. 2012 Linkages between patterned ground, alder shrubland development, and active layer temperature in the northwest Siberian Low Arctic. Proceedings of the Tenth International Conference on Permafrost, 1, 119-124.

Frost, G. V., Epstein, H. E., Walker, D. A., Matyshak, G., and Ermokhina, K. 2013. Patterned-ground facilitates shrub expansion in Low Arctic tundra. Environmental Research Letters, 8, 015035.

Furyaev, V. V., Vaganov, E. A., Tchebakova, N. M., and Valendik, E. N. 2001. Effects of fire and climate on successions and structural changes in the Siberian boreal forest. Eurasian Journal of Forest Research, 2, 1-15.

Gamache, I., and Payette, S. 2005. Latitudinal response of subarctic tree lines to recent climate change in eastern Canada. Journal of Biogeography, 32, 849-862. 
Hallinger, M., Manthey, M., and Wilmking, M. 2010. Establishing a missing link: warm summers and winter snow cover promote shrub expansion into alpine tundra in Scandinavia. New Phytologist, 186, 890-899.

Harsch, M. A., Hulme, P. E., McGlone, M. S., and Duncan, R. P. 2009. Are treelines advancing? A global meta-analysis of treeline response to climate warming. Ecology Letters, 12, 1040-1049.

Higuera, P. E., Brubaker, L. B., Anderson, P. M., Brown, T. A., Kennedy, A. T., and Hu, F. S. 2008. Frequent fires in ancient shrub tundra: implications of paleorecords for arctic environmental change. PLoS One, 3, e0001744.

Holtmeier, F.-K., and Broll, G. 2005. Sensitivity and response of northern hemisphere altitudinal and polar treelines to environmental change at landscape and local scales. Global Ecology and Biogeography, 14, 395-410.

Jorgenson, M. T., Racine, C. H., Walters, J. C., and Osterkamp T. E. 2001. Permafrost degradation and ecological changes associated with a warming climate in central Alaska. Climatic Change, 48, 551-579.

Kaplan, J. O., and New, M. 2006. Arctic climate change with a $2^{\circ} \mathrm{C}$ global warming: Timing, climate patterns and vegetation change. Climatic Change, 79, 213-241.

Kharuk, V. I., Dvinskaya, M. L., and Ranson, K. J. 2012. Fire return intervals within the northern boundary of the larch forest in central Siberia. International Journal of Wildland Fire, 22, 207-211.

Kharuk, V. I., Ranson, K. J., Im, S. T., and Naurzbaev, M. M. 2006. Forest-tundra larch forests and climatic trends. Russian Journal of Ecology, 37, 291-298. 
Khitun, O. V. 1995. Intralandscape diversity of the flora of the Tazovsky Peninsula. Pp. 365-377 in: Sippola, A.-L. (ed.) Northern Wilderness Areas: Ecology, Sustainability, Values. Arctic Centre, Rovaniemi, Finland.

Kirdyanov, A. V., Hagedorn, F., Knorre, A. A., Fedotova, E. V., Vaganov, E. A., Naurzbaev, M. M., Moiseev, P. A., and Ringling, A. 2012. 20th century tree-line advance and vegetation changes along an altitudinal transect in the Putorana Mountains, northern Siberia. Boreas, 41, 56-67.

Kozhevnikov, Y. P. 1996. Floristic features of the Enisei forest-tundra. Botanicheskii Zhurnal, 81, 68-82.

Kullman, L. 2007. Tree line population monitoring of Pinus sylvestris in the Swedish Scandes, 1973-2005: implications for tree line theory and climate change ecology. Journal of Ecology, 95, 41-52.

Lantz, T. C., Kokelj, S. V., Gergel, S. E., and Henry, G. H. R. 2009. Relative impacts of disturbance and temperature: persistent changes in microenvironment and vegetation in retrogressive thaw slumps. Global Change Biology, 15, 1664-1675.

Lantz, T. C., Marsh, P., and Kokelj, S. V. 2012. Recent shrub proliferation in the Mackenzie Delta uplands and microclimatic implications. Ecosystems, 15, 47-59.

Leibman, M. O. 1995. Cryogenic landslides on the Yamal Peninsula, Russia: prelimimary observations. Permafrost and Periglacial Processes, 6, 259-264.

Levis, S., Foley, J. A., and Pollard, D. 2000. Large-scale vegetation feedbacks on a doubled $\mathrm{CO}_{2}$ climate. Journal of Climate, 13, 1313-1325. 
Lewkowicz, A. G. 1992. Factors influencing the distribution and initiation of active-layer detachment slides on Ellesmere Island, Arctic Canada. Pp. 223-250 in: Dixon, J. C., and Abrahams, A. D. (eds.) Periglacial Geomorphology. John Wiley and Sons Ltd., Chichester.

Lin, D. H., Johnson, D. R., Andresen, C., and Tweedie, C. E. 2012. High spatial resolution decade-time scale land cover change at multiple locations in the Beringian Arctic (1948-2000s). Environmental Research Letters, 7, 025502.

Lloyd, A. H., Bunn, A. G., and Berner, L. 2011. A latitudinal gradient in tree growth response to climate warming in the Siberian taiga. Global Change Biology, 17, $1935-1945$.

Lloyd, A. H., and Fastie, C. L. 2002. Spatial and temporal variability in the growth and climate response of treeline trees in Alaska. Climatic Change, 52, 481-509.

Lozhkin, A. V., Anderson, P. M., Matrosova, T. V., and Minyuk, P. S. 2006. The pollen record from El'gygytgyn Lake: implications for vegetation and climate histories of northern Chukotka since the late middle Pleistocene. Journal of Paleolimnology, 37, 135-153.

Mazepa, V. S. 2005. Stand density in the last millennium at the upper tree-line ecotone in the Polar Ural Mountains. Canadian Journal of Forest Research, 35, 2082-2091.

McManus, K. M., Morton, D. C., Masek, J. G., Wang, D., Sexton, J. O., Nagol, J. R., Ropars, P., and Boudreau, S. 2012. Satellite-based evidence for shrub and graminoid tundra expansion in northern Quebec from 1986 to 2010. Global Change Biology, 18, 2313-2323. 
Moiseev, P. A., and Shiyatov, S. G. 2003. Vegetation dynamics at the treeline ecotone in the Ural Highlands, Russia. Pp. 423-435 in: Nagy, L., Grabherr, G., Korner, C., and Thompson, D. B. A. (eds.) Alpine Biodiversity in Europe, Ecological Studies, Springer, Dordrecht, Netherlands.

Myers-Smith, I. H., Forbes, B. C., Wilmking, M., et al. 2011. Shrub expansion in tundra ecosystems: dynamics, impacts and research priorities. Environmental Research Letters, 6, 045509.

Naito, A. T., and Cairns, D. M. 2011. Relationships between Arctic shrub dynamics and topographically derived hydrologic characteristics. Environmental Research Letters, 6, 045506.

Payette, S., and Gagnon, R. 1985. Late Holocene deforestation and tree regeneration in the forest-tundra of Quebec. Nature, 313, 570-572.

Petrovsky, V. V., and Koroleva, T. M. 1979. On the flora of the Kolyma River Delta. Botanicheskii Zhurnal, 64, 19-39.

Racine, C., Jandt, R., Meyers, C., and Dennis, J. 2004. Tundra fire and vegetation change along a hillslope on the Seward Peninsula, Alaska, USA. Arctic, Antarctic, and Alpine Research, 36, 1-10.

Rees, G., Brown, I., Mikkola, K., Virtanen, T., and Werkman, B. 2002. How can the dynamics of the tundra-taiga boundary be remotely monitored? Ambio Special Report, 12, 56-62.

Rigina, O. 2003. Detection of boreal forest decline with high-resolution panchromatic satellite imagery. International Journal of Remote Sensing, 24, 1895-1912. 
Ropars, P., and Boudreau, S. 2012. Shrub expansion at the forest-tundra ecotone: spatial heterogeneity linked to local topography. Environmental Research Letters, 7, 015501.

Shiyatov, S. G., Terent'ev, M. M., and Fomin, V. V. 2005. Spatiotemporal dynamics of forest-tundra communities in the Polar Urals. Russian Journal of Ecology, 36, 6975.

Soja, A. J., Sukhinin, A. I., Cahoon, D. R. Jr., Shugart, H. H., and Stackhouse, P. W. Jr. 2004. AVHRR-derived fire frequency, distribution and area burned in Siberia. International Journal of Remote Sensing, 25, 1939-1960.

Sturm, M., Tape, K., and Racine, C. 2001. Climate change: Increasing shrub abundance in the Arctic. Nature, 411, 546-547.

Tape, K. D., Hallinger, M., Welker, J. M., and Ruess, R. W. 2012. Landscape heterogeneity of shrub expansion in arctic Alaska. Ecosystems, 15, 711-724.

Tape, K. D., Sturm, M., and Racine, C. H. 2006. The evidence for shrub expansion in Northern Alaska and the Pan-Arctic. Global Change Biology, 12, 686-702.

Tchebakova, N. M., Parfenova, E., and Soja, A. J. 2009. The effects of climate, permafrost and fire on vegetation change in Siberia in a changing climate. Environmental Research Letters, 4, 045013.

Tremblay, B., Lévesque, E., and Boudreau, S. 2012. Recent expansion of erect shrubs in the Low Arctic: evidence from Eastern Nunavik. Environmental Research Letters, 7, 035501. 
U.S. Department of the Air Force. 1967. Summary Analysis of Program 206 (GAMBIT). U.S. Department of the Air Force, Los Angeles, CA.

Vargina, N. E. 1976. Floristic materials of the Hatanga River basin, southeast Taymyr. Vestnik Leningrad University, 21, 75-81.

Walker, X., Henry, G. H. R., McLeod, K., and Hofgaard, A. 2012a. Reproduction and seedling establishment of Picea glauca across the northernmost forest-tundra region in Canada. Global Change Biology, 18, 3202-3211.

Walker, D. A., Epstein, H. E., Raynolds, M. K., et al. 2012b. Environment, vegetation and greenness (NDVI) along the North America and Eurasia Arctic transects. Environmental Research Letters, 7, 015504.

Washburn, A. L. 1980. Geocryology: A Survey of Periglacial Processes and Environments. John Wiley \& Sons, Inc., Hoboken, NJ. 


\section{Supplemental Information}

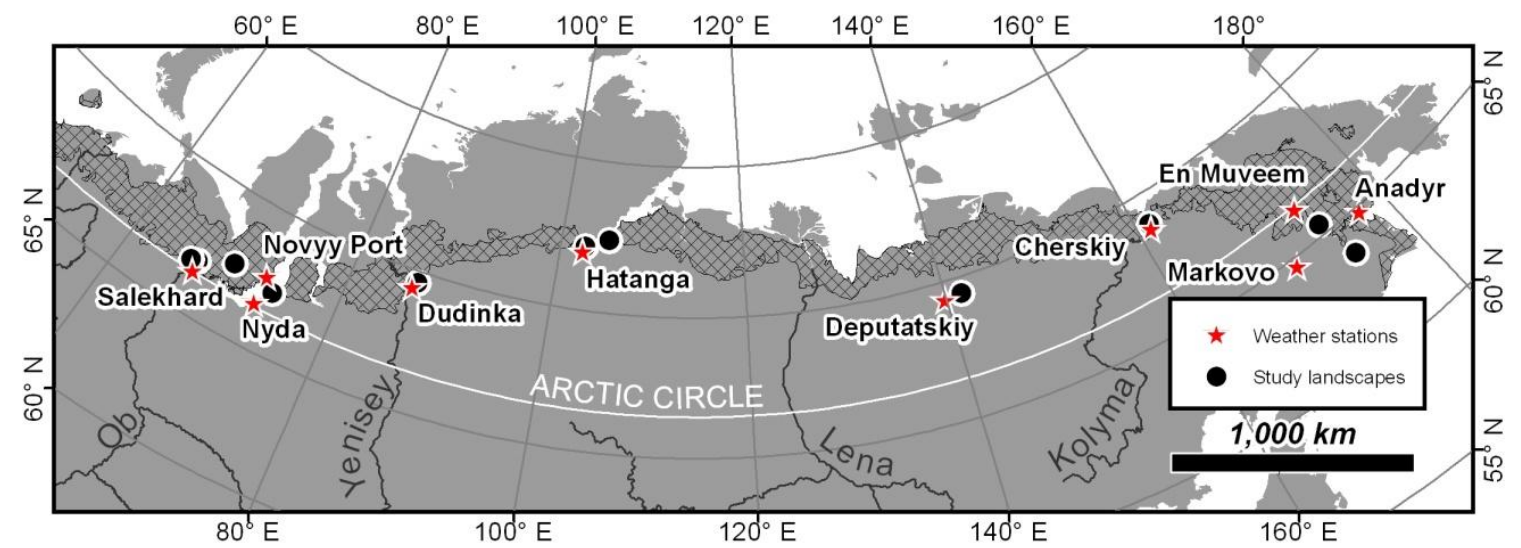

Fig. S1. Locations of meteorological stations near the study landscapes in northern Siberia. The study landscapes Tanlova, Taz, Pekulney, and Velikaya lacked a station within $45 \mathrm{~km}$; for these landscapes, we averaged values of temperature and precipitation from two approximately equidistant stations within $250 \mathrm{~km}$. 

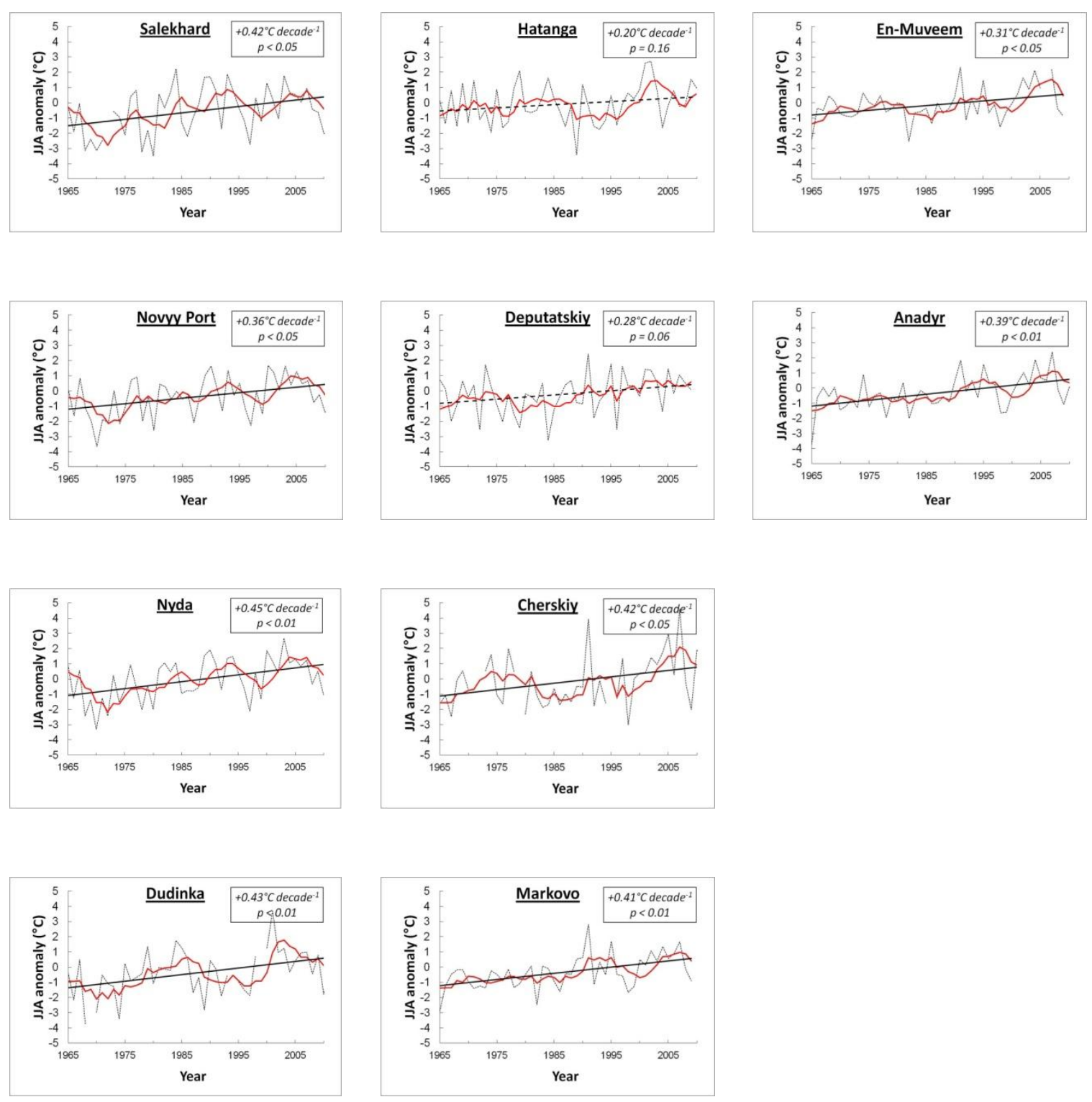

Fig. S2. Anomalies of growing-season (June-August) temperature for meteorological stations for 1965-2010. In each panel, the dotted line indicates annual values, the red line indicates the 5-year running-average, and the black line indicates the linear trend. Gaps in the dotted line for some stations indicate years with no data. Anomalies are calculated with respect to a 1981-2010 base period. 


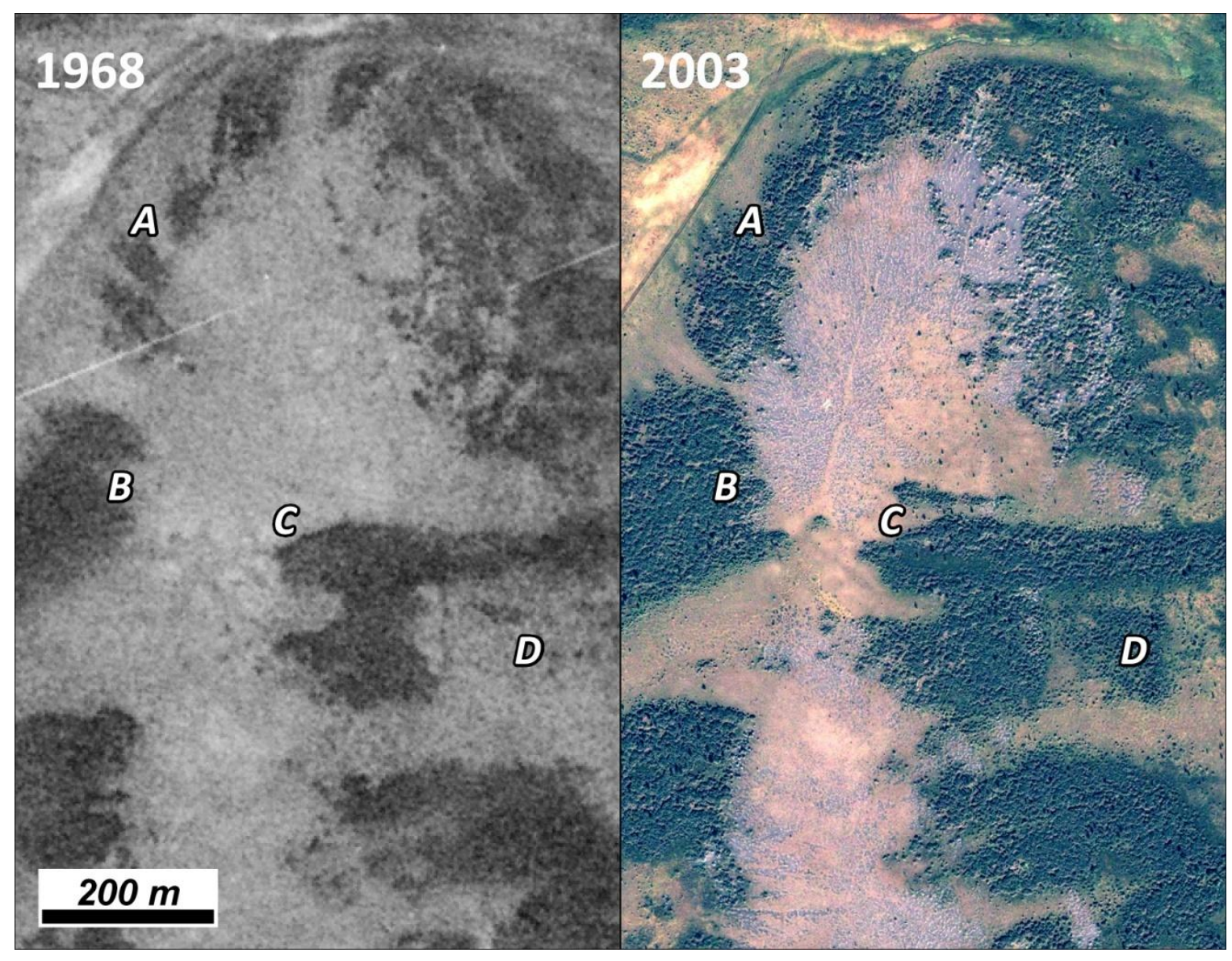

Fig. S3. Comparison of Corona (19 August 1968; left) and QuickBird (24 July 2003; right) imagery of hilltop at Kharp study landscape, southern Yamal Peninsula region. Dark patches are tall alder shrublands. Letters indicate common points in both images; photo-comparisons indicate substantial increases in alder abundance. Most alder increase occurred in areas of patterned-ground; patterned-ground features are abundant in the area shown, but are difficult to distinguish in imagery due to the small size $(<1$ meter) of individual features. QuickBird image (C) Digital Globe, Inc. 


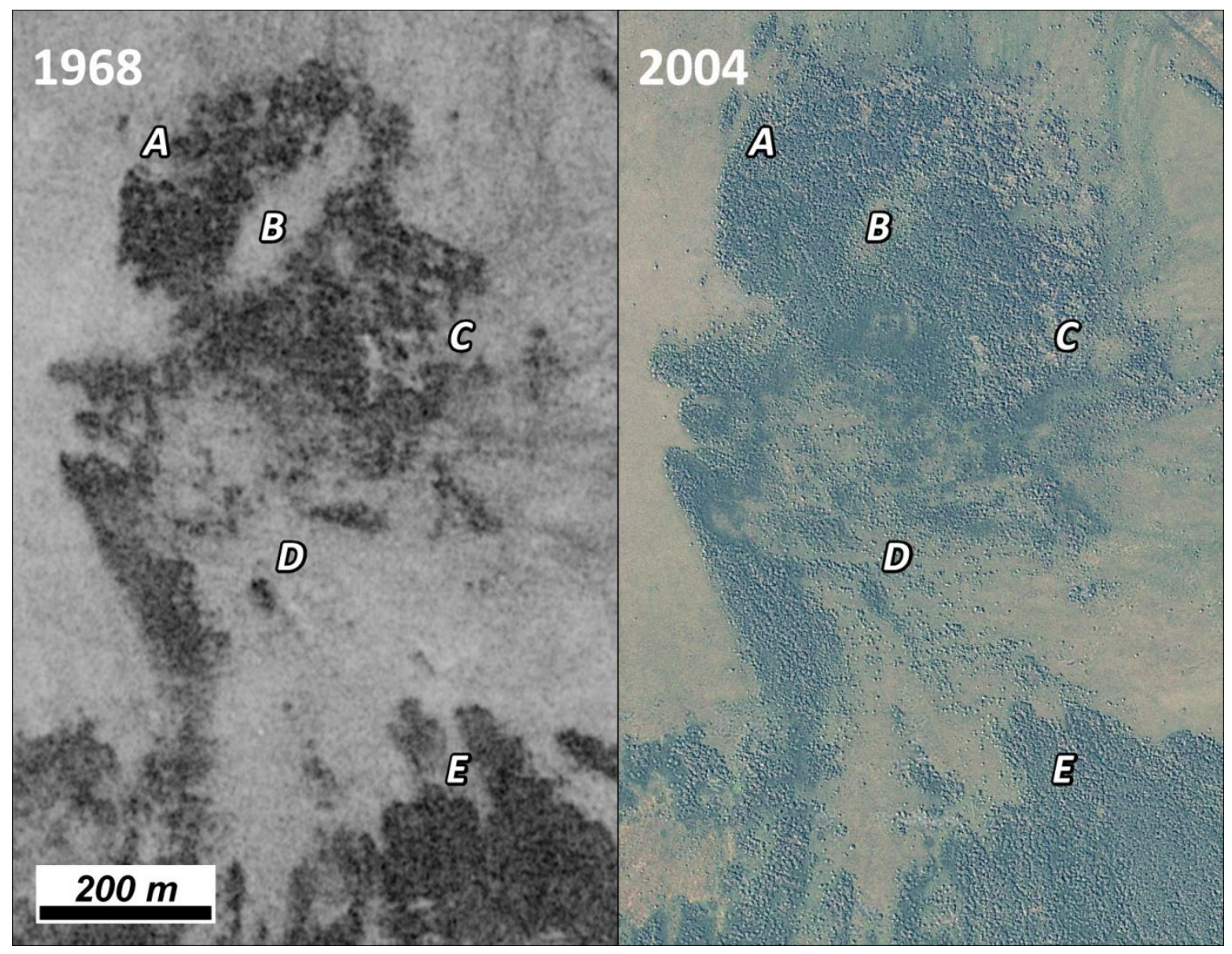

Fig. S4. Comparison of Corona (19 August 1968; left) and IKONOS (9 August 2002; right) imagery of hillslope at Obskaya study landscape, southern Yamal Peninsula region. Dark patches are tall alder shrublands. Letters indicate common points in both images; photo-comparisons indicate substantial increases in alder abundance. Most alder increase occurred in areas of patterned-ground; patterned-ground features are abundant in the area shown, but are difficult to distinguish in imagery due to the small size $(<1$ meter) of individual features. IKONOS image (C) Digital Globe, Inc. 


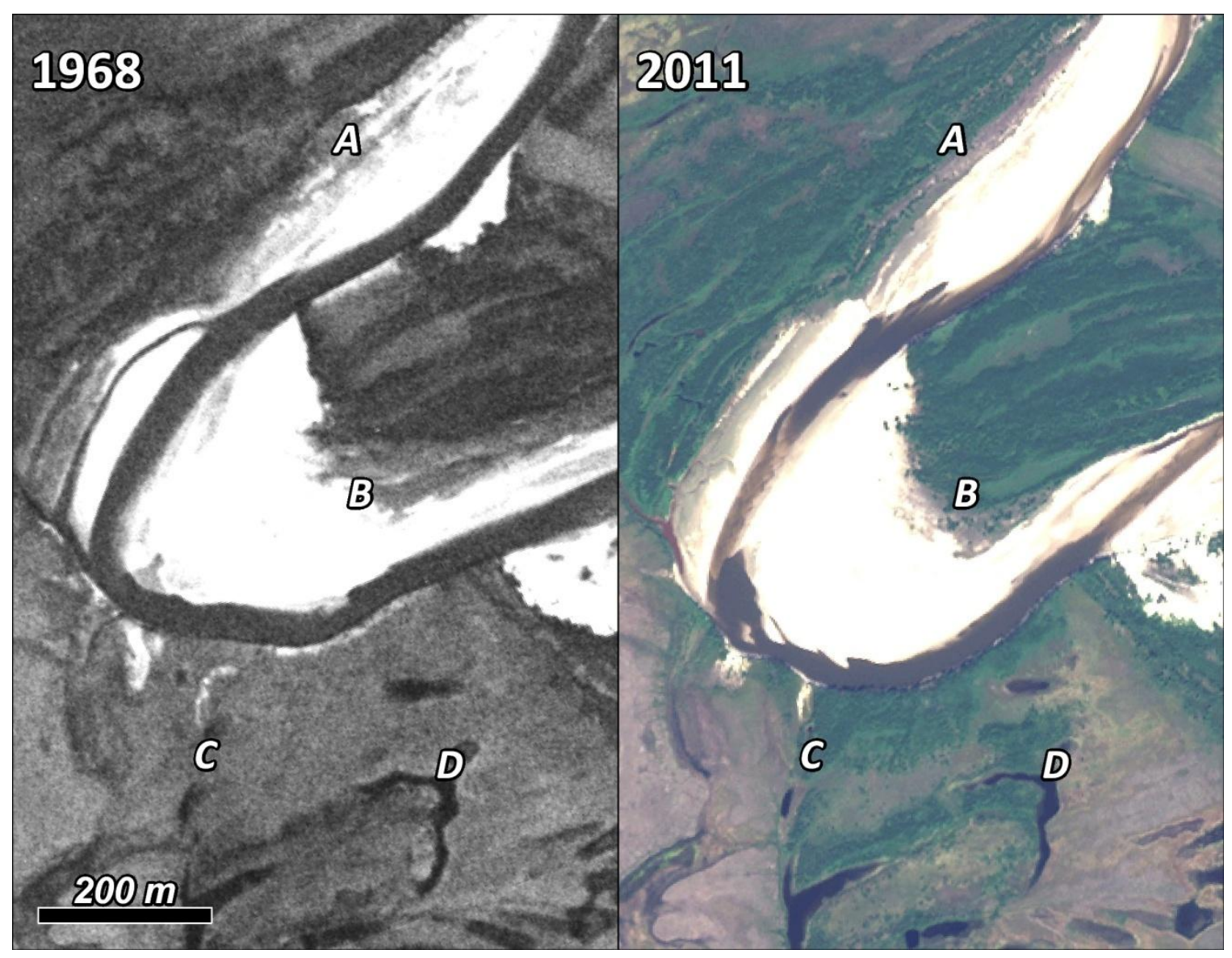

Fig. S5. Comparison of Corona (21 August 1968; left) and WorldView-2 (22 July 2011; right) imagery of Tanlova study landscape, southern Yamal Peninsula. Dark patches are tall alder shrublands; alders are primarily distributed on the floodplain of the Tanlova River, and on adjacent uplands. Letters indicate common points in both images. Although substantial mortality of alder occurred due to fluvial erosion, alder increase on point bars, abandoned channels, and upland areas resulted in a large net increase in alder abundance over the 43-year period-of-record. WorldView-2 image provided courtesy of the National Geospatial-Intelligence Agency Commericial Imagery Program, and @ Digital Globe, Inc. 


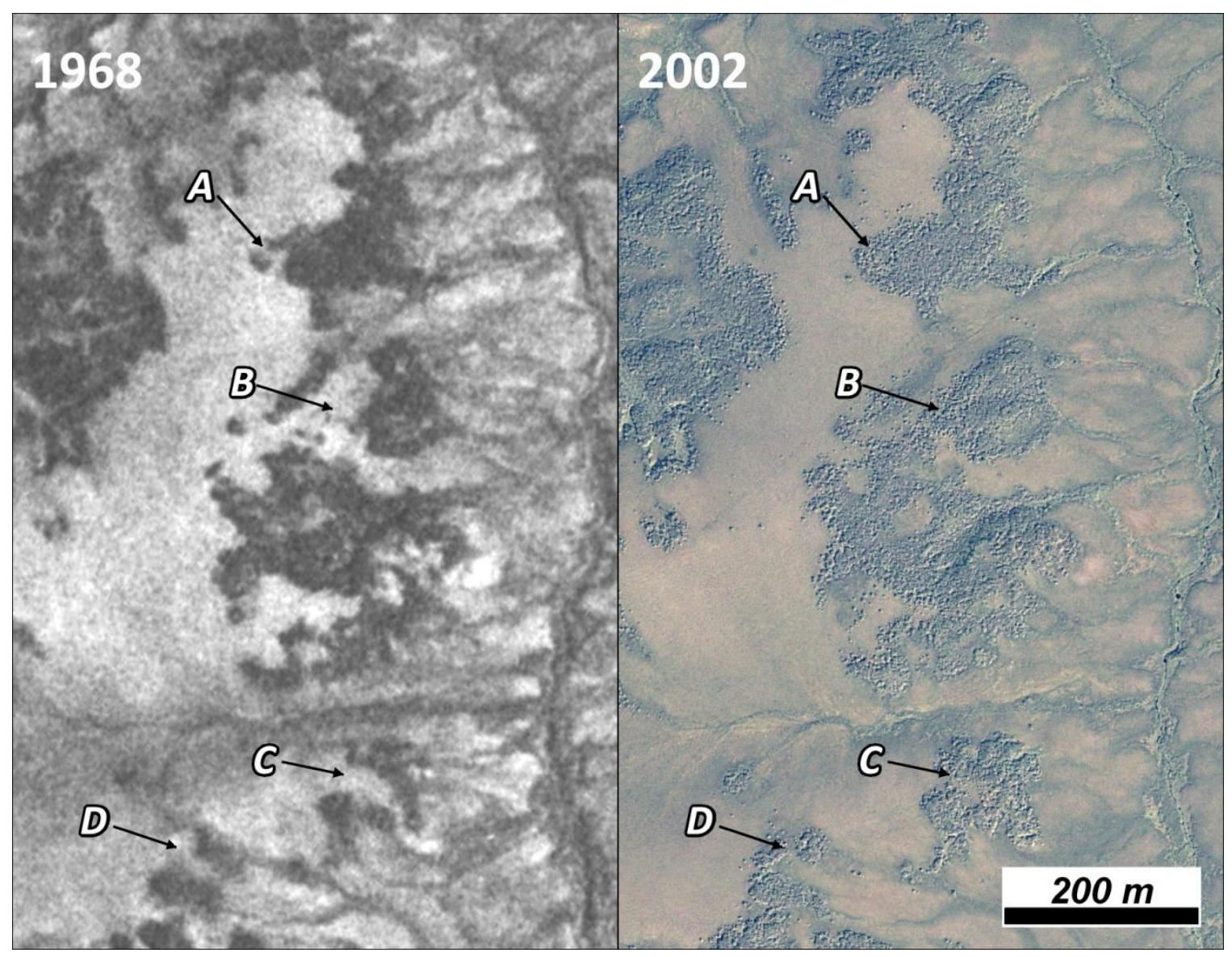

Fig. S6. Comparison of Corona (21 August 1968; left) and IKONOS (9 August 2002; right) imagery of Taz study landscape, Tazovskiy Peninsula. Dark patches are tall alder shrublands; alders are primarily distributed on active-layer detachments and other erosional features on sandy uplands. Letters indicate common points in both images; Modest increases in alder abundance occurred at the Taz study landscape. IKONOS image (C) Digital Globe, Inc. 


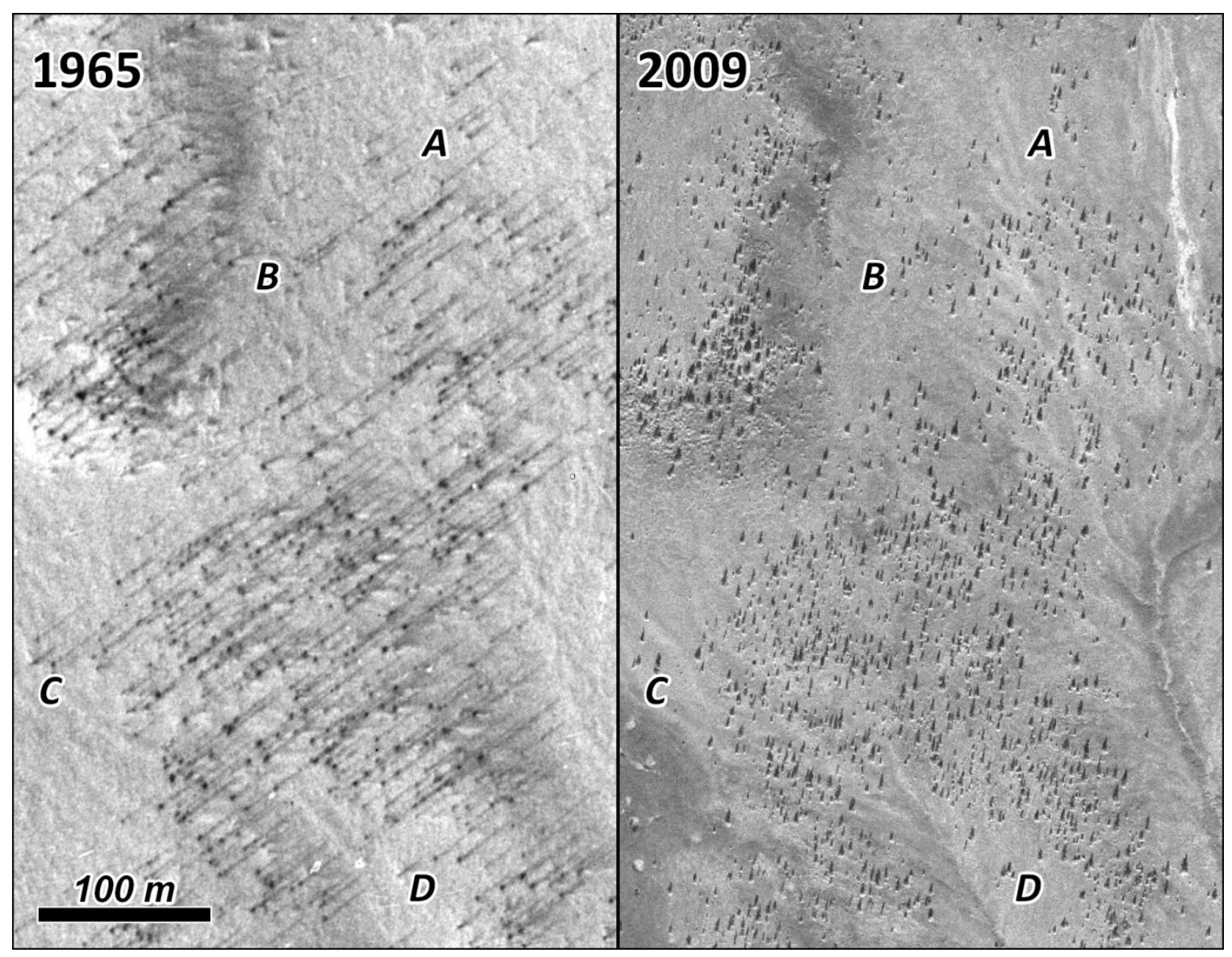

Fig. S7. Comparison of Gambit (13 March 1965; left) and GeoEye-1 (11 July 2009; right) imagery of low, undulating hills at Lukunsky study landscape, eastern Taymyr Peninsula. The Lukunsky landscape encompasses the world's northernmost forest. Larches are primarily distributed on gentle slopes and hilltops, and are generally absent from low-lying areas. Larches are conspicuous in the 1965 imagery due to their long shadows, which contrast strongly with sunlit snow. Letters indicate common points in both images; photo comparisons indicate that larches have become more abundant over the 44-year period-of-record. GeoEye-1 image provided courtesy of the National Geospatial-Intelligence Agency Commericial Imagery Program, and @ Digital Globe, Inc. 


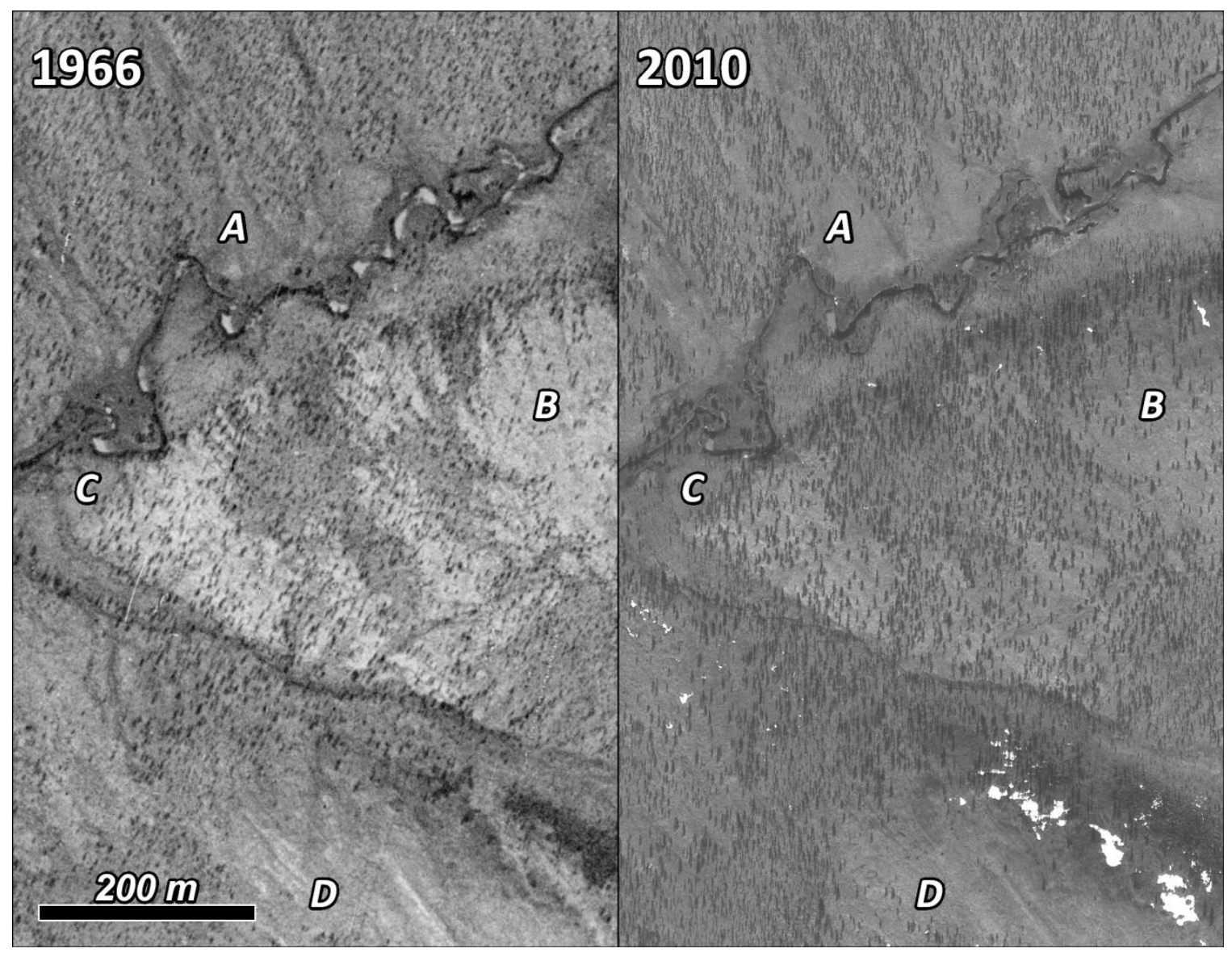

Fig. S8. Comparison of Gambit (13 July 1966; left) and GeoEye-1 (28 May 2010; right) imagery of low ridge and stream channels at Uyandi study landscape, north-central Yakutia. Larches are primarily distributed on upland slopes and plateaus, and are generally absent from low-lying areas. Letters indicate common points in both images; photo comparisons indicates that small increases in larch abundance occurred over the 44-year period-of-record. GeoEye-1 image provided courtesy of the National GeospatialIntelligence Agency Commericial Imagery Program, and (C) Digital Globe, Inc. 


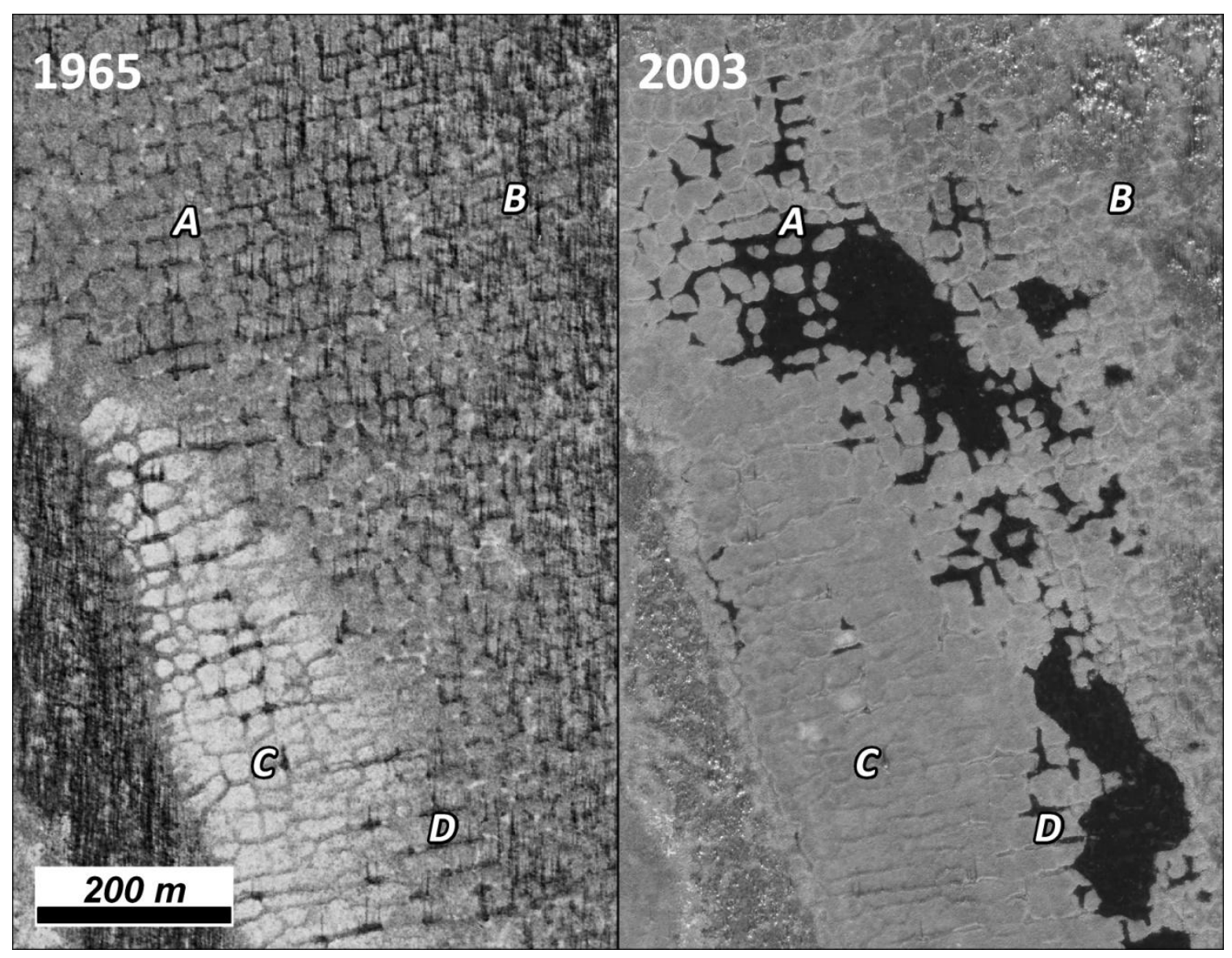

Fig. S9. Comparison of Gambit (1 October 1965; left) and QuickBird (16 September 2003; right) imagery of recent thermokarst area at Kolyma study landscape, eastern Yakutia. Larch trees are distributed along the elevated rims of ice-wedge polygons, many of which have died due to thaw of massive ice deposits underlying the polygons. Larches are more conspicuous in the 1965 imagery due to the strong contrast of tree shadows on snow. Letters indicate common points in both images; the Kolyma site is the only one at which a net loss of tree cover occurred. QuickBird image (C) Digital Globe, Inc. 


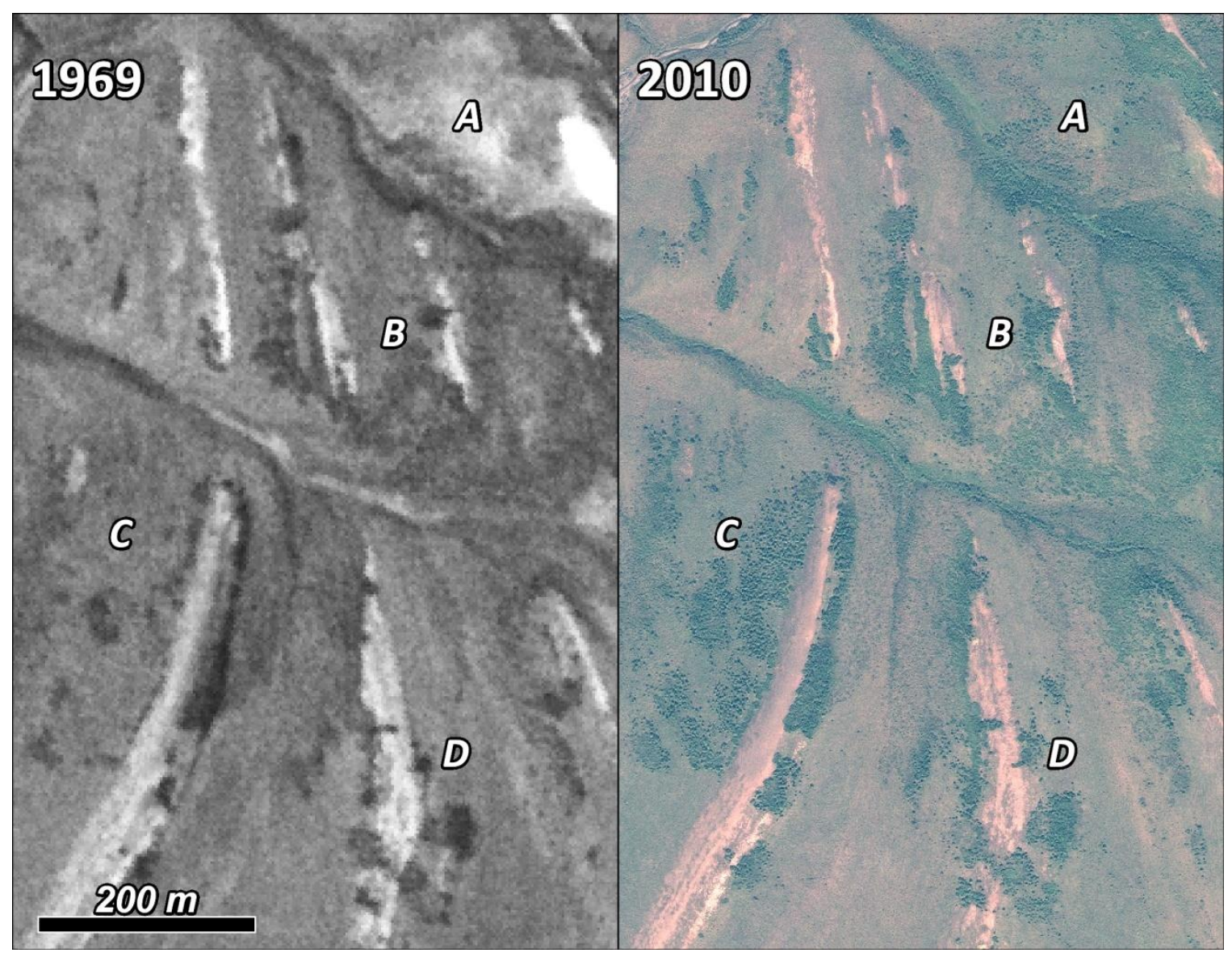

Fig. S10. Comparison of Corona (25 July 1969; left) and GeoEye-1 (29 July 2010; right) imagery of low hills at Pekulney study landscape, Chukotka. Dark patches are tall alder shrublands. Letters indicate common points in both images; photo-comparisons indicate substantial increases in alder abundance over the 41-year period-of-record. Most alder increase occurred on sparsely-vegetated hillslopes. GeoEye-1 image @ Digital Globe, Inc. 


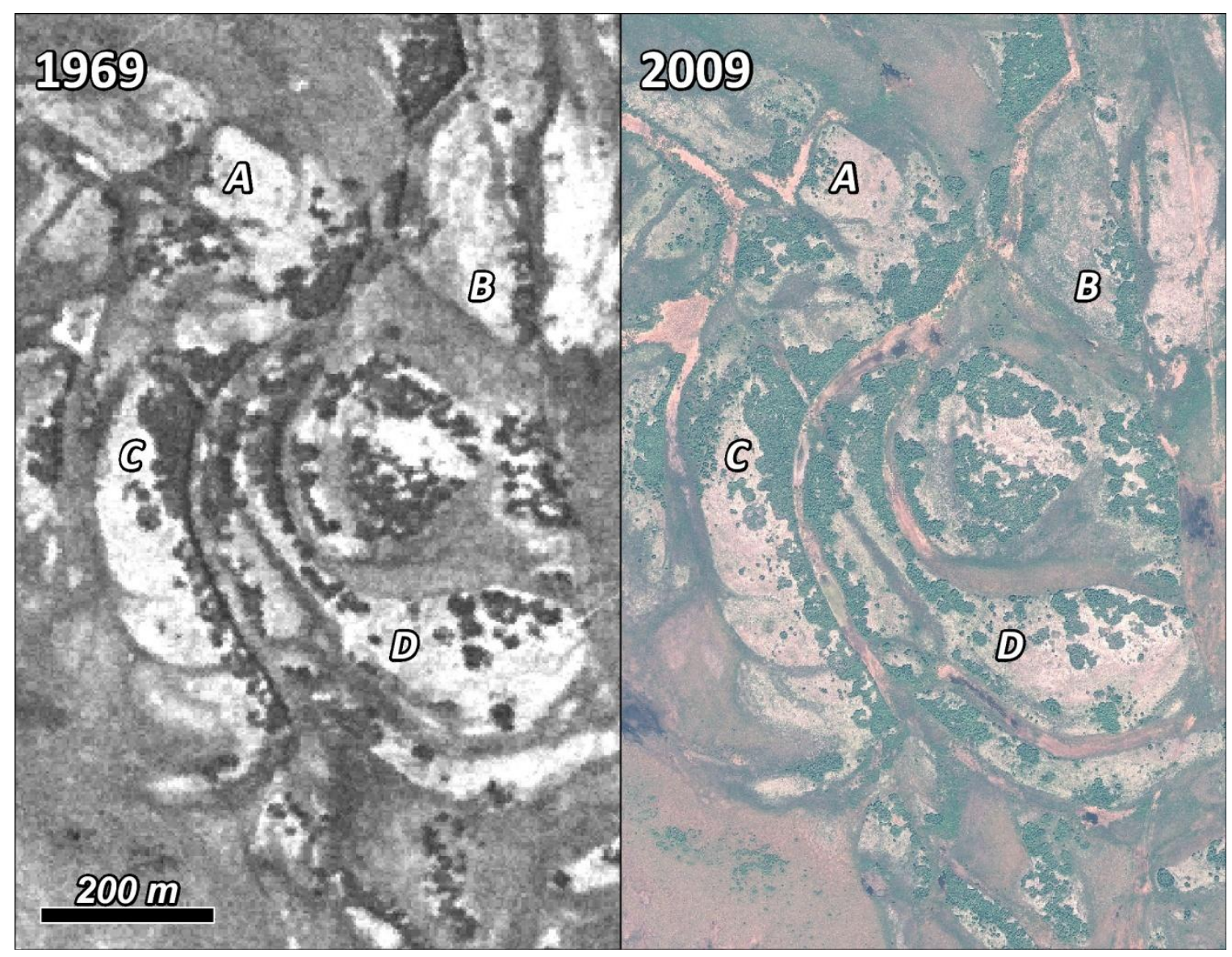

Fig. S11. Comparison of Corona (25 July 1969; left) and GeoEye-1 (22 June 2009; right) imagery of riverine terraces at Velikaya study landscape, eastern Chukotka. Dark patches are Siberian dwarf pine thickets. Letters indicate common points in both images; photocomparisons indicate small increases in dwarf pine abundance over the 40 -year periodof-record. GeoEye-1 image (C) Digital Globe, Inc. 


\title{
CHAPTER 3 - PATTERNED-GROUND FACILITATES SHRUB EXPANSION IN LOW ARCTIC TUNDRA ${ }^{2}$
}

\begin{abstract}
Recent expansion of tall shrubs in Low Arctic tundra is widely seen as a response to climate warming, but shrubification is not occurring as a simple function of regional climate trends. We show that establishment of tall alder (Alnus) is strongly facilitated by small, widely-distributed cryogenic disturbances associated with patterned-ground landscapes. We identified expanding and newly-established shrub stands at two northwest Siberian sites and observed that virtually all new shrubs occurred on bare microsites ("circles") that are disturbed by frost-heave. Frost-heave associated with circles is a widespread, annual phenomenon that maintains mosaics of mineral seedbeds with warm soils and few competitors that are immediately available to shrubs during favorable climatic periods. Circle facilitation of alder recruitment also plausibly explains the development of shrublands in which alders are regularly spaced. We conclude that alder abundance and extent have increased rapidly in the northwest Siberian Low Arctic since at least the mid- $20^{\text {th }}$ century, despite a lack of summer warming in recent decades. Our results are consistent with findings in the North American Arctic which emphasize that the responsiveness of Low Arctic landscapes to climate change is largely determined by the frequency and extent of disturbance processes that create mineral-rich seedbeds favorable for tall shrub recruitment. Northwest Siberia has high potential for continued
\end{abstract}

\footnotetext{
${ }^{2}$ Frost, G. V., Epstein, H. E., Walker, D. A., Matyshak, G., and Ermokhina, K. 2013. Patterned-ground facilitates shrub expansion in Low Arctic tundra. Environmental Research Letters, 8, 015035.
} 
expansion of tall shrubs and concomitant changes to ecosystem function, due to the widespread distribution of patterned-ground landscapes.

\section{Introduction}

The expansion of deciduous shrubs is one of the primary land-cover changes that is being observed and projected to accelerate with climate warming in Arctic terrestrial ecosystems. Observations of this phenomenon have been reported, mostly in North America (Sturm et al., 2001; Tape et al., 2006; Myers-Smith et al., 2011; Lantz et al., 2012; Tremblay et al., 2012; Ropars \& Boudreau, 2012), and are corroborated by experimental field studies (Chapin III et al., 1995; Walker et al., 2006). Shrub expansion is thought to be a major driver of widespread increases in the productivity of Arctic vegetation observed from space since the early 1980s (Jia et al., 2003; Bhatt et al., 2010), and future projections of shrub increase are supported by simulation modeling (Epstein $e t$ al., 2007; Yu et al., 2011). Shrubland expansion fundamentally changes biophysical properties of tundra ecosystems, affecting surface energy balance (Chapin et al., 2005; Marsh et al., 2010), hydrology (Sturm et al., 2005), nutrient cycling (Buckeridge et al., 2010; Kaarlejärvi et al., 2012) biodiversity (Pajunen et al., 2011) and permafrost temperature (Blok et al., 2010), as well as wildlife and human land-use (Forbes et al., 2009; Ehrich et al., 2012). In warmer parts of the Low Arctic, expansion of tall shrubs (>1.5 m height), chiefly alders, birches (Betula), and willows (Salix), represents a biome shift from tundra to tall shrubland. 
At large spatial and temporal scales, summer temperature is the primary factor controlling the extent of the Arctic tundra biome, and the zonation of vegetation within the biome (Walker et al., 2005). Landscape-scale responses of tundra vegetation to changes in summer temperature near the biome's southern margin, however, can vary dramatically due to complex interactions between climate and local environmental factors, such as soil environment, hydrology, permafrost, and disturbance regime (Naito \& Cairns, 2011; Ropars \& Boudreau, 2012; Tape et al., 2012). Recent studies have found that episodic disturbance events such as wildfire, landslides, and permafrost-thaw can trigger the expansion of tall shrubs by creating mineral-rich soils that favor shrub recruitment (Racine et al., 2004; Lantz et al., 2009, 2010; Walker et al., 2009), with little or no change observed in adjacent areas of undisturbed tundra. Thus, the northward expansion of tall shrubs may be greatly limited at local- to regional scales by the frequency of disturbance events - on the order of many decades or centuries - that create suitable substrates for shrub recruitment (Racine et al., 1985; Myers-Smith et al., 2011).

One aspect of tall shrub distribution in tundra landscapes that has received relatively little study concerns the spatial distribution of individuals within shrubland communities. Alder-dominated shrublands in the southern Low Arctic (Bioclimate Subzone E of the Circumpolar Arctic Vegetation Map [Walker et al 2005]) frequently exhibit unusual spatial distributions of individual shrubs, in which alders occur as regularly-spaced individuals or clumps of individuals, that overtop typical tundra shrubs, graminoids, and mosses (Figure 3.1). Such shrubland communities, colloquially referred 


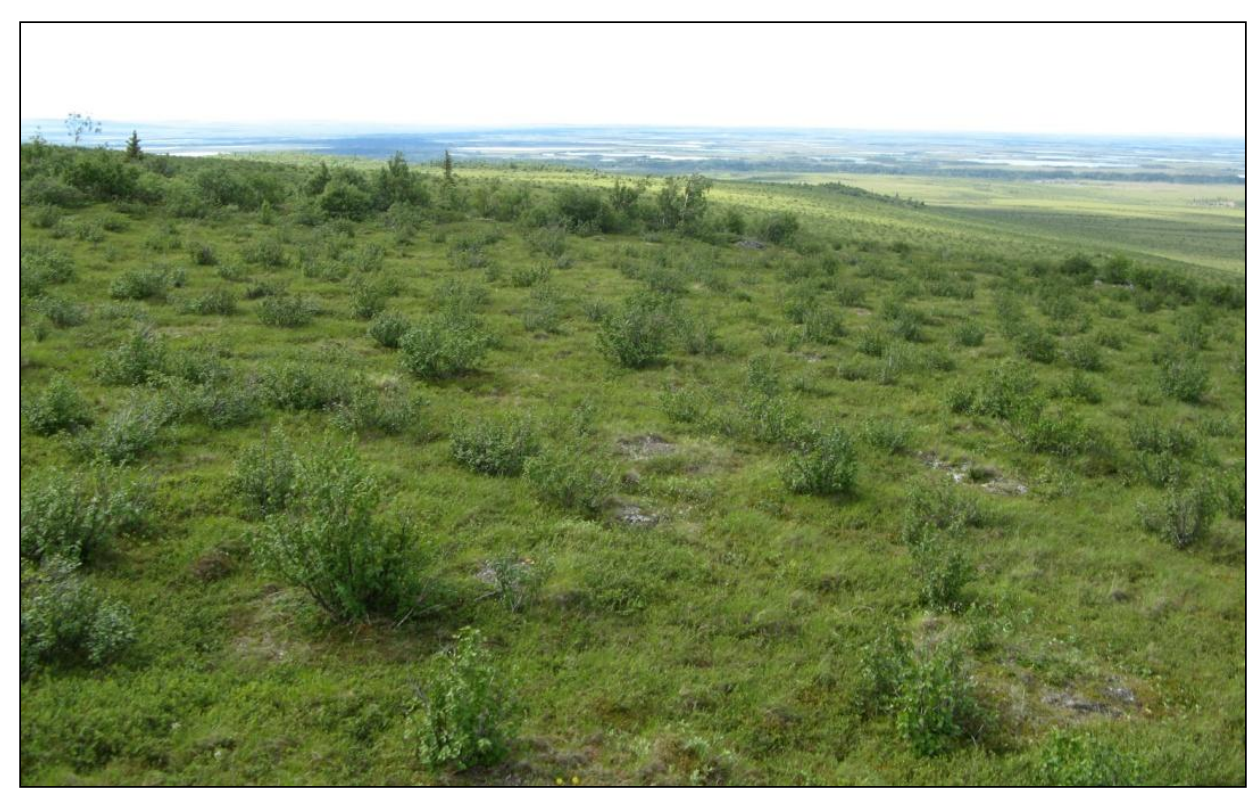

Figure 3.1. Aerial view of alder shrubland or "savanna" in which alders are regularly spaced, Selawik River area, northwest Alaska. Photo courtesy Matthew J. Macander.

to as "alder savannas," have been described at several locations in Low Arctic and interior montane Alaska (Racine, 1976; Racine \& Anderson, 1979; Chapin et al., 1989). Regular spacing of alders in "alder savannas" has been attributed to intra-specific competition for limiting nutrients (Chapin et al., 1989), but recent work highlighting the role of local geomorphology and disturbance in driving landscape-scale variability in shrub recruitment suggests that regular spacing of alders could also be linked to patterns of shrub recruitment on geomorphic microsites in permafrost patterned-ground that exhibit regular spacing at similar scales.

We integrated a remote-sensing data record spanning five decades, with fieldbased measurements to elucidate the role of local mechanisms, related to permafrost 
geomorphology, soils, and disturbance processes, in promoting tall shrub expansion in the northwest Siberian Low Arctic. In the areas that we studied, alder recruitment is closely linked to small, bare microsites within extensive patterned-ground landscapes (Figure 3.2). Here we describe a mechanism for the expansion of tall alder, whereby annual, meter-scale disturbance processes in patterned-ground maintain a mosaic of microsites that facilitate shrub recruitment across contiguous areas of tundra during periods of favorable climate. The facilitation of alder recruitment on regularly spaced microsites, in turn, promotes the development of tundra shrub communities in which alders are regularly spaced.

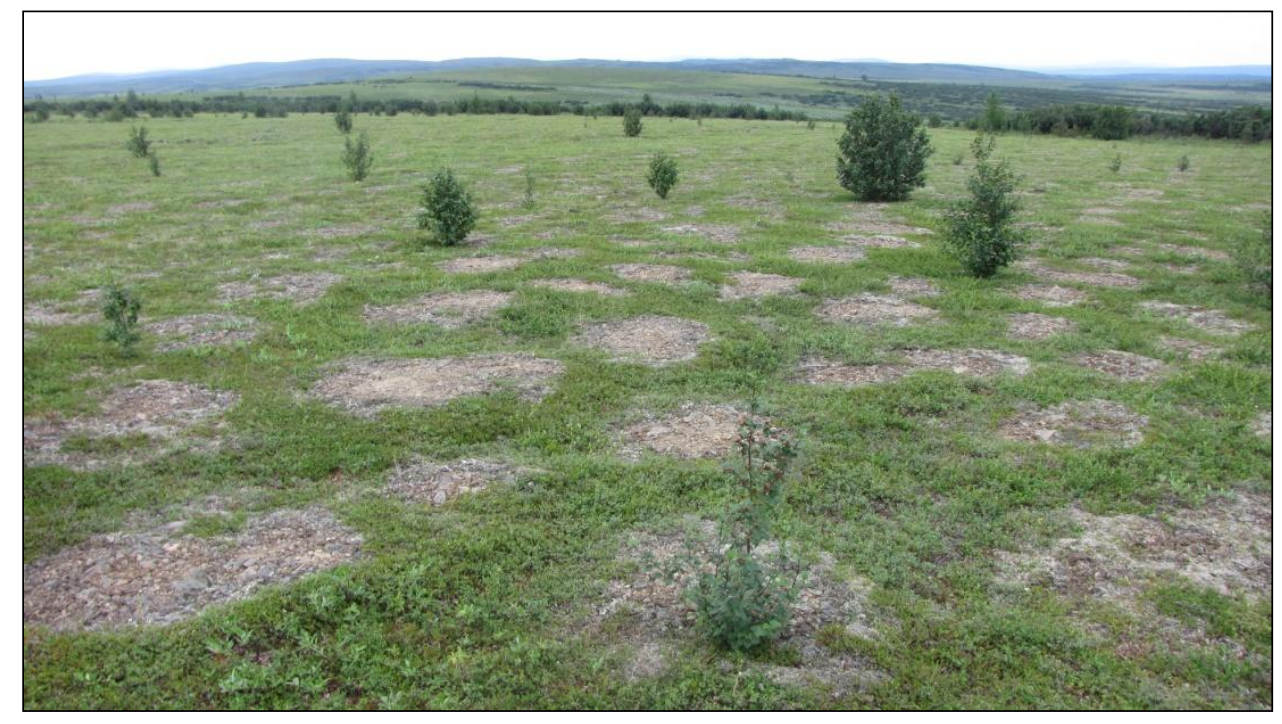

Figure 3.2. Patterned-ground with young alders growing on circles, Obskaya site, northwest Siberia. 


\section{Methods}

\section{Study areas}

We studied changes in Siberian alder (A. viridis ssp. fruticosa) extent at two ecotonal landscapes near the towns of Kharp $\left(66.83^{\circ} \mathrm{N}, 65.98^{\circ} \mathrm{E}\right)$ and Obskaya $\left(66.92^{\circ} \mathrm{N}\right.$, $65.61^{\circ}$ E), Russia (Figure 3.3). The Kharp and Obskaya study landscapes are $64 \mathrm{~km}^{2}$ and $59 \mathrm{~km}^{2}$ in area, respectively. Both sites are located in the eastern foothills of the northern Ural Mountains near the lowermost reach of the Ob River. Terrain features in the study areas consist of low, gently-sloping uplands separated by small alluvial valleys within an elevation range of $\sim 200-300 \mathrm{~m}$. Common vegetation types include dwarf-shrub tundra, low birch-ericaceous shrubland (shrubs $\leq 1 \mathrm{~m}$ height), and tall alder shrubland (shrubs $>$ $1.5 \mathrm{~m}$ height). Sparse stands of Siberian larch (Larix sibirica) occur locally at lower elevations. The region experiences a continental, sub-Arctic climate; long-term meteorological records (1883-2011) at Salekhard, $40 \mathrm{~km}$ southeast of the study sites, indicate a mean annual temperature of $-6.3^{\circ} \mathrm{C}$, mean summer (June-August) temperature of $11.2^{\circ} \mathrm{C}$, and mean annual precipitation of $464 \mathrm{~mm}$. Soils and geomorphic features are similar at the sites; soils are rich in fine silts derived from mafic parent materials, permafrost is widespread, and active patterned-ground features are abundant. However, the sites have contrasting disturbance histories; the Kharp site experienced a severe wildfire sometime before 1821 (based on examination of soil pits, and annual growthrings of living larch trees), while there is no evidence of historical wildfire at Obskaya.

Patterned-ground features (PGFs) are characteristic of permafrost-dominated regions of the world and are widely distributed throughout the Pan-Arctic (Washburn, 


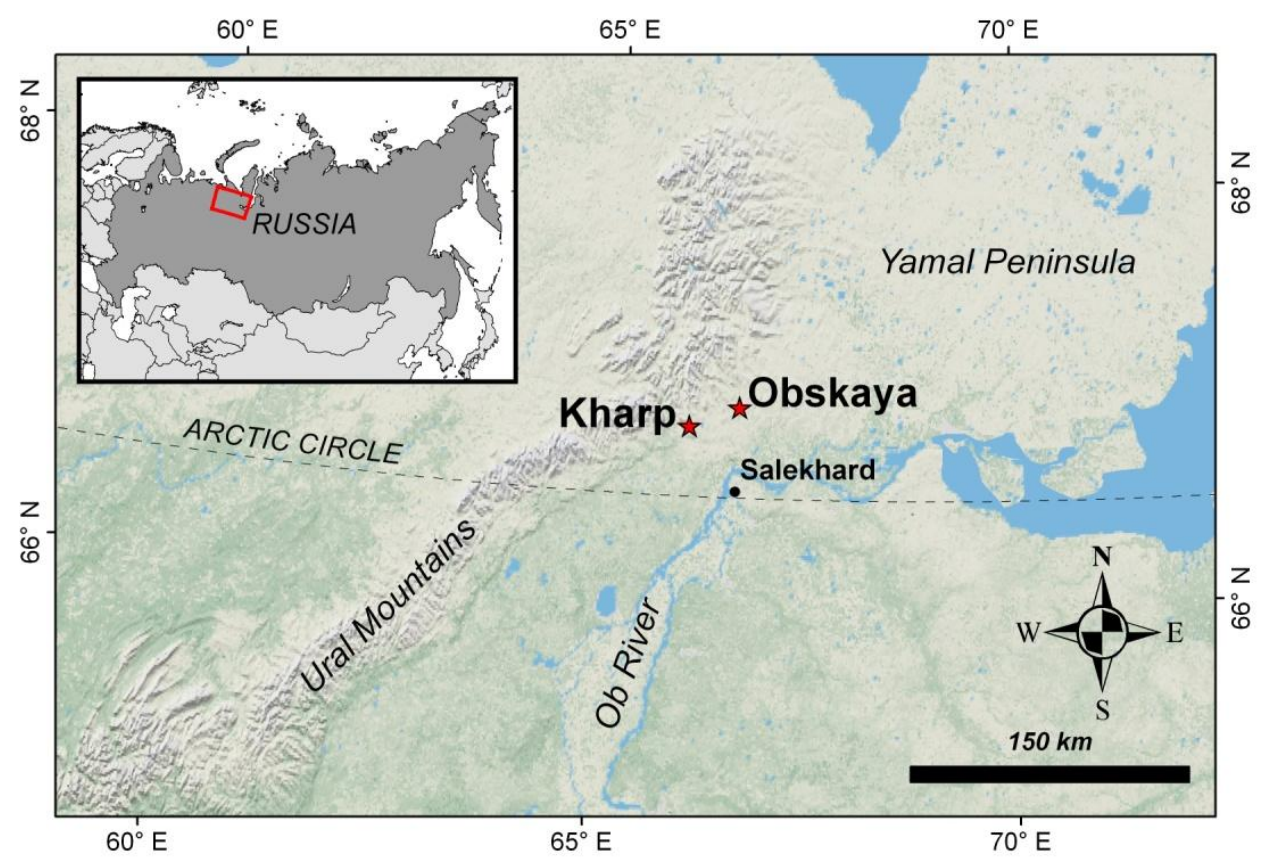

Figure 3.3. Map of southern Yamal Peninsula region, Russia, showing locations of Kharp and Obskaya study sites and other places mentioned in the text.

1980; Walker et al., 2008). "Circles," often termed "frost-boils," are a common PGF that occur as approximately circular patches of mineral soil within a highly symmetrical mosaic of microsites, repeating at intervals of $\sim 1-3 \mathrm{~m}$. Circles develop due to meterscale biogeophysical processes during seasonal freezing that cause differential frostheave (DFH), with enhanced frost-heave of circles relative to adjacent areas (“intercircles") (Taber, 1929; Peterson \& Krantz, 2003). As soils freeze each winter, complex interactions occur among soil, water, ground-ice, live vegetation, organic matter, and snow cover that cause downward freezing to proceed more rapidly at exposed surfaces relative to vegetated areas, resulting in DFH and a self-organizing pattern of bare circles surrounded by vegetation (see Supplementary Figure 1). Vegetation and organic 
matter are key controls of DFH because they shade and insulate the subsurface; an uneven distribution of vegetation promotes sharp contrasts in microsite thermal regimes. PGFs tend to be less conspicuous in the southernmost Low Arctic and northern boreal forest, where warmer summer temperatures promote vegetation growth and DFH is inhibited by the buildup of a continuous organic mat (Walker et al., 2004; Kade \& Walker, 2008).

\section{Methods}

We quantified changes in tall shrub extent at Kharp and Obskaya over the past 40 years using high-resolution satellite imagery from 1968 and recent years: panchromatic KH-4B "Corona" imagery from 19 August 1968, and multi-spectral QuickBird and IKONOS imagery and panchromatic WorldView-1 imagery from 20032010. We co-registered the imagery and overlaid a grid of sampling-points spaced $30 \mathrm{~m}$ apart for each site using ArcMap 9.3 (Environmental Systems Research Institute, Inc., Redlands, CA). We recorded the number of sampling-points with alder shrubland cover in 1968 and 2010 by visual interpretation of the imagery; due to their dark leaves and extensive canopy shadowing, alders produce a dark photo-signature that is readily identified in high-resolution $(\leq 2 \mathrm{~m}$ pixel) imagery of tundra-dominated areas (Figure 3.4). We recorded modern shrub cover mainly from 2010 imagery, but used imagery from 2003 and 2004 for some areas that had partial snow cover in the 2010 imagery. From the sampling-point data, we calculated the total areal extent of alder shrublands in 1968 and 2010, and calculated the percent difference in alder "hits" between 1968 and 


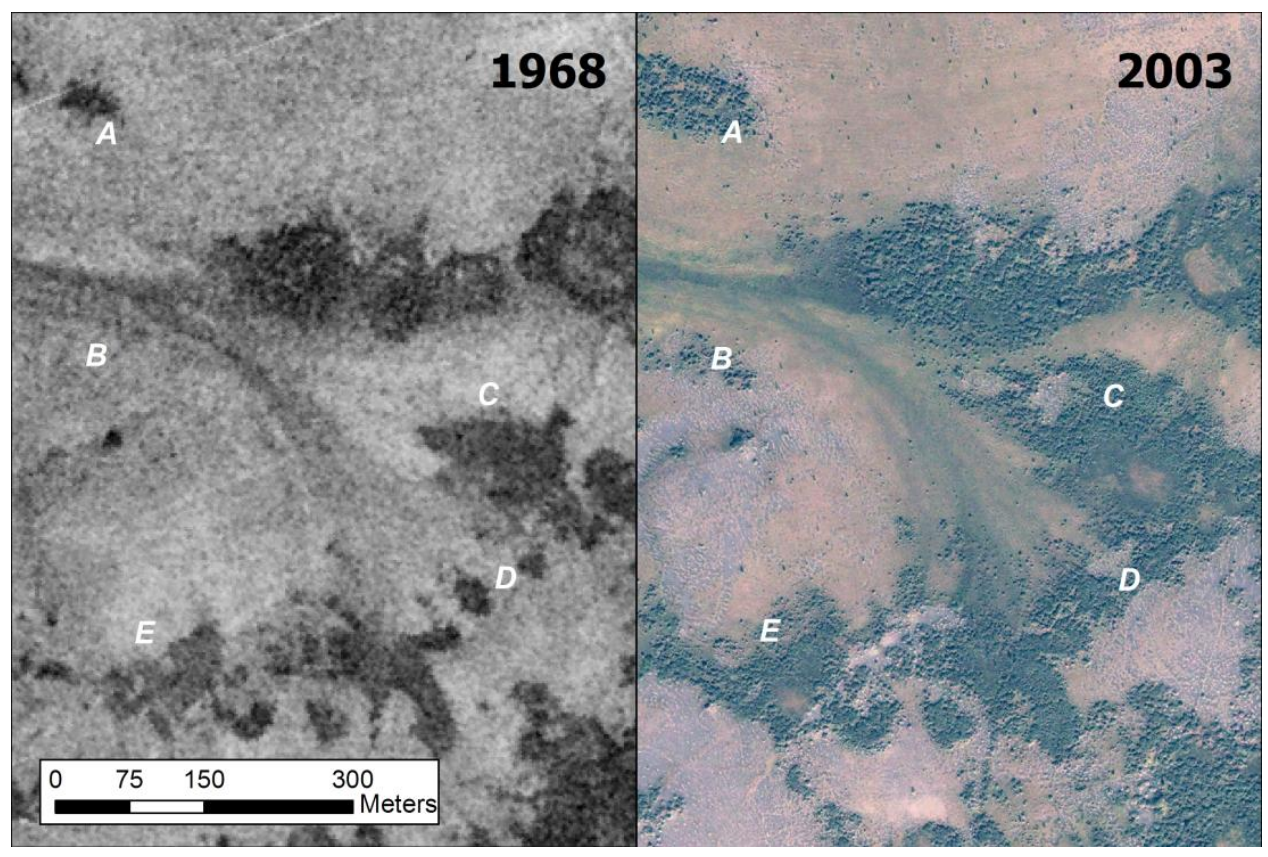

Figure 3.4. Comparison of 1968 (Corona) and 2003 (QuickBird) satellite images showing representative area of recent shrub expansion at Kharp site. Letters indicate alder stands that are expanding (A, C-E) or newly-established (B). Alder cover increased $29 \%$ within the $0.5 \mathrm{~km}^{2}$ area shown. QuickBird image copyright Digital Globe, Inc.

2010. We also identified expanding and stable shrub stands for field visits.

In the field, we collected soil- and vegetation data at the Kharp site to test if alder recruitment was facilitated by circles, and if shrub distribution in older stands was linked to underlying, inactive circles that were covered by vegetation. Because DFH is largelydriven by uneven distribution of vegetation between circles and inter-circles, the development of a continuous vegetation mat (e.g., as with shrub expansion) attenuates DFH. Active circles are easily recognized, but over time they can become covered by vegetation and cannot be visually identified if DFH has ceased. Subsurface soils remain 
strongly sorted, however, and we used simple measurements of two soil variablessurface organic depth and total thickness of mineral soil- to infer the presence of inactive circles. We also established transects in older shrub stands (i.e., those that were already evident in the 1968 satellite imagery) in order to test if the spatial distribution of mature shrubs could be explained by recruitment on circles. We did not make systematic field measurements at Obskaya, but we made qualitative observations there to determine if relationships between alder expansion and PGFs were consistent with those observed at Kharp, and to assess the disturbance history of the site.

We stratified shrub stands into three categories of stand-age: colonization zone, mature, and paludified. Colonization zones lacked shrub cover in 1968 Corona imagery and are mostly dominated by small alders $(\leq 1.5 \mathrm{~m}$ height). Mature stands were dominated by large shrubs ( $>2 \mathrm{~m}$ height) that were already present in 1968 , and most patterned-ground microsites were concealed by vegetation and organic matter. Paludified stands were also present in 1968 imagery, but were dominated by older, largely moribund shrubs and virtually all patterned-ground was concealed by a thick layer of moss and organic material. Although we did not age shrub ramets, shrubs in paludified stands have numerous characters that indicate greater age and reduced vigor relative to shrubs in mature stands, including dead ramets, reduced ramet height, short internode length, and abundant annual abscission scars. We established a total of 19 transects: 12 in colonization zones, 3 in mature stands, and 4 in paludified stands. Transect length varied from 20 to $100 \mathrm{~m}$ depending on the size and density of circles and alders; we established larger transects where shrubs and circles were widely-spaced. 
We measured surface organic depth and thaw-depth/depth-to-rock using a steel thaw-probe at 1-meter intervals along the transect centerline, and at the base of the alder nearest to the transect sampling-point, regardless of size, on all transects. Due to the rocky soils, thaw-probe measurements usually hit frost-shattered rock rather than the permafrost table. We determined the total thickness of mineral-dominated soil horizons by subtracting the surface organic thickness from the thaw-depth/depth-to-rock measurement. We also recorded the age-class of each alder as seedling ( $\leq 5 \mathrm{~cm}$ height), sapling ( $\leq 75 \mathrm{~cm}$ height and not reproductively active), or adult (reproductively active and usually $>75 \mathrm{~cm}$ height). Finally, we deployed 53 iButton thermochron dataloggers (Embedded Data Systems LLC, Lawrenceburg, USA) at $5 \mathrm{~cm}$ depth to obtain daily soil temperature time-series at circles (with alders) and at inter-circles (without alders) for each shrub stand-age; an additional 4 iButtons recorded air temperature at a height of $2 \mathrm{~m}$. We also obtained soil temperature time-series at circles and inter-circles in alder-free tundra adjacent to colonization zones. All iButtons recorded temperature simultaneously at 4-hour intervals. We then calculated the mean temperature for each 4-hour time-step, for each category of microsite and stand-age.

In colonization zone transects, circle microsites were easily recognized (i.e., not covered in vegetation), so we recorded the microsite from which alders emerged according to three categories: circle center, circle margin, and inter-circle. At three of these transects, we mapped the locations of alders and circles using $\mathrm{X} / \mathrm{Y}$ coordinates and recorded organic depth and thaw-depth/depth-to-rock at every alder in the transect area, in addition to the transect centerline measurements. 
We conducted statistical analyses of soil physical attributes and temperature using SAS 9.2 (SAS Institute Inc., Cary, USA). After testing variables for normality, we employed two-tailed t-tests and non-parametric Kruskal-Wallis tests for comparisons as appropriate. We also calculated the nearest-neighbor distance ratio (NNDR), a spatial statistic that identifies spatial distribution patterns (e.g., random, uniform, clumped), for the transect maps of alder and circle location.

In order to characterize the recent climate history of the study sites, we derived a time-series of mean growing-season temperature (June-August; hereafter, "JJA") from ground station data recorded $\sim 40 \mathrm{~km}$ southeast at Salekhard. We calculated JJA temperature from mean monthly temperature datasets downloaded from the National Climatic Data Center (NCDC, http://www.ncdc.noaa.gov/land-based-station-data) and evaluated liniear trends in JJA temperature for the entire period-of-record (1883-2011). We also evaluated linear trends for 1965-2011, which encompasses the time interval examined in the satellite imagery comparisons; we included three preceding years to account for short-term effects of preceding summer temperatures on viable seed production by pre-existing, mature shrubs. Due to the difference in elevation between the study sites $(\sim 250 \mathrm{~m})$ and Salekhard $(66 \mathrm{~m})$, we adjusted the mean monthly temperature values using a temperature lapse rate of $-6.2^{\circ} \mathrm{C} \mathrm{km}^{-1}$ generated for a subarctic region of Alaska (Haugen et al., 1971). 


\section{Results}

Comparisons of high-resolution satellite imagery from 1968 and 2010 indicate extensive areal expansion of tall alder at both sites. The total cover of alders increased $8.0 \%$ at Kharp and $21.0 \%$ at Obskaya (Table 3.1). Although many individual shrub stands did not expand, we detected no areal loss of shrub cover at either site.

Table 3.1. Total alder cover in 1968 and 2010, and areal and relative changes in alder cover (1968-2010), at Kharp and Obskaya study sites.

\begin{tabular}{lcccc}
\hline & \multicolumn{3}{c}{ Total alder cover (ha) } & \\
\cline { 2 - 4 } Site & 1968 & 2010 & $\Delta$ & Relative change (\%) \\
\hline Kharp & 721 & 779 & 58 & 8.0 \\
Obskaya & 482 & 583 & 101 & 21.0 \\
\hline
\end{tabular}

In the field, we observed at both sites that nearly all shrub expansion occurred in patterned-ground, and that shrub recruitment had occurred almost exclusively on active circles that lack vegetation and organic material; mean surface organic depth is significantly lower, and mineral thickness greater, at alders compared to the uniform transect measurements for all three shrub stand-ages (Kruskal-Wallis test; $p<0.001$ for all transects) (Table 3.2). In colonization zones, virtually all alders occur where surface organic material is thin or lacking altogether; $>85 \%$ of alders occurred at sites with $<3$ $\mathrm{cm}$ of surface organic material; sites with $<3 \mathrm{~cm}$ of organic matter comprised $<30 \%$ of available sites (Figure 3.5). In older shrub stands, contrasts in soil properties between alders and uniform transect measurements were qualitatively similar to those found in colonization zones; alders tended to occur where there was less surface organic matter 
Table 3.2. Median values of soil organic depth, mineral soil thickness, and sample sizes measured along transects and at adjacent alders at Kharp. Organic depth is significantly less, and mineral thickness significantly greater, at alders compared to transects for all stand-ages $(\mathrm{p}<0.001)$.

\begin{tabular}{lcccccccc}
\hline & \multicolumn{2}{c}{ Organic depth $(\mathrm{cm})$} & & \multicolumn{2}{c}{ Mineral thickness $(\mathrm{cm})$} & & \multicolumn{2}{c}{ Number of observations } \\
\cline { 2 - 3 } Stage & Transect & Alders & & Transect & Alders & & Transect & Alders \\
\hline \multirow{2}{*}{ colonization } & 4.5 & 0 & & 4.0 & 24.0 & & 252 & 630 \\
mature & 9.0 & 1.0 & & 6.0 & 33.0 & & 235 & 279 \\
paludified & 20.0 & 14.0 & & 15.5 & 33.0 & & 254 & 166 \\
\hline
\end{tabular}

and mineral soil thickness was high. Organic depth increases throughout stand development, indicating the accumulation of an organic mat on the circles and the cessation of DFH.

The spatial distribution of shrubs within transects in colonization zones shows that shrub recruitment is tightly linked to active circles in patterned-ground (Figure 3.6). Shrub recruitment declines as stands mature and essentially ceases in paludified stands (Table 3.3). Spatial statistics of shrub distribution using the NNDR indicate that young alders are found in evenly-spaced clumps that co-occur with circles. The NNDR at 3 transects in colonization zones indicates that young alders are highly clumped (mean Zscore $=-16.1 ; \mathrm{p}<0.001$ for all transects), while circles are evenly-spaced (mean Z-score $=$ 6.9; $\mathrm{p}<0.001$ for all transects). Although we only mapped the locations of alders and circles along three $80 \mathrm{~m}^{2}$ transects at Kharp, we repeatedly observed that alders were concentrated at circles in areas of recent shrub expansion throughout both study areas. 
Table 3.3. Relative abundance of shrub age classes, by shrub stand-age, at the Kharp site.

\begin{tabular}{lccc}
\hline & \multicolumn{3}{c}{ Age class } \\
\cline { 2 - 4 } Stage & Seedling (\%) & Sapling (\%) & Adult (\%) \\
\hline colonization & 43.7 & 39.7 & 16.7 \\
mature & 30.1 & 22.3 & 47.6 \\
paludified & 0 & 7.9 & 92.1 \\
\hline
\end{tabular}
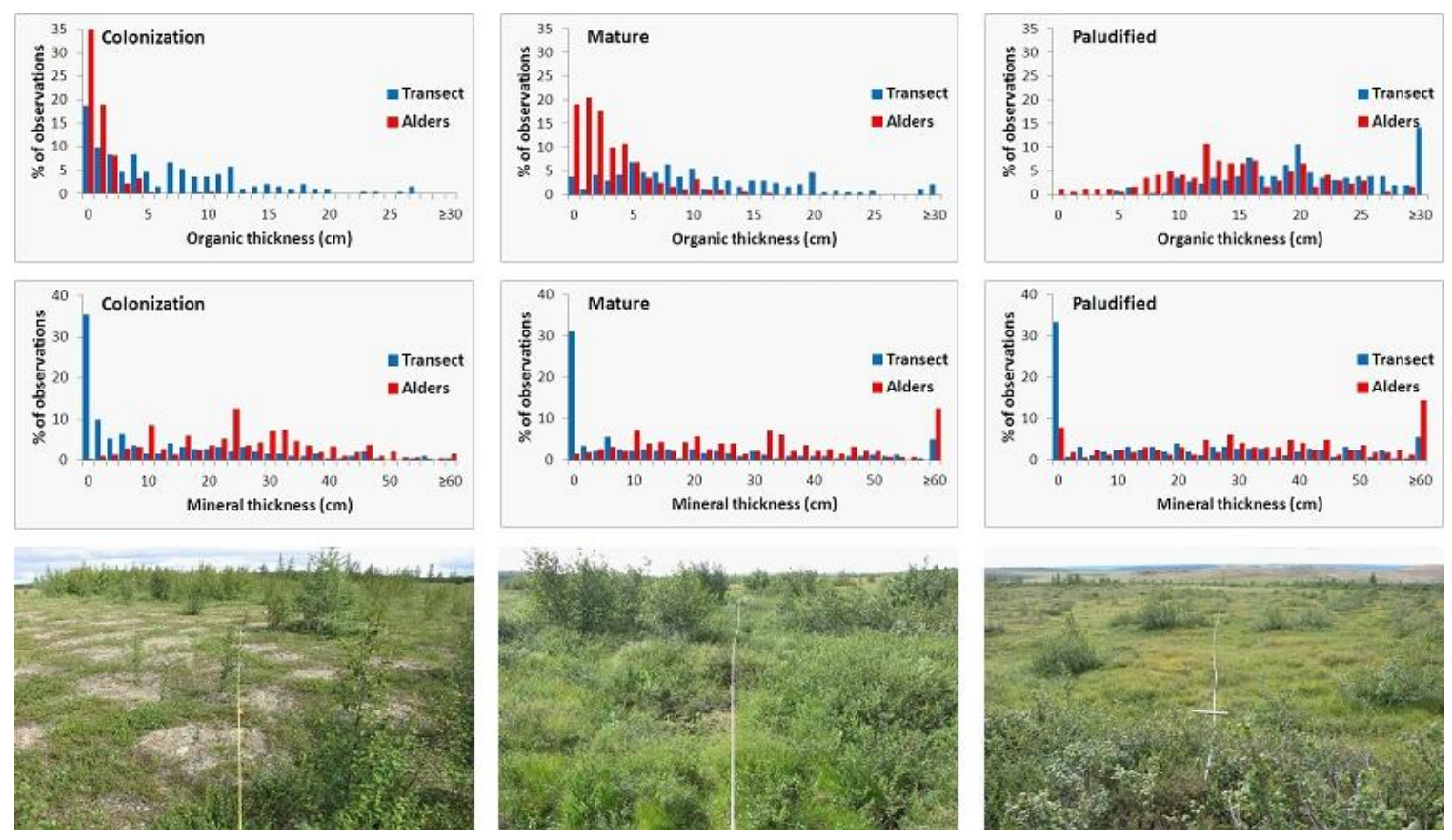

Figure 3.5. Soil characteristics in alder stands of varying age, shown as frequency distributions of organic thickness (top row) and total mineral horizon thickness (middle row) along transects and at alders in colonization zones (left column), mature stands (center column), and paludified stands (right column). Mineral horizon thickness is binned in $2 \mathrm{~cm}$ increments. Photos of each stand-age are also shown (bottom row). 

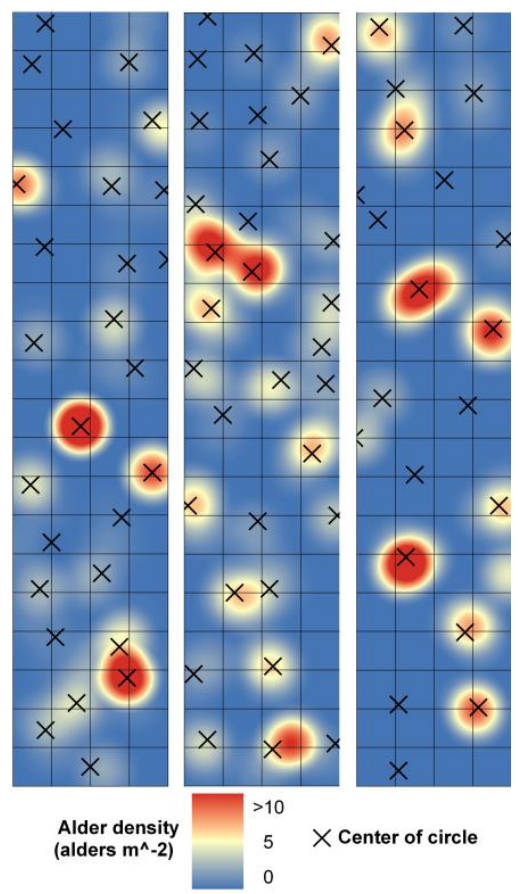

Figure 3.6. Maps of circle distribution and alder density for three 4 x $20 \mathrm{~m}$ transects, showing locations of circle centers and density of alders. Each square is $1 \mathrm{~m}^{2}$.

In tundra and colonization zones, mean near-surface soil temperatures at circles are warmer than at inter-circles (t-test; $\mathrm{p}<0.05)$ (Figure 3.7). This microsite pattern is reversed in paludified stands (t-test; $\mathrm{p}<0.05)$, and soil temperatures do not differ significantly between microsites in mature stands. Across stand-ages, mean soil temperature at circles declines from one category of stand-age to the next (t-test; $\mathrm{p}<0.05)$. 


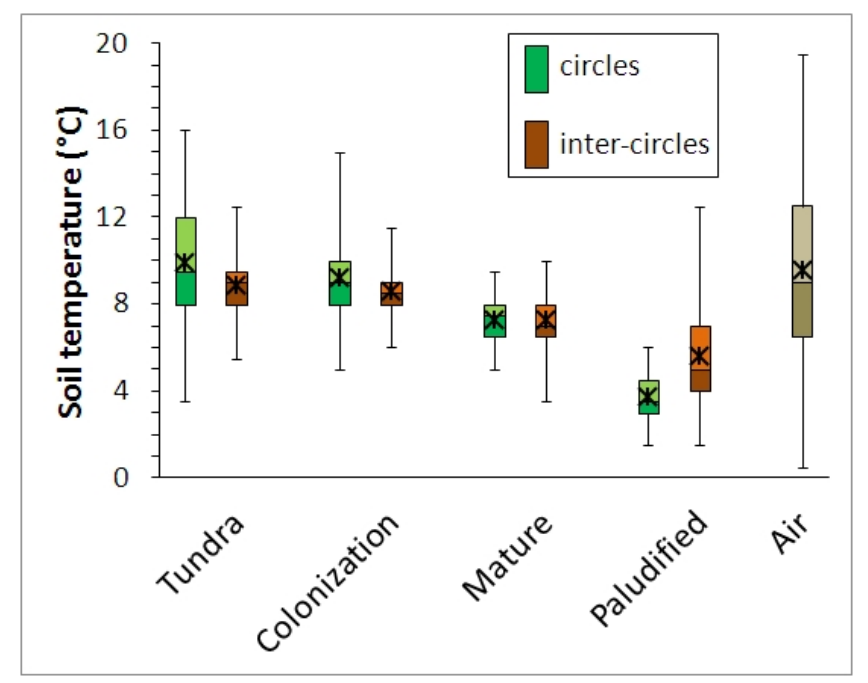

Figure 3.7. Mid-summer $5 \mathrm{~cm}$ soil temperatures. Measurements were taken at Kharp at 4-hour intervals from 24 July-1 August, 2011, at circles and intercircles, by stand-age; box-and-whisker plots indicate range, $1^{\text {st }}$ and $3^{\text {rd }}$ quartiles, median, and mean values (black markers).

\section{Discussion}

Our field observations, coupled with satellite observations dating to 1968, demonstrate direct linkages between disturbance processes in patterned-ground and the recruitment of individual alders and increases in the abundance and areal extent of tall shrub patches in the southern Yamal region. This finding is consistent with other studies that have linked tundra shrub increase to biotic and abiotic disturbance mechanisms that remove or suppress competing vegetation and promote mineral-rich substrates, such as wildfire, landslides, permafrost thaw, fluvial processes, and animals (e.g., Racine et al 2004, Tape et al 2006, Lantz et al 2009, Tremblay et al 2012). One implication of these studies is that the susceptibility of tundra landscapes to climate-induced vegetation 
changes in general, and to shrubification in particular, largely hinges on the frequency of disturbances and the spatial scale at which they operate. As a disturbance mechanism, DFH in patterned-ground is unusual because of its temporal and spatial attributes. First, unlike "pulse" disturbances that occur episodically on multi-decadal or centennial timescales, DFH occurs annually and thereby maintains mineral-rich microsites that are continually available for shrub recruitment. Second, although individual microsites are no more than a few meters in size, DFH is linked to large, contiguous areas where soils and topography are favorable, such as in gently-sloping terrain with unsaturated, silt-rich soils. These spatio-temporal attributes promote the development of extensive mosaics of mineral substrates that not only favor shrub recruitment, but are also immediately available to shrubs during periods of favorable climate.

The close correspondence between alder and evenly-spaced patterned-ground microsites plausibly explains the development of alder shrublands with evenly-spaced shrubs (or evenly-spaced clumps of shrubs), commonly termed "alder savannas," in disparate parts of the Low Arctic. Nutrient-limitation has been identified as a mechanism for regular spacing of alders in interior Alaska (Chapin et al., 1989), but we find that in the areas that we studied, such communities are strongly predisposed to regular spacing of shrubs at the recruitment stage. The development of these shrublands, in turn, initiates a cascade of powerful feedbacks in patterned-ground landscapes, beginning with the attenuation of DFH, followed by the establishment of continuous vegetation cover, a decline in summer soil temperatures, and the accumulation of organic matter, with implications for permafrost thermal regime, soil hydrology, and carbon balance. These 
feedbacks warrant further study, particularly in view of the large areal extent and abundance of patterned-ground landscapes in northwest Siberia and elsewhere in the circumpolar Arctic.

Virtually all of the tall shrub expansion that we observed at Kharp and Obskaya since 1968 is due to expansion of alder. We find that circles are "hotspots" for alder expansion for several reasons. Alder is minerotrophic (Zasada, 1986) and has higher potential growth-rates than do typical arctic species; these high growth-rates, coupled with the lack of established competitors on circles, likely enable alder to successfully colonize cryoturbated soils despite seasonal DFH. Alder also hosts symbiotic nitrogenfixing bacteria, which likely enhance growth on mineral-dominated substrates that might be low in $\mathrm{N}$ (Kaiser et al., 2005). Finally, alders strongly modify the surrounding microenvironment due to their tall stature. By shading the ground surface, and by trapping insulating snow, the developing alder canopies quickly begin to suppress the microsite thermal gradients that drive DFH. In other words, alders only experience strong DFH during the initial stages of shrubland development. These species traits-coupled with the warm summer soil temperatures on exposed circles-explain why alder successfully colonizes bare, cryoturbated microsites, where annual disturbance is too severe for slow-growing Arctic species. As DFH begins to decline, the establishment of understory vegetation - particularly mosses - promotes the accumulation of a continuous organic mat that further suppresses DFH. This feedback explains the lack of exposed circles in older stands. In paludified stands, DFH and shrub recruitment essentially cease: our satellite photo-comparisons revealed virtually no change in shrub distribution in 
paludified stands, despite conspicuous expansion in adjacent areas with active PGFs. The capacity of vegetation in paludified areas to respond to climate warming is probably very limited due to the cold soils and associated limitations on microbial decomposition and nutrient mineralization.

Meteorological records from Salekhard indicate that a warming summer climate has probably played a major role in shrub expansion observed since 1968 in this region. Growing-season temperature is the chief limitation on the growth of boreal trees and shrubs in tundra ecotones, with sharp increases in shrub abundance, growth, and reproduction evident above a threshold mean summer temperature of $10^{\circ} \mathrm{C}$ (Alexandrova, 1974; Lantz et al., 2010). Mean summer temperature at Salekhard has warmed about $1^{\circ} \mathrm{C}$ per century since $1883(\mathrm{p}<0.001)$ (Figure 3.8), a trend corroborated by growth-ring chronologies of tundra shrubs elsewhere in northwest Siberia (Forbes et al., 2010). Strong warming occurred from the late 1960s to 2010 - the satellite period-of-record examined here—with virtually all of the warming occurring from 1968-1980 ( $\mathrm{p}<0.001)$. Although summer temperatures have been highly variable and no trend is evident since 1980 , mean summer temperatures have usually exceeded the $10^{\circ} \mathrm{C}$ threshold $(21$ of 31 years); expansion of tall shrubs appears likely to continue in the areas we studied, even without additional increases in summer temperature. 


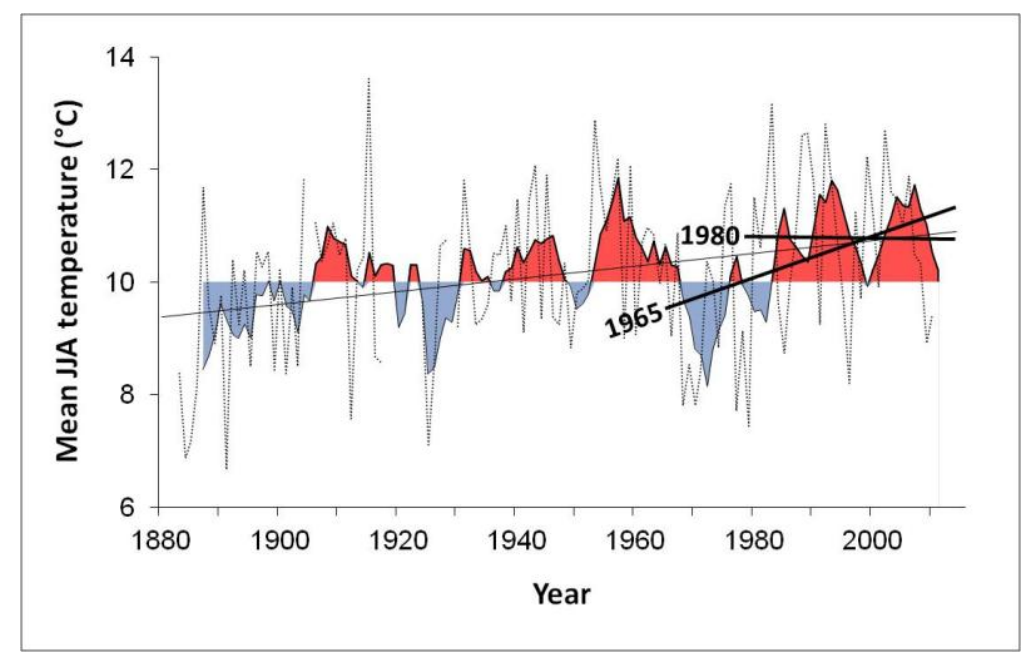

Figure 3.8. Time-series of mean June-August (JJA) temperature for Kharp and Obskaya. The dotted line indicates the raw values, the solid line indicates the 5-year moving average, and linear trendlines are shown for 1883-2011, 1965-2011, and 1980-2011. Warm periods, in which the 5-year moving average exceeds $10^{\circ} \mathrm{C}$, are colored red; periods below this threshold are colored blue.

The ecotonal landscapes we studied share very similar climate, soils, and geomorphology, but have different centennial-scale disturbance histories. Field observations indicated that virtually all of the Kharp site experienced severe wildfire at least 191 years ago, while there was no evidence of historical wildfire at the Obskaya site. These contrasting disturbance histories raise the question of whether the recent shrub expansion we observed at Kharp can be explained simply by alder colonization of burned substrates and successional processes after fire. We argue that neither the meter-scale patterns of shrub recruitment on circles, nor the landscape-scale patterns of shrub expansion in patterned-ground, can be readily explained by successional processes after 
historical fire. First, we recorded the largest increases in alder cover at the unburned Obskaya site, where microsite patterns of alder recruitment were identical to those observed at Kharp. Additionally, the increases in tall shrub abundance that we observed at Kharp occurred after at least 150 years of tundra vegetation development post-fire. Alder recruitment is rapid in early succession after fire in the boreal forest (Matthews, 1992), and available information indicates that alder responds similarly following tundra fire (Lantz et al., 2010). We suggest that a lag in the recruitment of alder exceeding 150 years is longer than would be expected at the Kharp site if other factors, such as patterned-ground processes or changes in climate, were not also involved. We conclude that the shrub expansion observed at Kharp probably occurred due to the interaction of climate effects on alder reproduction and growth, coupled with the wide availability of favorable seedbeds in active patterned-ground landscapes; however, historical wildfire probably played an important role in restoring DFH across much of the Kharp site, by removing vegetation and organic material from underlying patterned-ground.

PGFs are widespread in the northwest Siberian region and elsewhere in the Low Arctic, particularly where soils are silt-rich and prone to DFH (Walker et al., 2008). Although the regional and circumpolar extent of active circles is difficult to quantify from space due to the small size of individual microsites, we conservatively estimate that active features cover $\sim 35 \%$ of the landscapes that we studied. The distribution of active PGFs appears to be comparable in many other areas with high-resolution imagery across $\mathrm{a} \sim 1,200 \mathrm{~km}$ belt of the northwest Siberian Low Arctic (Supplementary Figures 2 and 3). Active patterned-ground is at least locally common in many other areas of the Low Arctic, 
including the Brooks Range foothills of arctic Alaska (Walker et al., 2008). Additionally, relic areas of patterned-ground, where DFH has been suppressed by the development of continuous vegetation and organic matter, are common and widespread in warmer parts of the Low Arctic; tundra fire in these areas could restore DFH and result in microsite recruitment patterns similar to those we have described here. Given alder's widespread distribution in the circumpolar Low Arctic, microsite facilitation of alder expansion in patterned-ground could account for the occurrence and spatial characteristics of shrublands in many other areas of the Low Arctic.

\section{Conclusions}

PGFs such as circles are widespread throughout the Arctic tundra biome. Our space- and field-based observations indicate that these features strongly facilitate tall shrubland development, and promote the development of shrubland communities in which alders are regularly spaced. We conclude that warmer parts of the Low Arctic that are rich in active PGFs are highly susceptible to shrub-induced biome shifts, because of the unusual spatio-temporal attributes of cryogenic disturbance in patterned-ground. DFH occurs annually, rather than episodically, and thereby maintains a mosaic of mineral substrates at the meter-scale that are immediately available for shrub recruitment during periods of favorable climate. These mosaics can extend across large parts of the landscape where soils and topography are favorable, such as in gently-sloping uplands with unsaturated, silt-rich soils. The northwest Siberian Low Arctic in particular appears highly susceptible to rapid, widespread, and persistent changes in ecological regime due 
to the ready availability of mineral-rich seedbeds in the extensive patterned-ground ecosystems of the region.

\section{Acknowledgements}

This work was funded by the National Aeronautics and Space Administration LandCover and Land-Use Change initiative, grants NNG6GE00A and NNX09AK56G, and by the Department of Environmental Sciences at the University of Virginia. We thank Marina Leibman and Roman Ivanov at the Earth Cryosphere Institute in Moscow for their help with logistics for the field studies. We also thank the National Geospatial-Intelligence Agency Commercial Imagery Program for providing some of the modern satellite imagery. Finally, we thank Matt Macander at ABR, Inc. - Environmental Research and Services, Fairbanks, AK, for sharing the aerial photograph shown in Figure 1.

\section{References}

Alexandrova, V. D. 1974. The Arctic and Antarctic: their division into geobotanical areas. Cambridge University Press, Cambridge, UK.

Bhatt U. S., Walker, D. A., Raynolds, M. K., Comiso, J. C., Epstein, H. E., Jia, G., Gens, R., Pinzon, J. E., Tucker, C. J., Tweedie, C. E., and Webber, P. J. 2010. Circumpolar Arctic tundra vegetation change is linked to sea ice decline. Earth Interactions, 14, 1-20. 
Blok, D., Heijmans, M. M. P. D., Schaepman-Strub, G., Kononov, A. V., Maximov, T. C., and Berendse, F. 2010. Shrub expansion may reduce summer permafrost thaw in Siberian tundra. Global Change Biology, 16, 1296-1305.

Buckeridge, K. M., Zufelt, E., Chu, H., and Grogan, P. 2010. Soil nitrogen cycling rates in low Arctic shrub tundra are enhanced by litter feedbacks. Plant and Soil, 330, 407-421.

Chapin, F. S. III, Shaver, G. R., Giblin, A. E., Nadelhoffer, K. J., and Laundre, J. A. 1995. Responses of Arctic tundra to experimental and observed changes in climate. Ecology, 76, 694-711.

Chapin, F. S. III, McGraw J. B., and Shaver, G. R. 1989. Competition causes regular spacing of alder in Alaskan shrub tundra. Oecologia, 79, 412-416.

Chapin, F. S. III, Sturm, M., Serreze, M. C., McFadden, J. P., Key, J. R., Lloyd, A. H., Schimel, J. P., Beringer, J., Chapman, W. L., Epstein, H. E., Euskirchen, E. S., Hinzman, L. D., Jia, G., Ping, C. L., Tape, K. D., Thompson, C. D. C., Walker, D. A., and Welker, J. M. 2005. Role of land-surface changes in Arctic summer warming. Science, 310, 657-660.

Ehrich, D., Henden, J. A., Ims, R. A., Doronina, L. O., Killengren, S. T., Lecomte, N., Pokrovsky, I. G., Skogstad, G., Sokolov, A. A., and Sokolov, V. A. 2012. The importance of willow thickets for ptarmigan and hares in shrub tundra: the more the better? Oecologia, 168, 141-151.

Epstein, H. E., Yu, Q., Kaplan, J.O, and Lischke, H. 2007. Simulating future changes in arctic and subarctic vegetation. Computing in Science \& Engineering, 9, 12-23. 
Forbes, B. C., Macias-Fauria, M., and Zetterberg, P. 2010. Russian Arctic warming and "greening" are closely tracked by tundra shrub willows. Global Change Biology, 16, 1542-1554.

Forbes, B. C., Stammler, F., Kumpula, T., Meschtyb, N., Pajunen, A., and Kaarlejärvi, E. 2009. High resilience in the Yamal-Nenets social-ecological system, West Siberian Arctic, Russia. Proceedings of the National Academy of Sciences, 106, $22041-22048$.

Haugen, R. K., Lynch, M. J., and Roberts, T. C. 1971. Summer temperatures in interior Alaska. United States Army Cold Regions Research and Engineering Laboratory Research Report, 244. U. S. Army Corps of Engineers, Hanover, NH.

Jia, G. J., Epstein, H. E., and Walker, D. A. 2003. Greening of arctic Alaska, 1981-2001. Geophysical Research Letters, 30, 2067.

Kaarlejärvi, E., Baxter, R., Hofgaard, A., Hytteborn, H., Khitun, O., Molau, U., Sjögersten, S., Wookey, P., and Olofsson, J. 2012. Effects of warming on shrub abundance and chemistry drive ecosystem-level changes in a forest-tundra ecotone. Ecosystems, 15, 1219-1233.

Kade, A. and Walker, D. A. 2008. Experimental alteration of vegetation on nonsorted circles: effects on cryogenic activity and implications for climate change in the Arctic. Arctic, Antarctic, and Alpine Research, 40, 96-103.

Kaiser, C., Meyer, H., Biasi, C., Rusalimova, O., Barsukov, P., and Richter, A. 2005. Storage and mineralization of carbon and nitrogen in soils of a frost-boil tundra ecosystem in Siberia. Applied Soil Ecology, 29, 173-183. 
Lantz, T. C., Gergel, S. E., and Henry, G. H. R. 2010. Response of green alder (Alnus viridis subsp. fruticosa) patch dynamics and plant community composition to fire and regional temperature in north-western Canada. Journal of Biogeography, 37, $1597-1610$.

Lantz, T. C., Kokelj, S. V., Gergel, S. E., and Henry, G. H. R. 2009. Relative impacts of disturbance and temperature: persistent changes in microenvironment and vegetation in retrogressive thaw slumps. Global Change Biology, 15, 1664-1675.

Lantz, T. C., Marsh, P., and Kokelj, S. V. 2012. Recent shrub proliferation in the Mackenzie Delta uplands and microclimatic implications. Ecosystems, 15, 47-59.

Marsh, P., Bartlett, P., MacKay, M., Pohl, S., and Lantz, T. C. 2010. Snowmelt energetics at a shrub tundra site in the western Canadian Arctic. Hydrological Processes, 24, 3603-3620.

Matthews, R. F. 1992. Alnus viridis subsp. crispa. United States Department of Agriculture, Forest Service. Available on-line at: http://www.fs.fed.us/database/feis/plants/shrub/alnvirc/all.html\#FIRE ECOLOGY Myers-Smith, I. H., Forbes, B. C., Wilmking, M., Hallinger, M., Lantz, T. C., Blok, D., Tape, K. D., Macias-Fauria, M., Sass-Klaassen, U., Lévesque, E., et al. 2011. Shrub expansion in tundra ecosystems: dynamics, impacts and research priorities. Environmental Research Letters, 6, 045509.

Naito, A. T. and Cairns, D. M. 2011. Relationships between Arctic shrub dynamics and topographically derived hydrologic characteristics. Environmental Research Letters, 6, 045506. 
Pajunen, A. M., Oksanen, J., and Virtanen, R. 2011. Impact of shrub canopies on understorey vegetation in western Eurasian tundra. Journal of Vegetation Science, 22, 837-846.

Peterson, R. A. and Krantz, W. B. 2003. A mechanism for differential frost heave and its implications for patterned-ground formation. Journal of Glaciology, 49, 69-80.

Racine, C. H. 1976. Flora and vegetation. Pp. 39-139 in: Melchior, H. R. (ed.) Biological survey of the proposed Kobuk Valley National Monument. Final report. Alaska Cooperative Park Studies Unit, Biology and Resource Management Program, University of Alaska, Fairbanks, AK.

Racine, C. H. and Anderson, J. H. 1979. Flora and vegetation of the Chukchi-Imuruk area. Pp. 38-113 in: Melchior, H. R. (ed.) Biological survey of the Bering Land Bridge National Monument: revised final report. Alaska Cooperative Park Studies Unit, Biology and Resources Management Program, University of Alaska, Fairbanks, AK.

Racine, C. H., Dennis, J. G., and Patterson, W. A. III. 1985. Tundra fire regimes in the Noatak River watershed, Alaska: 1956-83. Arctic, 38, 194-200.

Racine, C. H., Jandt, R., Meyers, C., and Dennis, J. 2004. Tundra fire and vegetation change along a hillslope on the Seward Peninsula, Alaska, USA. Arctic, Antarctic, and Alpine Research, 36, 1-10.

Ropars, P. and Boudreau, S. 2012. Shrub expansion at the forest-tundra ecotone: spatial heterogeneity linked to local topography. Environmental Research Letters, 7, 015501. 
Sturm, M., Douglas, T., Racine, C., and Liston, G. E. 2005. Changing snow and shrub conditions affect albedo with global implications. Journal of Geophysical Research, 110, G01004.

Sturm, M., Tape, K., and Racine, C. 2001. Climate change: increasing shrub abundance in the Arctic. Nature, 411, 546-547.

Taber, S. 1929. Frost heaving. Journal of Geology, 37, 428-461.

Tape, K. D., Hallinger, M., Welker, J. M., and Ruess, R. W. 2012. Landscape heterogeneity of shrub expansion in arctic Alaska. Ecosystems, 15, 711-724.

Tape, K. D., Sturm, M., and Racine, C. H. 2006. The evidence for shrub expansion in Northern Alaska and the Pan-Arctic. Global Change Biology, 12, 686-702.

Tremblay, B., Lévesque, E., and Boudreau, S. 2012. Recent expansion of erect shrubs in the Low Arctic: evidence from Eastern Nunavik. Environmental Research Letters, 7, 035501.

Walker, D. A., Epstein, H. E., Gould, W. A., Kelley, A. M., Kade, A. N., Knudson, J. A., Krantz, W. B., Michaelson, G., Peterson, R. A., Ping, C. L., Raynolds, M. K., Romanovsky, V. E., and Shur, Y. 2004. Frost-boil ecosystems: complex interactions between landforms, soils, vegetation and climate. Permafrost and Periglacial Processes, 15, 171-188.

Walker, D. A., Epstein, H. E., Romanovsky, V. E., Ping, C. L., Michaelson, G. J., Daanen, R. P., Shur, Y. L., Peterson, R. A., Krantz, W. B., Raynolds, M. K., et al. 2008. Arctic patterned-ground ecosystems: a synthesis of field studies and models 
along a North American Arctic transect. Journal of Geophysical Research, 113, G03S01.

Walker, D. A., Leibman, M. O., Epstein, H. E., Forbes, B. C., Raynolds, M. K., Comiso, J. C., Gubarkov, A. A., Khomutov, A. A., Jia, G. J., et al. 2009. Spatial and temporal patterns of greenness on the Yamal Peninsula, Russia: interactions of ecological and social factors affecting the Arctic normalized difference vegetation index. Environmental Research Letters, 4, 045004.

Walker, D. A., Raynolds, M. K., Daniëls, F. J. A., Einarsson, E., Elvebakk, A., Gould, W. A., Katenin, A. E., Kholod, S. S., Markon, C. J., Melnikov, E. S., et al. 2005. The circumpolar Arctic vegetation map. Journal of Vegetation Science, 16, 267-282.

Walker, M. D., Wahren, C. H., Hollister, R. D., Henry, G. H. R., Ahlquist, L. E., Alatalo, J. M., Bret-Harte, M. S., Calef, M. P., Callaghan, T. V., Carroll, A. B., et al. 2006. Plant community responses to experimental warming across the tundra biome. Proceedings of the National Academy of Sciences of the United States of America, 103, 1342-1346.

Washburn, A. L. 1980. Geocryology: a survey of periglacial processes and environments. John Wiley \& Sons, Inc., Hoboken, NJ.

Yu, Q., Epstein, H. E., Walker, D. A., Frost, G. V., and Forbes, B. C. 2011. Modeling dynamics of tundra plant communities on the Yamal Peninsula, Russia, in response to climate change and grazing pressure. Environmental Research Letters, 6, 045505 . 
Zasada, J. C. 1986. Natural regeneration of trees and tall shrubs on forest sites in interior Alaska. Pp. 44-73 in: Van Cleve, K., et al. (eds.) Forest ecosystems in the Alaska taiga: a synthesis of structure and function. Springer-Verlag, New York, NY. 


\section{Supplementary Information}

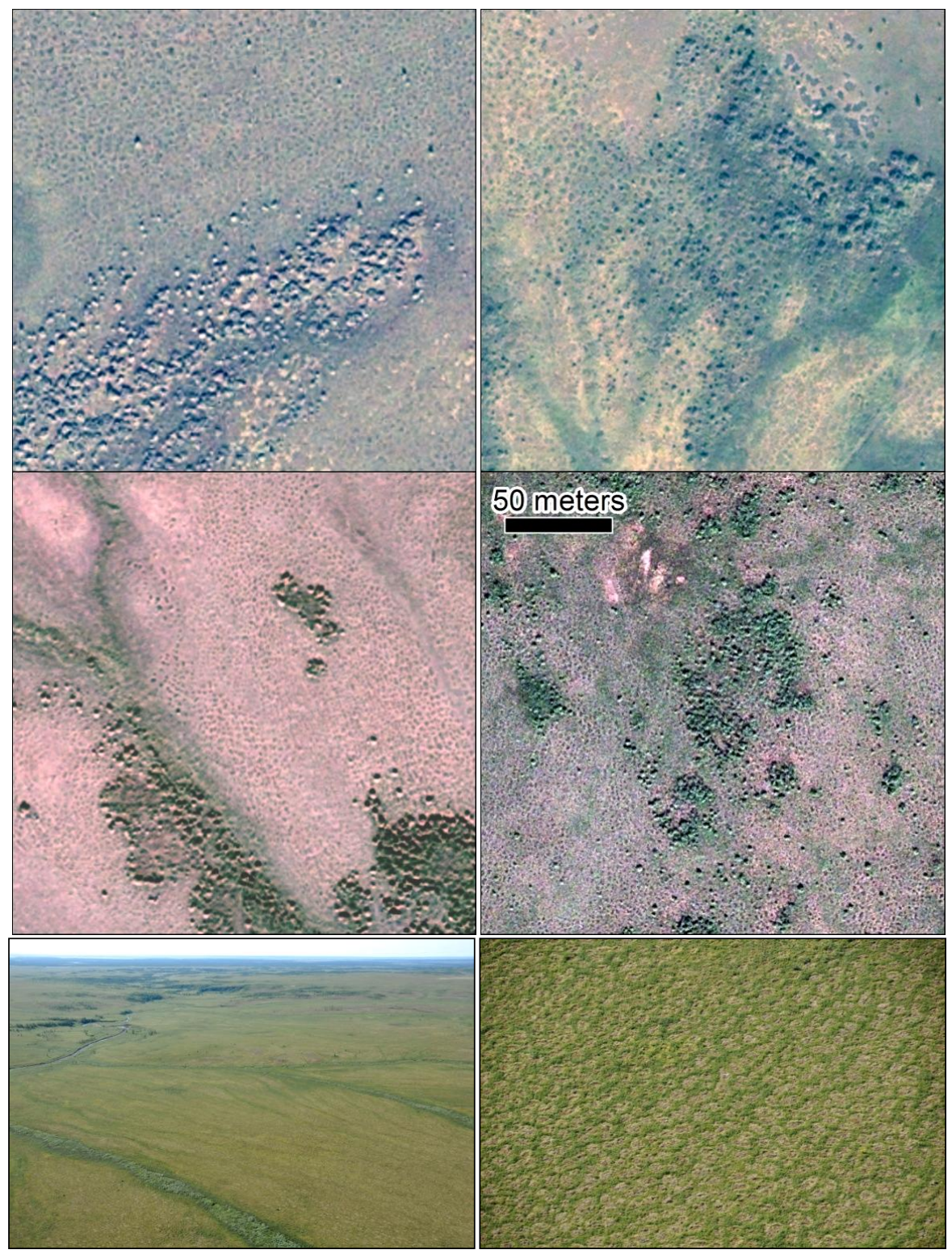

Figure S2. Satellite and aerial photographs showing northwest Siberian patterned-ground landscapes. Obskya site (upper left), Kharp site (upper right), Gy'dan Peninsula (middle left), western Taymyr Peninsula (middle right), and aerial photos near Obskaya site (bottom row). Satellite imagery copyright GeoEye, Inc. and Digital Globe, Inc., provided courtesy of National Geospatial-Intelligence Agency Commercial Imagery Program. 


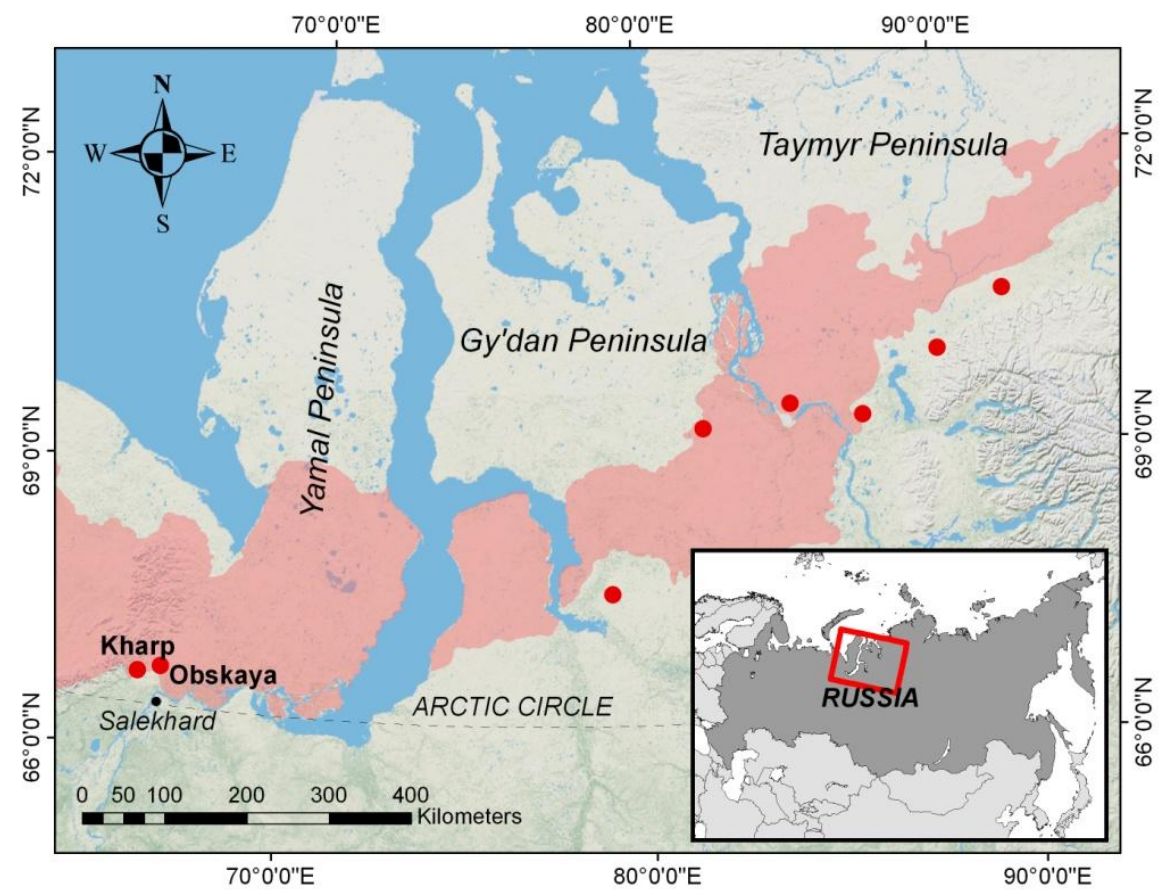

Figure S3. Map of northwest Siberian Arctic showing some locations with modern highresolution imagery (red markers) of alder shrublands in patterned-ground landscapes. The shaded area indicates the warmest portion of the arctic tundra biome, Bioclimate Subzone E (Walker et al, 2005), where boreal shrublands are commonly observed. Although it is difficult to quantify the regional extent of active patterned-ground landscapes with available imagery, the wide extent of active patterned-ground at the locations shown and the wide extent of frost-susceptible soils regionally suggests that much of the ecotonal belt is highly susceptible to the spread of boreal shrublands. 


\title{
CHAPTER 4 - LANDSCAPE AND REGIONAL-SCALE VARIABILITY OF VEGETATION DYNAMICS AND SHRUB PROLIFERATION IN NORTHWEST SIBERIAN ARCTIC TUNDRA ${ }^{3}$
}

\begin{abstract}
Widespread increases in Arctic tundra productivity have been documented for decades using coarse-scale satellite observations, but finer-scale observations indicate that changes have been very uneven, with a high degree of landscape- and regional-scale heterogeneity. Here we analyze time-series of the Normalized Difference Vegetation Index (NDVI) observed by Landsat (1984-2012), to assess landscape- and regional-scale variability of tundra vegetation dynamics in the northwest Siberian Low Arctic, a littlestudied region with varied soils, landscape histories, and permafrost attributes. We also estimate spatio-temporal rates of land-cover change associated with expansion of tall alder (Alnus) shrublands, by integrating Landsat time-series with very-high-resolution imagery dating to the mid-1960s. We compiled Landsat time-series for eleven widelydistributed landscapes, and performed linear regression of NDVI values on a per-pixel basis. We found positive net NDVI trends ("greening") in nine of eleven landscapes. Net greening occurred in alder shrublands in all landscapes, and strong greening closely corresponded to shrublands that developed since the 1960s. Much of the spatial variability of greening within landscapes is linked to landscape physiography and permafrost attributes, while between-landscape variability largely corresponds to differences in surficial geology. We conclude that future increases in tundra productivity
\end{abstract}

${ }^{3}$ Frost, G. V., Epstein, H. E., and Walker, D. A. In review, Environmental Research Letters. 
in the region are most likely in upland tundra landscapes with fine-textured, cryoturbated soils; these areas currently tend to support discontinuous vegetation cover, but are nonetheless highly susceptible to land-cover changes associated with tall shrubland development.

\section{Introduction}

Rapid changes in climate are driving a suite of changes to the physical and biological properties of Arctic terrestrial and marine ecosystems. The dramatic reduction in the extent of summer sea-ice in recent decades has garnered the most attention, and is a key driver of a phenomenon known as "Arctic amplification," by which climate-induced changes to the Arctic land- and sea surface create positive feedbacks that promote further warming (Serreze and Barry 2011). Changes to terrestrial vegetation are also dynamically linked with the climate system (Chapin et al 2005), and affect a wide range of processes in Arctic landscapes including biogeochemical cycling, hydrology, permafrost dynamics, and land-use by wildlife and humans (Hinzman et al 2005, Forbes et al 2009, MyersSmith et al 2011). Changes to tundra vegetation are relatively difficult to assess, however, as most tundra plant communities are dominated by long-lived, slow-growing species and observable changes generally require decades.

Widespread increases in remotely-sensed measures of vegetation productivity, primarily the Normalized Difference Vegetation Index (NDVI), have been observed at high latitudes using Advanced Very High Resolution Radiometer (AVHRR) datasets obtained since 1981 (Myneni et al 1997, Jia et al 2003, Bhatt et al 2010), a phenomenon 
frequently referred to as the "greening of the Arctic." AVHRR provides a daily, global dataset with a relatively long period-of-record (1981-present), thus making it well-suited for circumpolar-scale trend detection. At the $\sim 8 \mathrm{~km}$ spatial resolution of global AVHRR datasets, however, landscape-scale changes to vegetation and land-cover are rendered as "sub-pixel" effects; field-based and remote-sensing observations at finer scales indicate that recent vegetation dynamics have been very uneven, with a high degree of heterogeneity evident at both regional- and landscape scales (McManus et al 2012, Tape et al 2012, Raynolds et al 2013). Circumpolar greening therefore describes a general pattern of increasing tundra productivity, but other techniques are necessary to determine specific changes to vegetation and their underlying, biophysical causes. Bridging this gap is a critical component of efforts to understand how tundra vegetation is changing in space and time, the concomitant impacts to landscape processes, and to improve projections of future environmental change.

Several recent studies have applied $30 \mathrm{~m}$ spatial resolution multi-spectral data from the Thematic Mapper (TM) and Enhanced Thematic Mapper (ETM+) instruments aboard the Landsat family of satellites, to investigate Arctic tundra vegetation dynamics in Canada (Fraser et al 2011, McManus et al 2012) and Alaska (Raynolds et al 2013). Landsat data offer an intermediate spatial scale that is adequate to isolate spectral trends within landscape components of interest, such as individual vegetation types, geomorphic landforms, and human-affected areas. Landsat data are well-suited for time-series analysis, because the data are well-calibrated over time, and robust methods have been developed to correct for atmospheric conditions at the time of image acquisition (e.g., the 
Landsat Ecosystem Disturbance Adaptive Processing System [LEDAPS] [Masek et al 2006]). Additionally, Landsat data encompass a multi-decadal period-of-record (1984present) that is similar to that of AVHRR, thus facilitating greater integration and contextualization of information obtained from the field-scale (meters) to the circumpolar scale.

The northwest Siberian Arctic, here defined as the area extending from the eastern slope of the Polar Ural Mountains eastward to the Taymyr Peninsula, is a geographically large region which has experienced pronounced environmental, societal, and land-use changes in recent decades (Stammler 2005, Walker et al 2009a, Forbes et al 2009, 2010). Observations from AVHRR indicate a great deal of heterogeneity in NDVI trends in the region, with spatially-contiguous zones of both greening and browning evident (Bhatt et al 2010). One possible explanation for this spatial variability, is that the wide variation in surficial geology, soils, and permafrost attributes in the region (Leibman 1995, Drozdov et al 2005, Walker et al 2009a, 2012) strongly modulate the local responses of vegetation to recent changes in temperature and precipitation regime. Northwest Siberian tundra has received comparatively little study, but available information highlights increases in the productivity and extent of tundra shrubs as a key driver of regional greening patterns (Forbes et al 2010, Walker et al 2012, Frost et al 2013), as has been reported elsewhere in the Arctic (Myers-Smith et al 2011, McManus et al 2012).

In this paper, we apply time-series of Landsat NDVI to assess landscape- and regional-scale variability of tundra vegetation dynamics across a series of Low Arctic landscapes spanning northwest Siberia. We also focus on an important form of land- 
cover change in the region, the proliferation of tall shrublands dominated by Siberian alder (Alnus viridis ssp. fruticosa). We chose alder as a focal species, because it typically forms a tall canopy (> $2 \mathrm{~m}$ ) and its establishment represents a fundamental change to tundra vegetation structure (Figure 4.1). Our specific objectives were to (1) map statistically-significant trends of Landsat NDVI across eleven widely-distributed northwest Siberian tundra landscapes, and relate the spatial variability of trends to local attributes of landscape physiography, soils, permafrost, and disturbance regime interpreted from modern VHR imagery; (2) isolate the spectral trends of recentlyestablished tall shrubland patches, by applying results from a previous study that quantified changes in shrubland cover at five of the landscapes using very-highresolution imagery from the 1960s and recent years (Frost and Epstein in review); and (3) develop empirical functions to estimate rates of recent shrub expansion in six, much larger landscapes based on the spectral trends of shrublands.

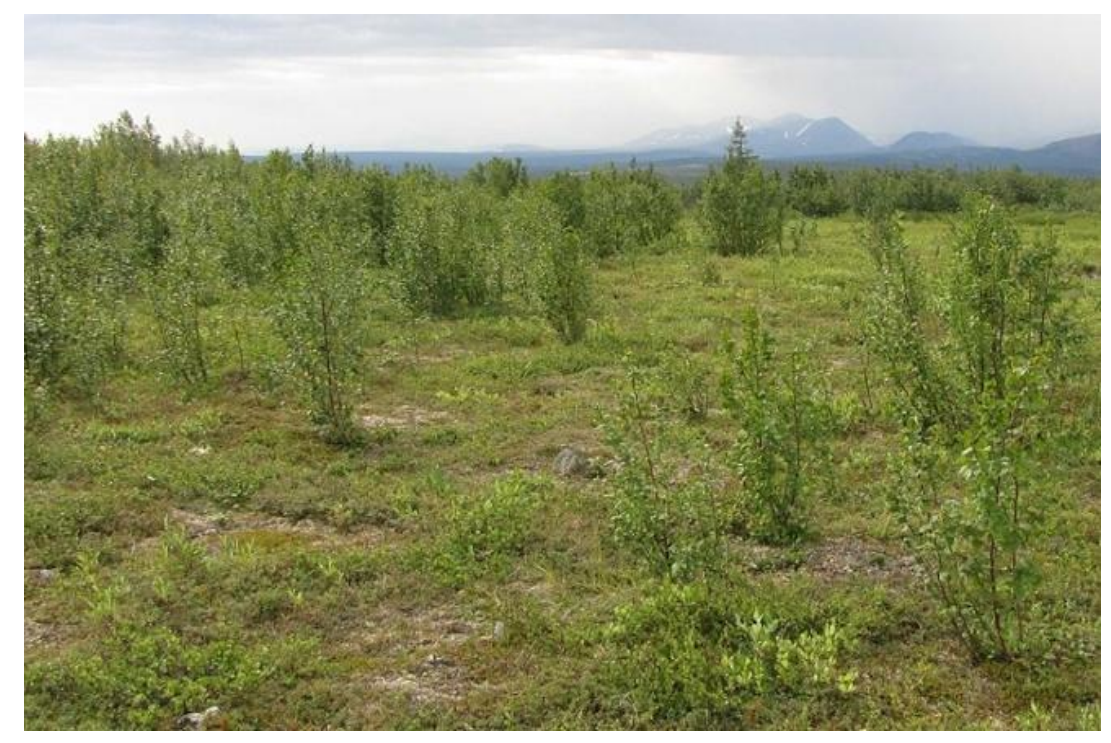

Figure 4.1. Ground photo of recently-established alders in Kharp study landscape. 


\section{Methods}

\section{Data sources}

We utilized three sources of satellite data: (1) Landsat TM/ETM+ imagery acquired during 1984-2012; (2) commercial VHR (very-high-resolution; $\leq 2$ m per pixel) satellite imagery from recent years; and (3) declassified VHR photographs acquired during 1966-1968 by KH-4B "Corona" and KH-7 "Gambit" satellite surveillance systems. We compiled Landsat imagery for each study landscape using the USGS Global Visualization Viewer (GLOVIS) at http://glovis.usgs.gov/. Landsat data for northwest Siberia come from 1984-1988 and 1999-2012; Landsat data acquisition was suspended for most Arctic regions during 1989-1998, so we only analyzed landscapes for which at least two observations exist for the mid-1980s. We restricted analyses to imagery acquired during a 30-day period in mid- to late summer (Julian days 203-233; 22 July to 21 August), when live phytomass and NDVI are at their seasonal peak (hereafter, "peak NDVI"). In order to maximize the number of time-steps available for analysis, we accepted some scenes with partial cloud cover; for such scenes, we manually masked clouds, and cloud shadows. We also used scenes acquired by Landsat 7 after 2003, which contain "scan-line" data gaps. We converted the top-of-atmosphere radiance values in the raw imagery to surface reflectance using the LEDAPS algorithm (Masek et al 2006). We then calculated the NDVI for each pixel using the surface reflectance values in the nearinfrared and red bands (Tucker and Sellers 1986). To evaluate potential bias in the timing of peak NDVI within this 30-day window, we determined the correlation between 
observed NDVI and the Julian day of imagery acquisition; we found no correlation for any landscape $\left(r^{2} \leq 0.12 ; p \geq 0.3\right)$ (Supplementary Figure S1).

Modern VHR imagery came from commercial vendors, and the U. S. National Geospatial-Intelligence Agency Commercial Imagery Program. We ortho-rectified modern VHR imagery using Digital Elevation Models (DEMs) acquired from the European Space Agency's Data User Element Permafrost Project http://www.ipf.tuwien.ac.at/permafrost/. These DEMs were derived from Russian topographic maps and have a nominal horizontal resolution of $\sim 70 \mathrm{~m}$.

We acquired 1960s-era Corona and Gambit satellite photography available for the intensive study landscapes from the U. S. Geological Survey Earth Explorer website

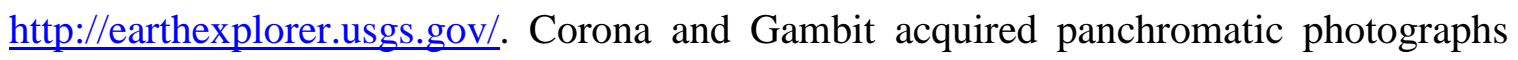
with a nominal spatial resolution of $\sim 2 \mathrm{~m}$ and $0.7 \mathrm{~m}$, respectively.

\section{Study areas}

We identified study landscapes by examining archives of modern VHR imagery in bioclimate subzone "E" of the Circumpolar Arctic Vegetation Map (Walker et al 2005); this subzone refers to the warmest, southernmost part of the Arctic tundra biome, where the proliferation of tall shrubs is an important land-cover change issue (MyersSmith et al 2011). Modern VHR imagery coverage is relatively sparse in northwest Siberia, so we made opportunistic use of cloud-free, summer imagery acquired by five commercial satellites: IKONOS, QuickBird-2, GeoEye-1, WorldView-1, and WorldView-2. After compiling the footprints of suitable imagery, we then evaluated the 
availability of co-incident Landsat data and delineated six widely-distributed, regional study landscapes $\left(\sim 500-1,200 \mathrm{~km}^{2}\right)$ (Table 4.1; Figure 4.2). Descriptions of the five, smaller intensive study landscapes (for which we have 1960s satellite photography) can be found in Frost and Epstein (in review).

Most of the study landscapes lie entirely within bioclimate Subzone "E;" those that do not are strongly dominated by tundra vegetation and have little or no tree cover. Most landscapes primarily encompass gently-sloping, upland terrain dissected by small alluvial valleys; some landscapes also encompass well-developed river floodplains. Direct disturbance by humans is virtually absent from all landscapes, except Laborovaya, where a narrow corridor has been disturbed by railroad construction activities that began in the early 1980s. Instrumental records for 1965-2010 from six meteorological stations in the region indicate mean annual temperatures of $-11.4--6.1^{\circ} \mathrm{C}$, mean growing-season temperatures (June-August) of $8.7-11.5^{\circ} \mathrm{C}$, and mean annual precipitation of $293-515$ mm. All of these stations recorded significant warming trends in growing-season temperature since the mid-1960s (i.e., the period-of-record for VHR imagery at the intensive study landscapes); however, no trend is evident in growing-season temperature since the early 1980s (Supplementary Figure S2).

\section{Imagery analysis}

At the five intensive study landscapes, we quantified changes in alder shrubland cover since the 1960s by comparing 1960s VHR imagery with VHR imagery from recent years; a detailed description of methods can be found in Frost and Epstein (in review). 
Table 4.1. Summary of locations, historical and modern VHR imagery attributes, and Landsat period-of-record for the eleven study landscapes.

\begin{tabular}{lcccccc}
\hline Landscape & $\begin{array}{c}\text { Latitude } \\
\left({ }^{\circ} \mathrm{N}\right)\end{array}$ & $\begin{array}{c}\text { Longitude } \\
\left({ }^{\circ} \mathrm{E}\right)\end{array}$ & $\begin{array}{c}\text { Area } \\
\left(\mathrm{km}^{2}\right)\end{array}$ & $\begin{array}{c}\text { Historical VHR } \\
\text { imagery }^{\mathrm{a}}\end{array}$ & $\begin{array}{c}\text { Modern VHR } \\
\text { imagery }^{\mathrm{b}}\end{array}$ & $\begin{array}{c}\text { Landsat } \\
\text { period-of- } \\
\text { record }\end{array}$ \\
\hline Kharp & 66.8 & 66.0 & 66 & $19 / 8 / 1968(\mathrm{KH}-4 \mathrm{~B})$ & $21 / 6 / 2010(\mathrm{WV}-1)$ & $1985-2010$ \\
Obskaya & 66.9 & 66.6 & 62 & $19 / 8 / 1968(\mathrm{KH}-4 \mathrm{~B})$ & $3 / 6 / 2011(\mathrm{WV}-2)$ & $1984-2010$ \\
Laborovaya & 67.7 & 68.1 & 364 & - & $11 / 7 / 2005(\mathrm{QB}-2)$ & $1984-2012$ \\
Tanlova & 67.6 & 69.8 & 69 & $21 / 8 / 1968(\mathrm{KH}-4 \mathrm{~B})$ & $22 / 7 / 2011(\mathrm{WV}-2)$ & $1986-2011$ \\
Taz & 67.2 & 74.0 & 75 & $21 / 8 / 1968(\mathrm{KH}-4 \mathrm{~B})$ & $20 / 8 / 2010(\mathrm{WV}-1)$ & $1987-2012$ \\
Mesoyakha & 67.8 & 78.82 & 964 & - & $2 / 9 / 2005(\mathrm{QB}-2)$ & $1985-2011$ \\
Gydan & 68.2 & 81.6 & 1,080 & - & $9 / 7 / 2009(\mathrm{GE}-1)$ & $1985-2011$ \\
Tanama & 69.7 & 82.2 & 1,223 & - & $23 / 8 / 2009(\mathrm{QB}-2)$ & $1985-2012$ \\
Yenisey & 70.2 & 84.8 & 1,259 & - & $6 / 7 / 2010(\mathrm{GE}-1)$ & $1985-2010$ \\
Dudinka & 69.6 & 86.5 & 65 & $15 / 7 / 1966(\mathrm{KH}-7)$ & $9 / 7 / 2009(\mathrm{GE}-1)$ & $1985-2012$ \\
Taymyr & 71.2 & 88.2 & 1,226 & - & $9 / 7 / 2010(\mathrm{GE}-1)$ & $1985-2012$ \\
\hline
\end{tabular}

${ }^{\mathrm{a}} \mathrm{KH}-4 \mathrm{~B}=$ Corona, $\mathrm{KH}-7$ = Gambit

${ }^{\mathrm{b}} \mathrm{WV}-1$ = WorldView-1, WV-2 = WorldView-2, QB-2 = QuickBird, GE-1 = GeoEye-1

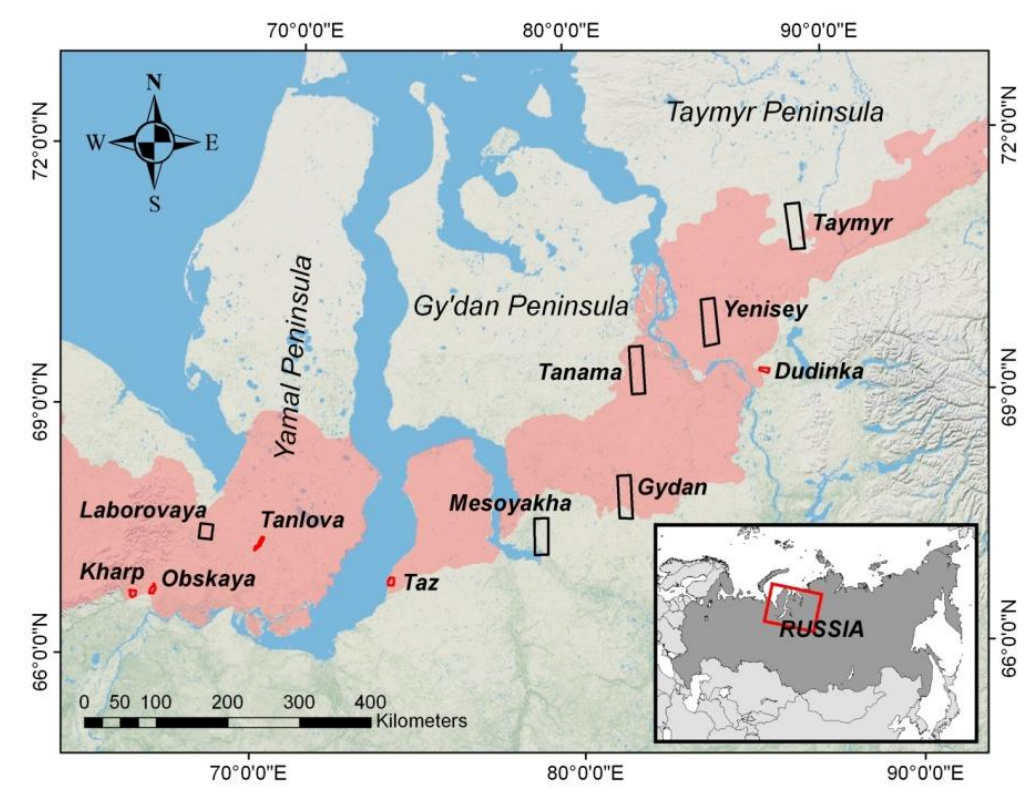

Figure 4.2. Map of northwest Siberian Low Arctic showing locations of the study landscapes; the shaded area represents bioclimate subzone E (CAVM Team 2003). Intensive landscapes used to associate shrub expansion areas with temporal NDVI trends are outlined in red; regional landscapes are outlined in black. 
Briefly, we co-registered the 1960s imagery with the modern VHR ortho-images, and overlaid a uniform grid of sampling-points at $30 \mathrm{~m}$ spacing, so as to match the spatial resolution of Landsat imagery. Each grid was oriented such that sampling-points were at the center of each corresponding Landsat pixel. We then visually recorded the presence/absence of alder shrub cover at each sampling-point for 1960s, and modern VHR imagery.

For the six regional study landscapes, we delineated present-day alder shrublands using modern multi-spectral VHR imagery. The tall stature, high biomass, dark foliage, and extensive intra-canopy shadowing of alder shrublands are distinctive in tundradominated landscapes and produce spectral signatures that facilitate the use of automated delineation techniques. We used the Interactive Supervised Classification tool in ArcMap v. 10.1 (ESRI; Redlands, CA) to delineate alder shrublands, based on the spectral attributes of small "training" polygons that we manually digitized in representative shrubland patches. We iteratively assessed the classifications for each landscape and delineated additional training polygons as needed, until alder shrublands were distinguished satisfactorily (kappa statistic $K \geq 0.8$ ) (Congalton et al 1983). We used similar techniques to delineate lakes and other waterbodies, which we excluded from subsequent NDVI time-series analysis. Finally, we generated a grid of sampling-points as described for the intensive study landscapes, and assigned the corresponding land-cover class (tall alder, tundra, or water) and Landsat NDVI pixel stack to each sampling-point.

At all landscapes, we performed least-squares linear regression for each land pixel stack, with year as the independent variable and NDVI as the response variable. We then 
calculated the slope of the trendline (the annual rate of "greening" or "browning") for all stacks with significant trends $(\mathrm{p} \leq 0.05)$. At the five intensive study landscapes, we used the vegetation sampling-grid data to stratify pixel stacks according to three landcover classes: (1) newly-established shrubland (i.e., alder cover that did not exist in the 1960s); (2) pre-existing shrubland (i.e., alder cover that was already present in the 1960s); and (3) low-growing tundra. At the six regional study landscapes, we distinguished present-day alder shrublands as a single class (because the 1960s shrubland extent was unknown), and a tundra land-cover class.

We applied DEMs and VHR imagery to delineate four physiographic divisions within each landscape: upland, lowland, riverine, and waterbody (Table 4.2). These physiographic divisions integrate multiple environmental state factors related to soils, moisture regime, disturbance regime, and landscape-forming processes. To delineate the lowland physiographic unit, we first applied hydrologic and topographic geospatial tools to classify DEM grid cells that received hydrologic inputs from $\geq 200$ upslope grid cells. This step identified drainage corridors, ranging in size from small, first-order streams, to large rivers. We then classified as lowland, all DEM grid cells that had a slope angle of $\leq 1^{\circ}$, and were linked to drainages by a spatially continuous field of other flat or nearly flat grid cells. The upland physiographic unit included all areas with a slope angle of $>1^{\circ}$, and flat grid cells that were not linked to drainages (i.e., upland plateaus). We manually digitized the riverine physiographic unit through visual photo-interpretation of modern VHR imagery. We then stratified all Landsat pixel stacks by physiographic unit. 
Table 4.2. Physiographic units used to stratify the study landscapes.

\begin{tabular}{ll}
\hline Physiographic unit & Description \\
\hline Upland & $\begin{array}{l}\text { Slopes and plateaus with high position in local topography } \\
\text { Lowland }\end{array}$ \\
$\begin{array}{l}\text { Moisture-gathering, non-floodplain areas occupying low position in local } \\
\text { topography, flat or with low relief }\left(\leq 1^{\circ} \text { slope }\right)\end{array}$ \\
Riverine & $\begin{array}{l}\text { Active floodplains and adjacent landforms formed by fluvial processes } \\
\text { Waterbody }\end{array}$ \\
\hline
\end{tabular}

We estimated the rate of recent alder shrubland expansion in the six regional study landscapes, based on patterns of variation in greening trends observed in newlyestablished and pre-existing shrublands recorded at the intensive landscapes. In the intensive landscapes, we first calculated frequency distributions of rates of greening and browning for pixel stacks with significant trends $(\mathrm{p}<0.05)$ in newly-established, and preexisting alder shrublands; we hereafter refer to these frequency distributions as "NDVI response curves." To generate NDVI response curves, we binned all significant NDVI trend observations into small increments (.005 NDVI units decade $\left.{ }^{-1}\right)$, and plotted the percentage of all pixels in each shrubland class (regardless of the degree of significance) that belonged to each bin. We also calculated the integral of each NDVI response curve, to determine the percentage of all pixels in each shrubland class that had significant NDVI trends.

To estimate the rate of alder expansion at the six regional study landscapes, we used the NDVI response curves to determine the probability that a given shrubland pixel corresponded to recently-established alder cover, based on its rate of greening. We multiplied the number of shrubland pixels within each bin of NDVI trend, by a coefficient that represents the proportion of alder pixels for that bin that belonged to the 
recently-established shrubland class at the intensive study landscapes. We then summed the number of pixels assigned to recently-established shrubland for each bin, according to the equation

$$
\sum_{i=1}^{n}=p_{i}\left(x_{i}\right)
$$

where $n=$ the total number of bins of NDVI trend, $p$ is the probability that a pixel in bin $n$ corresponded to recently-established shrub cover, and $x$ is the total number of pixels for that bin. We calculated the extent of new shrubs on a percent basis, by normalizing the number of recently-established shrubland pixels against the total number of pre-existing shrubland pixels. We then converted this value to a decadal expansion rate $(\%$ shrub increase decade ${ }^{-1}$ ), based on the period-of-record for VHR observations (42 or 43 years).

\section{Results}

Landscape-wide NDVI trends

We observed net greening at nine landscapes, and net browning at two landscapes (Tanlova and Mesoyakha) (Table 4.3). Among the nine landscapes in which net greening occurred, the proportion of Landsat pixel stacks with significant, positive trends varied widely $(4.8-63.9 \%$; median $23.4 \%)$, but very few stacks had negative trends $(0-0.8 \%$; median $0.2 \%$ ). Among the two landscapes in which net browning occurred, the proportion of pixel stacks with negative trends was comparatively small (5.7 and 10.6\%), and greening occurred in some areas (3.3 and 6.2\%). 
Within each landscape, the net direction of NDVI trends was the same for all physiographic units, but the extent of greening was disproportionately high in uplands at most landscapes (Figure 4.3). Among the nine landscapes in which net greening occurred, the percentage of pixels with greening trends was highest for uplands in five landscapes (5.7-65.1\%; median 42.2\%), for lowlands in two landscapes (5.4 and 29.2\%), and for riparian areas in two landscapes (44.4 and 61.1\%). The spatial extent of uplands was much greater than that of other physiographic units in seven of these landscapes, however, and greening in uplands accounted for most of the total greening in eight landscapes. At Laborovaya and Yenisey, the proportion of greening pixel stacks was highest in lowlands, but we observed a similar proportion of greening pixels in upland stacks; additionally, much of the lowland greening at Laborovaya occurred along a corridor that has been affected by construction activities beginning in the 1980s. Spectral trends varied the most in riverine areas; although we observed widespread greening in riverine areas in several landscapes, the extent of riparian areas was very limited in most landscapes, and net browning occurred in the two landscapes in which riparian areas were most extensive (Tanlova and Mesoyakha).

\section{Shrubland spectral trends}

Net greening occurred in alder shrublands at all eleven study landscapes (4.6 $81.8 \%$; median $53.1 \%$ ), including two landscapes in which browning was widespread in tundra communities (Table 4.3). We observed virtually no browning in alder shrublands except at two landscapes (Tanlova and Mesoyakha) (0.7 and 2.5\% of shrubland pixels). 
Table 4.3. Summary of Landsat NDVI trends at the study landscapes for alder shrublands and tundra.

\begin{tabular}{|c|c|c|c|c|c|c|c|}
\hline \multirow[b]{2}{*}{ Landscape } & \multirow{2}{*}{$\begin{array}{c}\text { Mean } n \text { of } \\
\text { Landsat } \\
\text { observations }\end{array}$} & \multicolumn{3}{|c|}{$\%$ of landscape greening } & \multicolumn{3}{|c|}{$\%$ of landscape browning } \\
\hline & & Total & Alder & Tundra & Total & Alder & Tundra \\
\hline Kharp & 11.6 & 61.9 & 81.8 & 59.1 & 0.1 & 0 & 0.1 \\
\hline Obskaya & 10.8 & 58.5 & 70.4 & 57.2 & 0 & 0 & 0 \\
\hline Laborovaya & 11.9 & 10.9 & 18.2 & 10.8 & 0.8 & 0 & 0.8 \\
\hline Tanlova & 9.7 & 6.2 & 19.4 & 5.0 & 10.6 & 4.6 & 11.2 \\
\hline Taz & 8.8 & 4.8 & 4.6 & 4.9 & 0.2 & 0 & 0.2 \\
\hline Mesoyakha & 11.1 & 3.3 & 15.4 & 3.2 & 5.7 & 0.7 & 5.7 \\
\hline Gydan & 8.9 & 22.4 & 54.6 & 21.5 & 0.3 & 0 & 0.3 \\
\hline Tanama & 8.6 & 23.4 & 58.4 & 22.4 & 0.2 & 0 & 0.2 \\
\hline Yenisey & 10.2 & 28.9 & 27.4 & 28.9 & 0.2 & 0.1 & 0.2 \\
\hline Dudinka & 12.4 & 63.9 & 53.1 & 68.7 & 0 & 0 & 0 \\
\hline Taymyr & 9.2 & 9.7 & 54.6 & 9.6 & 0.3 & 0 & 0.3 \\
\hline
\end{tabular}

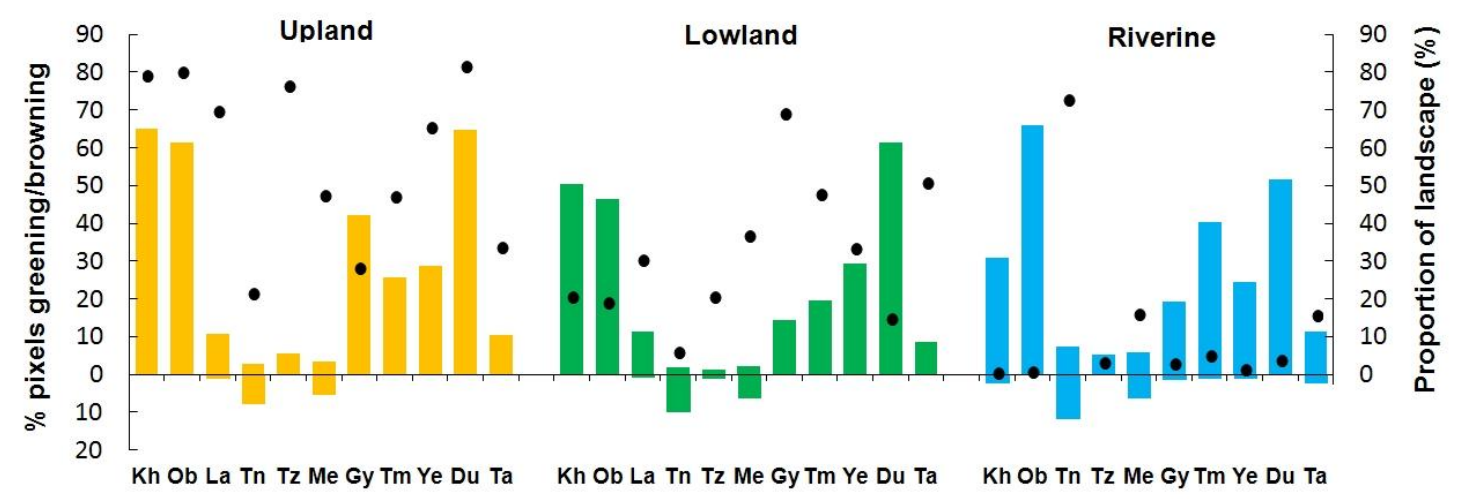

Figure 4.3. Proportion of Landsat pixel stacks with significant NDVI trends by physiographic unit (colored bars, plotted on left axis), and the proportion of each landscape comprised by each physiographic unit (black markers, right axis). Values above the $\mathrm{x}$-axis indicate greening; values below the $\mathrm{x}$-axis indicate browning. 
The proportion of present-day alder shrubland pixels with greening trends was greater than the proportion of tundra pixels with greening trends at eight landscapes, but was slightly lower at three landscapes.

At the five intensive study landscapes, we divided alder shrublands into two categories - "recently-established" and "pre-existing"-using comparisons of VHR imagery from the 1960s and recent years. Alder shrubland cover increased $5.3-21.0 \%$ in these landscapes (Frost et al., in review), and Landsat pixel stacks with strong greening trends tended to coincide with known shrub expansion areas (Figure 4.4). Across all five

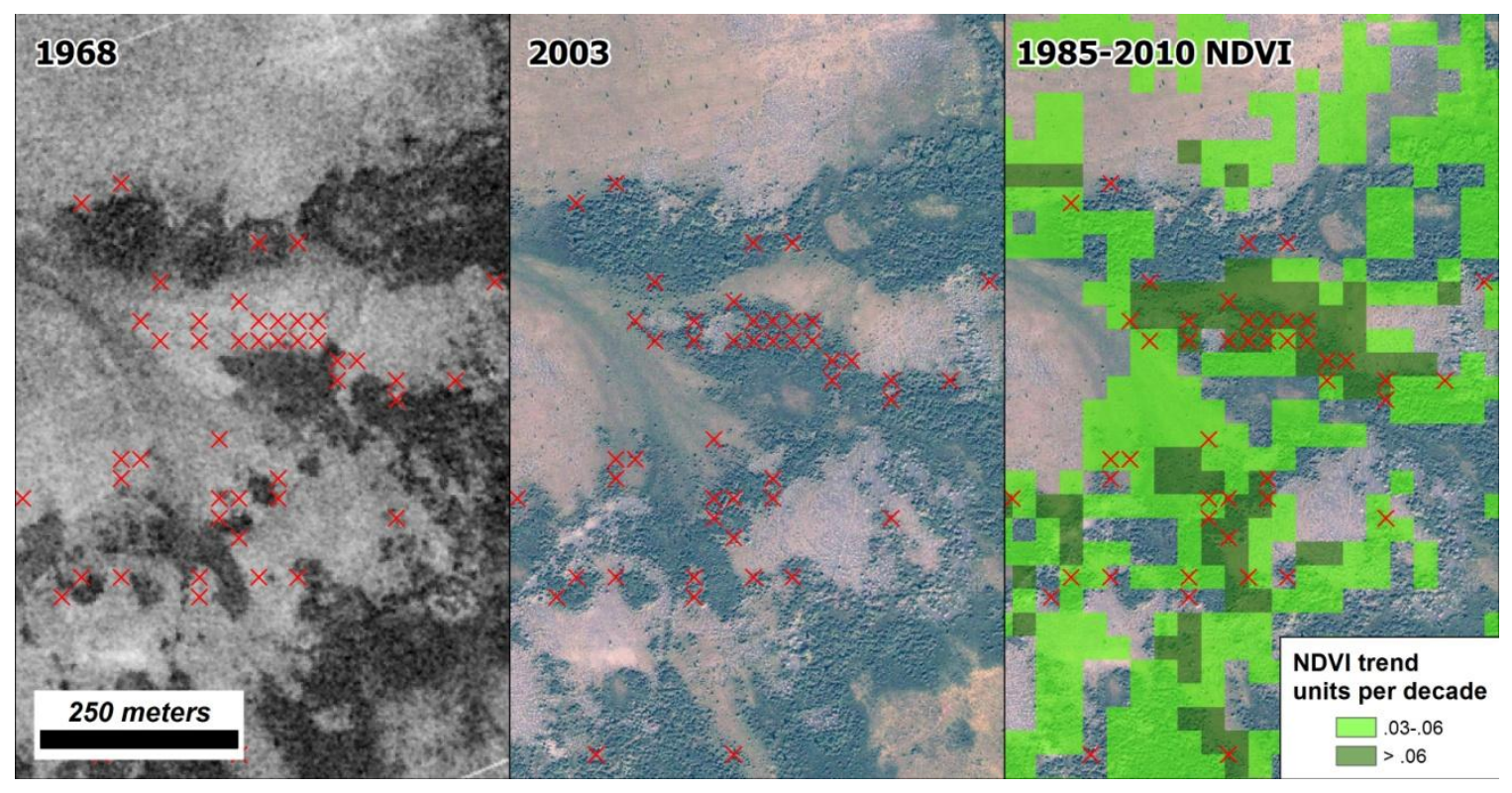

Figure 4.4. Corona (19 Aug 1968; left) and QuickBird (24 Jul 2003; center) images of shrub-tundra at the Kharp landscape. Alder shrublands (dark patches) contrast sharply with tundra; red markers indicate Landsat pixel stacks with recently-established shrub cover. Landsat data for 1985-2010 (right) show disproportionately high greening in shrublands; pixels with non-significant trends ( $\mathrm{p}>0.05)$ are not shown. 
intensive landscapes, $70.3 \%$ of Landsat pixel stacks in recently-established shrublands had significant greening trends, and the mean rate of greening was 0.047 NDVI units decade $^{-1}$ (landscape mean range $0.040-0.051$ ). In pre-existing shrublands, $42.3 \%$ of Landsat pixels had significant greening trends, and the mean rate of greening was 0.035 NDVI units decade ${ }^{-1}$ (landscape mean range $0.023-0.041$ ). NDVI response curves indicate that low rates of greening $\left(<0.03\right.$ NDVI units decade $\left.{ }^{-1}\right)$ occurred in similar proportions of Landsat pixels in pre-existing and newly-established shrublands; however, shrublands with greening trends $\geq 0.045$ units decade $^{-1}$ were at least twice as likely to correspond to newly-established shrublands (Figure 4.5). We applied the NDVI response curves to estimate decadal rates of shrub cover increase expansion using Landsat NDVI trends. Estimated rates of recent (post-1965) shrub expansion in these landscapes range from $+0.7-+5.7 \%$ decade $^{-1}$ (Table 4.4); however, there was substantial disagreement

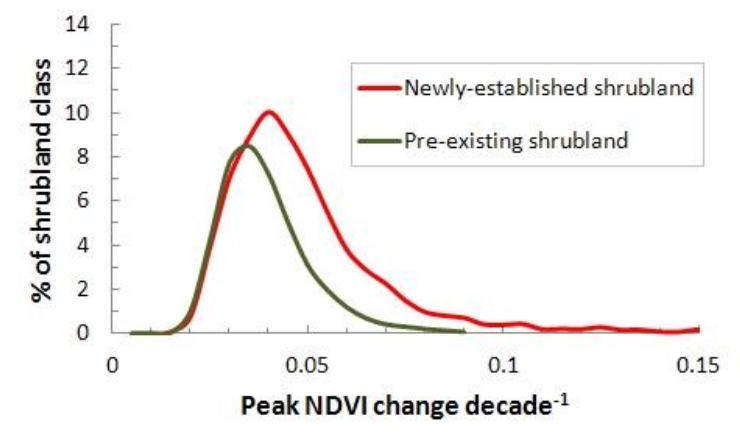

Figure 4.5. NDVI response curves for Landsat pixel stacks in pre-existing and newlyestablished shrublands derived using comparisons of 1960s and modern satellite imagery at the five intensive landscapes. Curves are plotted as a percentage of all pixel stacks for the two shrubland categories. 
between shrub expansion rates estimated from Landsat data, and rates derived from direct comparisons of 1960s and modern VHR imagery at the Kharp landscape.

Table 4.4. Decadal rate of change in alder shrubland extent estimated from Landsat NDVI trends for all landscapes, and observed from comparisons of VHR imagery from the 1960s and recent years for the five intensive study landscapes.

\begin{tabular}{lccc}
\hline Landscape & $\begin{array}{c}\text { Modern } \\
\text { shrub cover } \\
(\text { ha })\end{array}$ & $\begin{array}{c}\text { Estimated shrub } \\
\text { expansion rate } \\
\left(\% \Delta \text { decade }^{-1}\right)\end{array}$ & $\begin{array}{c}\text { Observed shrub } \\
\text { expansion } \\
\text { rate } \% \Delta \text { decade }^{-1}\end{array}$ \\
\hline Kharp & 773 & 5.2 & 2.0 \\
Obskaya & 585 & 5.7 & 4.8 \\
Laborovaya & 260 & 0.8 & - \\
Tanlova & 395 & 2.4 & 4.5 \\
Taz & 1,277 & 0.4 & 1.3 \\
Mesoyakha & 1,116 & 0.7 & - \\
Gydan & 2,652 & 3.7 & - \\
Tanama & 3,207 & 2.8 & - \\
Yenisey & 1,624 & 1.3 & - \\
Dudinka & 1,617 & 3.9 & 6.0 \\
Taymyr & 128 & 3.2 & - \\
\hline
\end{tabular}

\section{Discussion}

\section{Landscape NDVI trends}

We observed greening in all three physiographic units at eight landscapes distributed in the foothills of the Polar Ural Mountains, and the Gydan and Taymyr Peninsula regions; however, greening was generally most widespread in upland areas (Figure 4.6). The prevalence of greening that we observed in upland terrain is somewhat inconsistent with other landscape-scale studies that have applied Landsat NDVI timeseries elsewhere in the Arctic. For example, greening observed in the Canadian Arctic by 
Fraser et al (2011) was primarily concentrated in valleys and other low-lying areas, and McManus et al (2012) observed similar landscape-scale patterns of NDVI trend in Low Arctic Quebec. These apparent inconsistencies highlight that although spatial patterns of greening can be generalized to some degree at landscape- and even regional scales, unifying explanations for spatial patterns of greening and their causal mechanisms at the circumpolar scale remain elusive. Widespread warming observed across most of the circumpolar Arctic during the $20^{\text {th }}$ century offer a compelling explanation for the positive trends evident in coarse-scale datasets, such as AVHRR, but findings derived from fine-

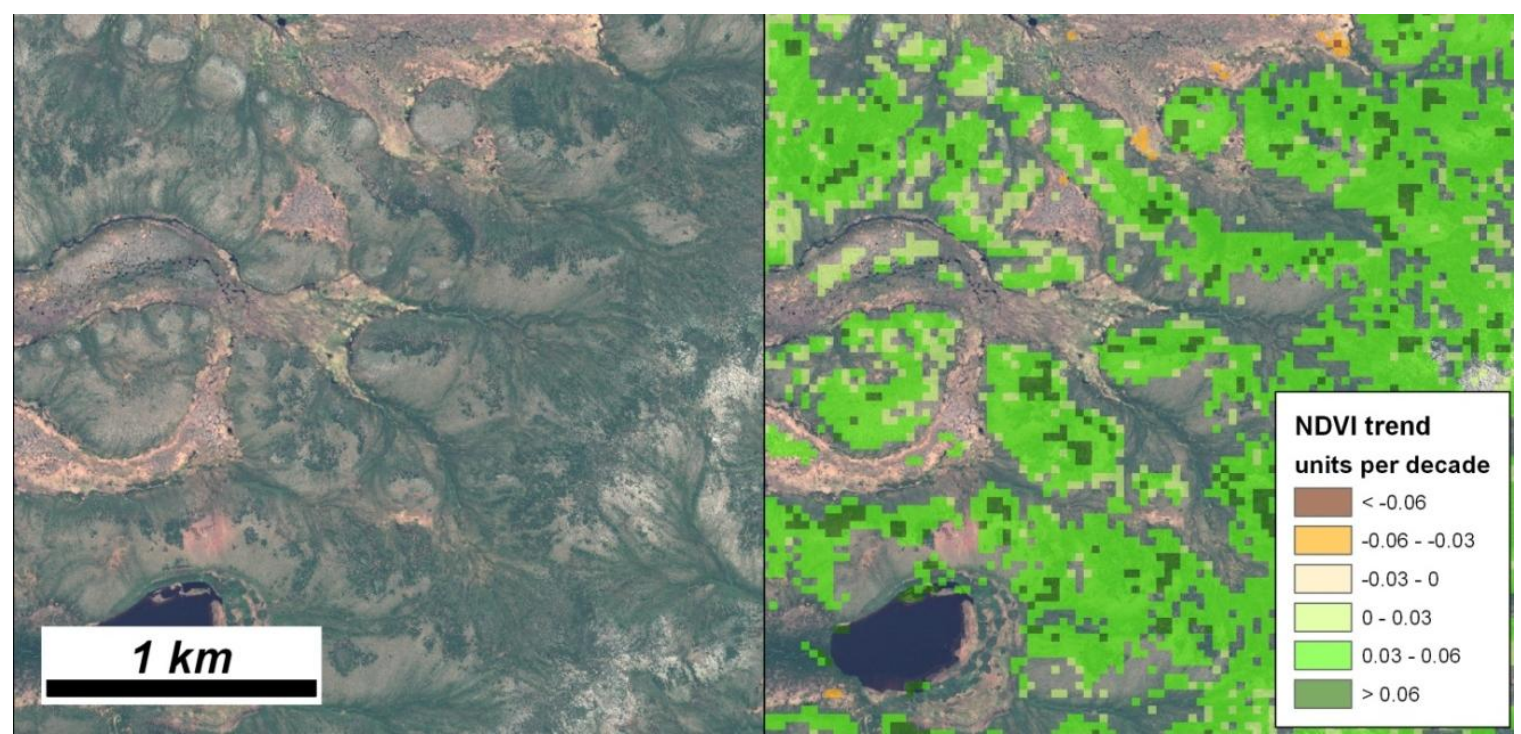

Figure 4.6. Upland and lowland terrain at Gydan landscape (GeoEye; left), and overlay of significant trends of Landsat NDVI (right); pixels lacking significant trends are not shown. In the GeoEye image, lowlands are yellowish, upland tundra is grayish-green, and darkest green patches correspond to alder shrublands. Little greening occurred in lowland tundra, and the strongest greening is coincident with shrubby areas. 
scale datasets indicate that other environmental factors, such as differences in substrates, geomorphic processes, and disturbance regime, result in a high degree of variability in the susceptibility of Arctic landscapes to environmental change.

Net trends of NDVI were positive at most of the landscapes that we studied, but we did observe browning in two landscapes (Tanlova and Mesoyakha), and very little net trend in a third landscape (Taz) (Figure 4.3). All three of these landscapes are located in the southern Yamal and Tazovskiy Peninsula regions, which share similar surficial geology that is dominated by sandy marine sediments (Drozdov et al 2005). In a study of spatial patterns of peak NDVI on the Yamal Peninsula, Walker et al (2009a) noted a close correspondence between low-productivity tundra communities and sand-dominated uplands; soils in these areas are relatively old and tend to be highly leached, with low concentrations of nitrogen and cations (Walker et al 2009b). Modern VHR imagery indicates that upland surfaces at Tanlova and Mesoyakha have not been extensively disturbed by cryogenic landslides and other erosional processes, which expose underlying marine clay sediments with much higher nutrient content (Leibman 1995, Walker et al 2009a). Comparison of 1960s and modern VHR imagery at Tanlova indicates that although alder shrubland extent increased markedly, virtually all of the increase occurred on floodplains and there was virtually no change in sandy, undisturbed uplands. Sandy uplands are also extensive at the Taz intensive study landscape, but erosional features are more widespread, and shrub expansion occurred locally on hillslopes affected by cryogenic landslides (Figure 4.7a). This pattern of shrub occurrence is consistent with the 
distribution of highly-productive willow shrublands on landslides farther north on the Yamal Peninsula (Leibman 1995, Ermokhina and Myalo 2012).

Contrasts in the relative extent of greening between the southern Yamal and Tazovskiy peninsulas, and the rest of the study region are striking considering that multidecadal climate trends and variability have been similar over the entire study domain. One explanation for these regional-scale differences in vegetation dynamics, is that differences in surficial geology and landscape-forming processes result in large contrasts in edaphic conditions and disturbance regime, which promote the development of dissimilar tundra communities on sandy and fine-textured substrates (see Walker et al 2012). These communities, in turn, can be expected to exhibit different responses to shared climatic trends in recent decades. In contrast to the sandy marine sediments of the Yamal and Tazovskiy regions, soils at the Ural foothills landscapes are derived from mafic bedrock, while clayey marine and fluvio-glacial deposits are widespread in the Gydan and Taymyr Peninsula regions (Drozdov et al 2005). These parent materials promote the formation of fine-textured soils, which have markedly different hydrologic and chemical properties compared to sandy substrates. Additionally, fine-textured soils are more subject to permafrost processes related to seasonal frost (Peterson and Krantz 2003, Walker et al 2004). Examination of VHR imagery, and field studies at two sites (Kharp and Obskaya; see Frost et al [2013]), indicate that much of the upland greening at landscapes in the Urals, Gydan, and Taymyr regions is strongly linked to cryogenic disturbance processes in areas of patterned-ground with abundant, sorted- and non-sorted circles (hereafter, "circles") (Figure 4.7b). Although it is difficult to quantify the spatial 


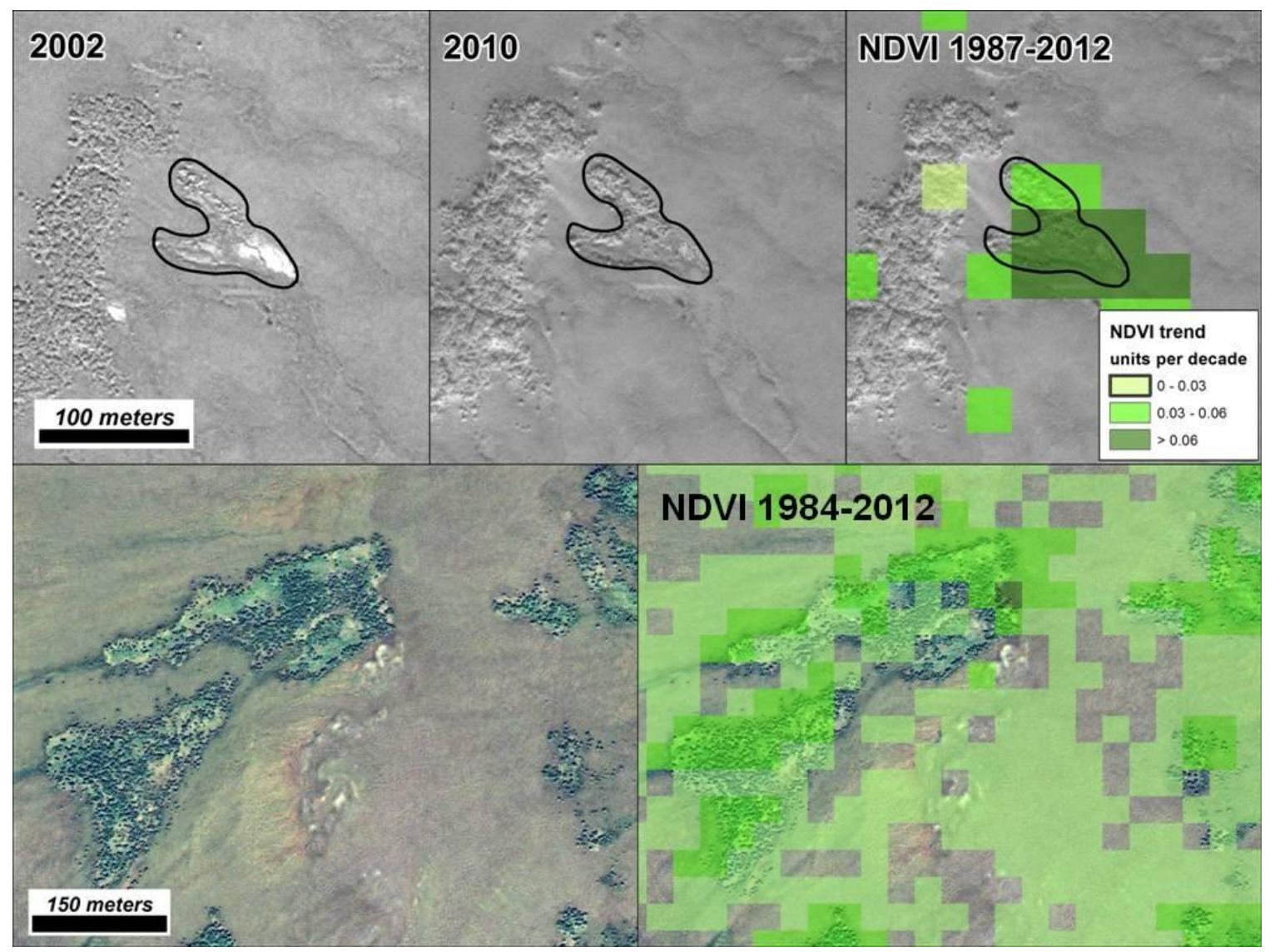

Figure 4.7. (a) Cryogenic landslide (black outline) at Taz landscape shown in 2002 (IKONOS; upper left), and 2010 (WorldView-1; upper center), and significant trends of Landsat NDVI (upper right). Note the rapid development of alder shrubs over only 8 years. (b) Patterned-ground area at Laborovaya; note the reticulated photo-signature of non-sorted circles in tundra (QuickBird; lower left); widespread greening occurred in patterned-ground and especially in alder shrublands (lower right).

extent of circles over large areas due to the small size of individual features, patternedground mosaics are widespread in upland terrain in much of the northwest Siberian Low Arctic, particularly in landscapes dominated by fine-textured mineral soils that are highly 
susceptible to cryoturbation (Supplemental Figure S2). These areas tend to support discontinuous vegetation cover, because strong cryogenic disturbance at circles inhibits the establishment of vegetation. In warmer parts of the Arctic, however, these microsites can be rapidly colonized by vegetation, where the encroachment of relatively fastgrowing species can attenuate cryoturbation and promote the development of continuous vegetation cover (Walker et al 2008, Shur et al 2009).

\section{Alder shrubland spectral trends}

In the five intensive study landscapes, we observed disproportionately strong greening trends in alder shrublands that were known to have become established since the 1960s, but we also observed extensive greening in pre-existing shrublands. The overlap in NDVI trends observed in shrublands of varying age introduced considerable error in the empirical functions used to estimate shrubland increase in the regional study landscapes (Table 4.4; Figure 4.5). Recently-established and pre-existing shrublands had been classified using a point-intercept sampling approach, such that any changes in the cover or density of shrubs elsewhere within a $900 \mathrm{~m}^{2}$ Landsat pixel were not taken into account. This mismatch in sampling of points, versus pixels undoubtedly introduced confusion between pre-existing and recently-established shrubland classes. Additionally, the sensitivity of Landsat NDVI observations to incremental increases in biomass is substantially reduced where high biomass is already present (Figure 4.8), a relationship that has also been noted in AVHRR data (Raynolds et al 2012). Therefore, while the development of alder shrublands on sparsely-vegetated sites can be expected to produce 


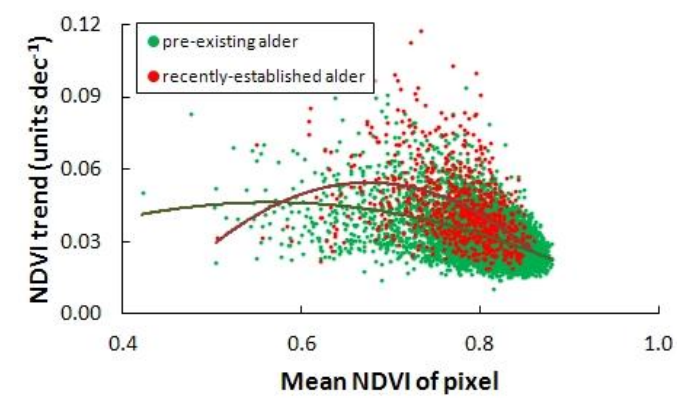

Figure 4.8. Scatterplot of mean NDVI, versus mean NDVI trend for pre-existing, and expanding alder shrublands at Kharp study landscape. Note the diminishing magnitude of NDVI trends at increasing absolute values of NDVI.

strong positive NDVI trends, increases in shrub density within pre-existing, high-biomass stands are likely to have a small influence on Landsat-observed NDVI.

The widespread, and disproportionate positive trends in NDVI that we observed in alder shrublands throughout the study area are broadly consistent with increased shrubland extent and productivity, regardless of the timing of shrub establishment. Although the overall extent of alder shrublands is low in several of the study landscapes, the ubiquity of greening in high-biomass shrublands - even at the margin of alder's distribution at the coldest, Taymyr landscape —indicates that tall shrubland development is occurring at a wide scale in northwest Siberian Low Arctic tundra, and there appears to be high potential for further increase. The facilitation of alder recruitment on meter-scale patterned-ground features, such as non-sorted circles, has been described in detail from field studies at the Kharp and Obskaya landscapes (see [Frost et al 2013]) and plausibly explains the widespread greening seen in alder shrublands at most of the other landscapes. Broad patterns of greening indicates, however, that alder shrubland devleopment is likely 
only one, conspicuous part of a broader pattern of vegetation development in active patterned-ground areas of the northwest Siberian Low Arctic.

Agreement with other NDVI time-series

One limitation of Landsat-based analyses of tundra vegetation dynamics is the lack of data for 1989-1998 for much of the Arctic, thus raising the possibility that the linear NDVI trends reported here might mask non-linear dynamics that would have been apparent if data were available for this "lost decade." One way to address this issue is to compare our findings with those from studies that applied similar techniques to NDVI datasets from AVHRR, which has provided a continuous record since 1982. The three landscapes in which we observed flat, or negative trends of Landsat NDVI correspond with areas of little or no change in time-series of AVHRR NDVI (Bhatt et al 2010); additionally, the widespread greening that we observed in regional landscapes in the Gydan and Taymyr Peninsula regions is corroborated by AVHRR data. The strong greening we report for three intensive study landscapes in the Ural foothills and southwestern Taymyr, however, is not evident in AVHRR time-series. This inconsistency is likely attributable in part to a mismatch in the spatial resolution of the two datasets; these three landscapes represent areas of only $\sim 60 \mathrm{~km}^{2}$, and therefore likely encompass small portions of several adjacent AVHRR pixels. Nonetheless, this lack of agreement warrants further investigation, because the greening observed by Landsat in these areas is corroborated by historical and modern VHR imagery, which indicates widepread increases in the extent of high-biomass shrublands in these landscapes. 


\section{Acknowledgements}

This work was funded by the NASA Land-Cover Land-Use Change Initiative (LCLUC), grants NNG6GE00A and NNX09AK56G; the Virginia Space Grant Consortium (VSGC); and the Department of Environmental Sciences at the University of Virginia. We also thank the National Geospatial-Intelligence Agency (NGA) Commercial Imagery Program for permitting access to NGA satellite imagery archives for scientific use. Special thanks go to Jaime Nickeson at NASA and Paul Morin at the University of Minnesota, for querying the NGA archives and delivering useful data. Finally, we thank Kathy Holcomb at the University of Virginia Alliance for Computational Science and Engineering for her help in scripting processing steps for Landsat data.

\section{References}

Bhatt U. S., Walker, D. A., Raynolds, M. K., Comiso, J. C., Epstein, H. E., Jia, G., Gens, R., Pinzon, J. E., Tucker, C. J., Tweedie, C. E., and Webber, P. J. 2010. Circumpolar Arctic tundra vegetation change is linked to sea ice decline. Earth Interactions, 14, 1-20.

CAVM Team. 2003. Circumpolar Arctic Vegetation Map (1:7,500,000 scale). Conservation of Arctic Flora and Fauna (CAFF) Map No. 1. U. S. Fish and Wildlife Service, Anchorage, AK.

Chapin, F. S. III, Sturm, M., Serreze, M. C., McFadden, J. P., Key, J. R., Lloyd, A. H., Schimel, J. P., Beringer, J., Chapman, W. L., Epstein, H. E., Euskirchen, E. S., Hinzman, L. D., Jia, G., Ping, C. L., Tape, K. D., Thompson, C. D. C., Walker, D. 
A., and Welker, J. M. 2005. Role of land-surface changes in Arctic summer warming. Science, 310, 657-660.

Congalton, R. G., Oderwald, R. G., and Mead, R. A. 1983. Assessing Landsat classification accuracy using discrete multivariate analysis statistical techniques Photogrammetric Engineering and Remote Sensing, 49, 1671-1678

Drozdov, D. S., Rivkin, F. M., Rachold, V., Ananjeva-Malkova, G. V., Ivanova, N. V., Chehina, I. V., Koreisha, M. M., Korostelev, Y. V., and Melnikov, E. S. 2005. Electronic atlas of the Russian Arctic coastal zone. Geo-Marine Letters, 25, 8188

Ermokhina, K. A. and Myalo, E. G. 2012. Phytoindicators of landslide disturbances in the central Yamal. Proceedings of the Tenth International Conference on Permafrost, 2, 531-536

Forbes, B. C., Macias-Fauria, M., and Zetterberg, P. 2010. Russian Arctic warming and "greening" are closely tracked by tundra shrub willows. Global Change Biology, 16, 1542-1554.

Forbes, B. C., Stammler, F., Kumpula, T., Meschtyb, N., Pajunen, A., and Kaarlejärvi, E. 2009. High resilience in the Yamal-Nenets social-ecological system, West Siberian Arctic, Russia. Proceedings of the National Academy of Sciences, 106, $22041-22048$.

Fraser, R. H., Olthof, I., Carrière, M., Deschamps, A., and Pouliot, D. 2011. Detecting long-term changes to vegetation in northern Canada using the Landsat satellite image archive Environmental Research Letters, 6, 045502 
Frost, G. V., Epstein, H. E., Walker, D. A., Matyshak, G., and Ermokhina, K. 2013. Patterned-ground facilitates shrub expansion in Low Arctic tundra. Environmental Research Letters, 8, 015035.

Frost, G. V. and Epstein, H. E. In review Tall shrub and tree expansion in Siberian tundra ecotones since the 1960s.

Jia, G. J., Epstein, H. E., and Walker, D. A. 2003. Greening of arctic Alaska, 1981-2001. Geophysical Research Letters, 30, 2067.

Leibman, M. O. 1995. Cryogenic landslides on the Yamal Peninsula, Russia: prelimimary observations. Permafrost and Periglacial Processes, 6, 259-264.

Masek, J. G., Vermote, E. F., Saleous, N. E., Wolfe, R., Hall, F. G., Huemmrich, K. F., Gao, F., Kutler, J. and Lim, T.-K. 2006. A Landsat surface reflectance dataset for North America, 1990-2000. IEEE Geoscience and Remote Sensing Letters, 3, 6872

McManus, K. M., Morton, D. C., Masek, J. G., Wang, D., Sexton, J. O., Nagol, J. R., Ropars, P., and Boudreau, S. 2012. Satellite-based evidence for shrub and graminoid tundra expansion in northern Quebec from 1986 to 2010. Global Change Biology, 18, 2313-2323

Myers-Smith, I. H., Forbes, B. C., Wilmking, M., Hallinger, M., Lantz, T. C., Blok, D., Tape, K. D., Macias-Fauria, M., Sass-Klaassen, U., Lévesque, E., et al. 2011. Shrub expansion in tundra ecosystems: dynamics, impacts and research priorities. Environmental Research Letters, 6, 045509. 
Myneni, R. B., Keeling, C. D., Tucker, C. J., Asrar, G., and Nemani, R. R. 1997. Increased plant growth in the northern high latitudes from 1981 to 1991. Nature, 386, 698-702

Raynolds, M. K., Walker, D. A., Verbyla, D., and Munger, C. A. 2013. Patterns of change within a tundra landscape: 22-year Landsat NDVI trends in an area of the northern foothills of the Brooks Range, Alaska. Arctic, Antarctic, and Alpine Research, 45, 249-260

Raynolds, M. K., Walker, D. A., Epstein, H. E., Pinzon, J. E., and Tucker, C. J. 2012. A new estimate of tundra-biome phytomass from trans-Arctic field data and AVHRR NDVI. Remote Sensing Letters, 3, 403-411

Serreze, M. C. and Barry, R. G. 2011. Processes and impacts of Arctic amplification: A research synthesis. Global and Planetary Change, 77, 85-96

Shur, Y., Jorgenson, T., Kanevskiy, M., and Ping, C.-L. 2009. Proceedings of the Ninth International Conference on Permafrost

Tape, K. D., Hallinger, M., Welker, J. M., and Ruess, R. W. 2012. Landscape heterogeneity of shrub expansion in arctic Alaska. Ecosystems, 15, 711-724.

Tucker, C. J. and Sellers, P. J. 1986. Satellite remote sensing of primary production International Journal of Remote Sensing, 16, 1395-1416

Walker, D. A., Epstein, H. E., Raynolds, M. K., Kuss, P., Kopecky, M. A., Frost, G. V., et al. 2012. Environment, vegetation and greenness (NDVI) along the North America and Eurasia Arctic transects Environmental Research Letters, 7, 015504. 
Walker, D. A., Leibman, M. O., Epstein, H. E., Forbes, B. C., Raynolds, M. K., Comiso, J. C., Gubarkov, A. A., Khomutov, A. A., Jia, G. J., et al. 2009a. Spatial and temporal patterns of greenness on the Yamal Peninsula, Russia: interactions of ecological and social factors affecting the Arctic normalized difference vegetation index. Environmental Research Letters, 4, 045004.

Walker, D. A., et al. 2009b. Data Report of the 2008 and 2008 Yamal Expeditions: Nadym, Laborovaya, Vaskiny Dachi, and Kharasavey. Fairbanks, AK: Alaska Geobotany Center, Institute of Arctic Biology, University of Alaska.

Walker, D. A., Epstein, H. E., Romanovsky, V. E., Ping, C. L., Michaelson, G. J., Daanen, R. P., Shur, Y. L., Peterson, R. A., Krantz, W. B., Raynolds, M. K., et al. 2008. Arctic patterned-ground ecosystems: a synthesis of field studies and models along a North American Arctic transect. Journal of Geophysical Research, 113, G03S01.

Walker, D. A., Raynolds, M. K., Daniëls, F. J. A., Einarsson, E., Elvebakk, A., Gould, W. A., Katenin, A. E., Kholod, S. S., Markon, C. J., Melnikov, E. S., et al. 2005. The circumpolar Arctic vegetation map. Journal of Vegetation Science, 16, 267-282. 


\section{Supplemental Figures}
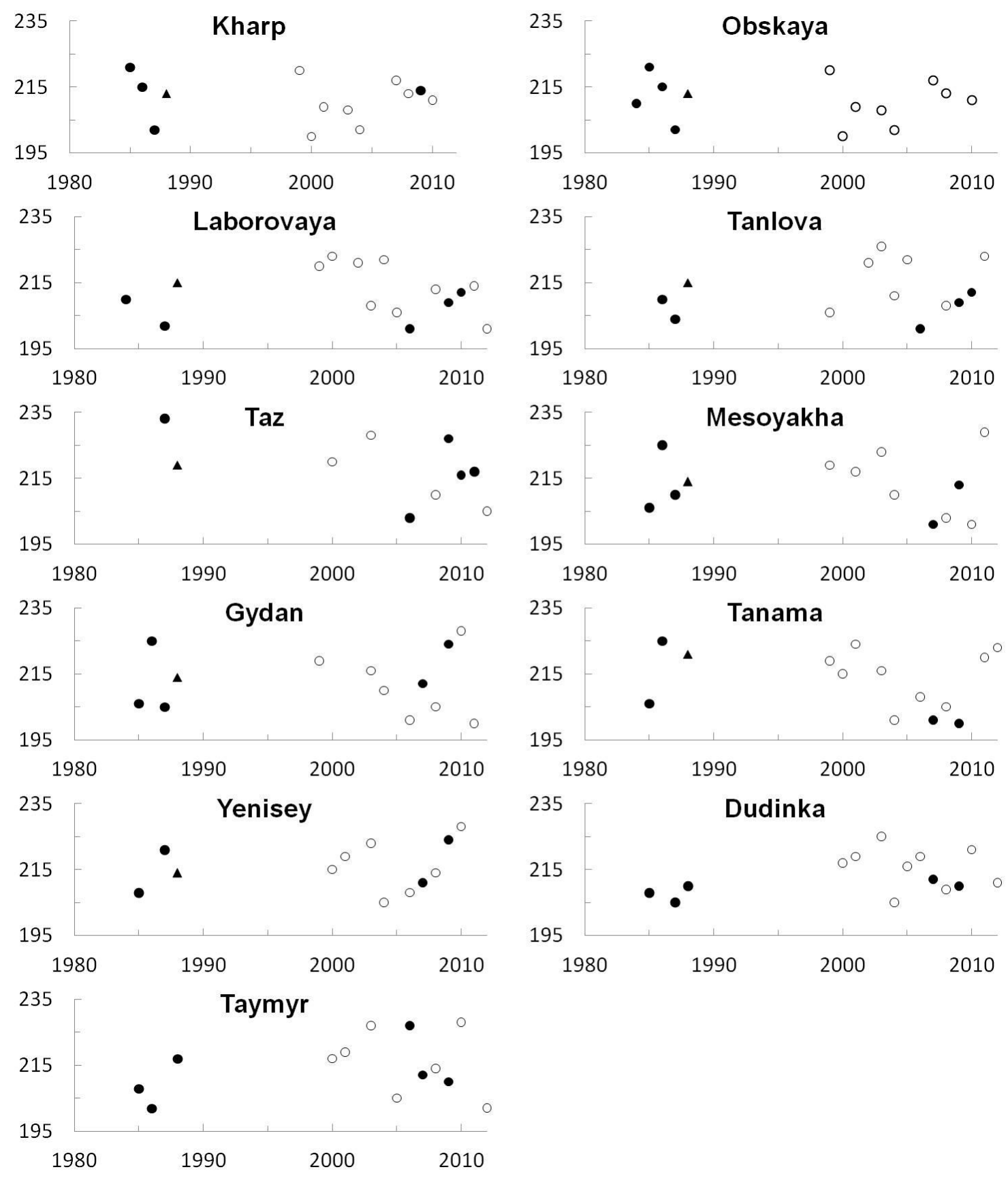

Figure S1. Plots of Julian day of Landsat TM/ETM+ data acquisition (y-axis), by year (x-axis) for the study areas. Open circles are Landsat-7, closed circles are Landsat-5, and closed triangles are Landsat-4. 


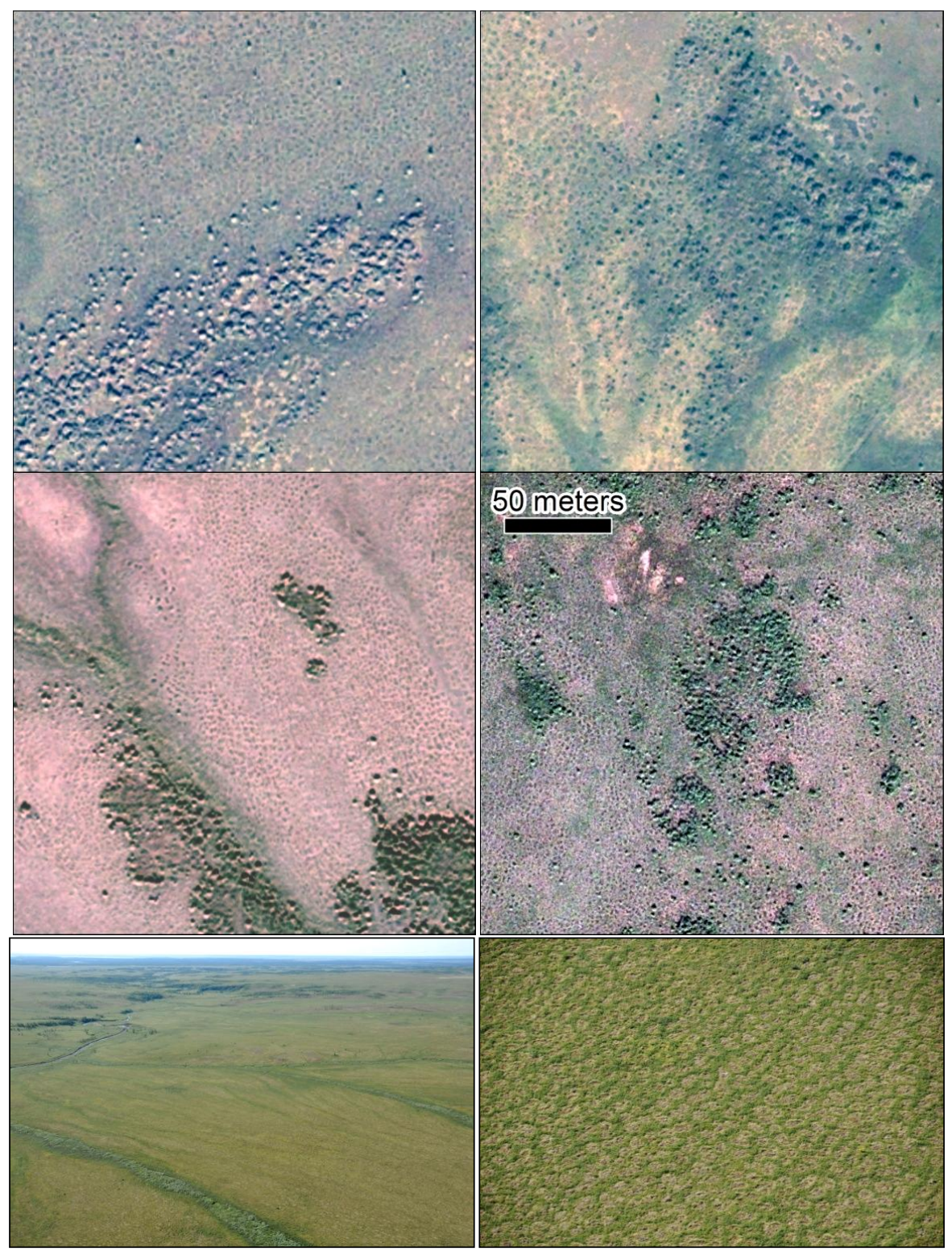

Figure S2. Satellite and aerial photographs showing northwest Siberian patterned-ground landscapes. Obskya site (upper left), Kharp site (upper right), Gy’dan Peninsula (middle left), western Taymyr Peninsula (middle right), and aerial photos near Obskaya site (bottom row). Satellite imagery copyright GeoEye, Inc. and Digital Globe, Inc., provided courtesy of National Geospatial-Intelligence Agency Commercial Imagery Program. 


\section{CHAPTER 5 - SYNTHESIS AND CONCLUSIONS}

In this dissertation, I have evaluated recent changes in the distribution and abundance of tall, canopy-forming shrubs and larch trees in forest-tundra ecotones of the Siberian Low Arctic, a vast region which is experiencing rapid environmental changes but nonetheless remains greatly understudied compared to other parts of the circumpolar Arctic. I employed three general approaches to address questions regarding ecotonal vegetation changes and their causal mechanisms: (1) the direct comparison of satellitebased, very-high-resolution (VHR) imagery dating from the mid-1960s and recent years; (2) field-based studies that identified local-scale geomorphic mechanisms which promote, and constrain the proliferation of tall shrubs in ecotonal environments of the Low Arctic; and (3) time-series analysis of the Normalized Difference Vegetation Index (NDVI), a spectral metric of plant phytomass derived from multi-temporal datasets acquired by the Landsat family of satellites since 1984. Each of these approaches have unique capabilities, and limitations that are largely related to the spatial and temporal scales available for investigation; however, each of these techniques have led to new insights into the response of vegetation in Siberian forest-tundra ecotones to changing environmental

conditions during the latter $20^{\text {th }}$ century. Many of the findings described in this dissertation are also broadly applicable to questions regarding shifts in Low Arctic tundra vegetation at the circumpolar scale. 
Shrub-driven changes in ecotonal land-cover

The vast majority of previous investigations of ecotonal vegetation change in the Siberian Pan-Arctic have applied dendroecological techniques to assess the temporal dynamics of larch growth (e.g., Briffa et al., 1995; Esper and Schweingruber, 2004). By contrast, very little information exists pertaining to the dynamics of tall, boreal shrubs in northern Siberia (but see Blok et al., 2011; Forbes et al., 2010). Several dendroecological studies have inferred that the abundance of larch is increasing at large geographic scales in Siberian forest-tundra, on the basis of stand demographics which indicate recent pulses of tree recruitment in ecotonal environments (e.g., Devi et al., 2008; Esper and Schweingruber, 2004; Shiyatov et al., 2005). One of the key findings presented in Chapter 2 of this dissertation, however, is that the most rapid and extensive changes in ecotonal land-cover have been driven by increases in the abundance of thicket-forming tall shrubs, rather than trees. This finding, established on the basis of spatially-explicit assessments using imagery acquired by earth-observing satellites dating to the early Space Age, suggests that future land-cover changes in the Low Arctic are likely to be driven primarily by changes in the density and extent of shrublands, rather than changes in the position of latitudinal "treelines." Changes in the latitudinal treeline are the focal point of many process-based models that seek to project responses of high-latitude vegetation in a warmer world (ACIA, 2005; Kaplan and New, 2006). Although I also found evidence of increasing larch abundance in most of my study landscapes, the much more extensive increases in shrub abundance that I observed suggest that most current projections of land-cover change and their concomitant effects on landscape system- 
properties do not adequately represent shrub-driven vegetation changes. One implication of this is that prevailing, biome-based perspectives on Arctic terrestrial environmental change, which tend to focus on contrasts between Arctic tundra and boreal forest, may need to be revisited.

Multiple lines of evidence indicate that circumpolar tree distribution in the early and mid-Holocene extended into much more northerly areas than at present (MacDonald et al., 2008, 2000; Payette and Gagnon, 1985). The relatively subtle changes in tree abundance documented in this dissertation, observed during a period of rapid warming that has occurred after nearly a century of gradual warming following the Little Ice Age, prompt the question, why have northern treelines exhibited such little change in recent decades? Mechanisms for large-scale treeline changes in northern Siberia largely hinge on interactions between life-history and genetic properties of boreal trees-primarily the deciduous conifer, larch - and biophysical properties of northern environments, such as soils, climate regime, and disturbance processes, and the degree to which they promote or constrain tree growth and opportunities for the recruitment of new individuals.

Siberian treelines are almost universally formed by the deciduous conifer, larch. Like treeline-forming, boreal conifers of the Nearctic, such as spruce (Picea), larch is highly adapted to environments in which the availability of nutrients is low, the growing season is short, and extremely cold winter temperatures necessitate deep dormancy. Larches exhibit very conservative strategies of resource allocation and growth, such that potential growth rates are very low compared to most tree species in temperate climates. Additionally, newly-established larches generally require several decades of development 
before they begin producing viable seed. A logical consequence of these traits, is that changes in the distribution and abundance of conifers in treeline environments tend to lag changes in climate by many decades, and even centuries (Abaimov et al., 2000; MacDonald et al., 2008).

Tall, thicket-forming shrubs experience the same environmental stressors as larch, but their very different growth form and reproductive strategies enable them to spread much more quickly on the landscape during periods of favorable climate. Of particular significance with respect to land-cover change, is that the multi-stemmed growth habit of shrubs produces an areal footprint that is high both at the individual, and stand-level. By contrast, larches generally form single-stemmed, columnar canopies which overtop little ground area. Additionally, most of the shrub species investigated in this dissertation require only a decade or so to become reproductively active; for example, field studies at the Kharp and Obskaya landscapes revealed many large, fecund alders in areas which lacked shrub cover in 1968 VHR imagery (see Chapter 3). Seeds produced by alder are smaller than those of larch, and can be effectively dispersed across greater distances by wind over hard-packed snow. Additionally, the shrub species implicated in most of the land-cover changes documented in this dissertation-Siberian alder-hosts symbiotic bacteria (Frankia) which fix atmospheric nitrogen. Although nitrogen-fixation generally requires high availability of phosphorus, this symbiotic relationship may largely relieve constraints on growth imposed by the low concentrations of bio-available nitrogen in cold, permafrost-affected soils. Although I did not investigate the role of nitrogen-fixation in facilitating alder proliferation, the virtually ubiquitous correspondence between alder 
establishment, and sparsely-vegetated, mineral-rich substrates-in which nitrogen concentrations are low, and in which phosphorus is presumably not limiting — suggests that alder's ability to exploit atmospheric nitrogen may be a critical factor enabling it to quickly invade mineral-rich microsites. Additionally, given the virtually universal, nitrogen-limited condition of Arctic soils, I suggest that ecosystem nitrogen inputs by alder in tundra environments, for which very little information exists, is likely to be a fruitful area of future research addressing nutrient cycling in a warmer Arctic.

Contrasts in the resource allocation and life-history strategies of larch trees and tall shrubs (primarily alder) summarized above likely account for the disproportionate contribution of tall shrubs to land-cover changes summarized in Chapter 2. One implication of these contrasts, is that while the multi-decadal period-of-record for VHR imagery is likely adequate to capture the response of tall shrubs to recent climatic warming, the response of larch to changes in climate since the 1960s — and perhaps even since the end of the Little Ice Age - is likely only beginning to unfold, and will likely require many more decades to become fully evident. Thus, while I conclude that shrubs have been far more important in driving ecotonal land-cover changes in the recent past, and are likely to continue to dominate land-cover changes in the near term, it is possible that cotemporaneous increases in larch recruitment-which is relatively difficult to observe-could result in striking land-cover changes over longer, centennial timescales. 


\section{Quaternary perspectives on recent vegetation changes}

This dissertation demonstrated that extensive and persistent increases in tall shrubland cover can occur within multi-decadal timescales in Low Arctic ecotones, particularly in landscapes with high availability of mineral-rich substrates. These changes appear likely to continue in many areas even without further climatic warming (see Chapter 3), and are likely to accelerate if the Arctic climate continues to warm. The high likelihood of continued infilling, and northward expansion of tall shrubs and trees raises the question of how contemporary vegetation changes compare to large-scale vegetation shifts that occurred earlier in the Quaternary. For example, Siberian treelines extended much farther north during the early- and mid-Holocene (approximately 3,500 - 9,000 years ago) than they do at present, and the northward migration of trees to the approximate location of the modern Arctic Ocean coast occurred within only a millennium or two of the end of the Pleistocene (MacDonald et al., 2000). The proliferation of conifers and other boreal species in the early Holocene, as well as the development of modern tundra vegetation in areas too cold for tree growth, took place over large geographic areas that were formerly occupied by the "mammoth steppe" biome. The causal mechanisms for the disappearance of mammoth steppe and the spectacular assemblages of large mammals that inhabited it are still debated (e.g., Zimov et al., 1995; Guthrie, 2006); however, once the northward proliferation of trees and woody shrubs began, northern landscapes of the early Holocene appear to have been highly susceptible to rapid changes in vegetation composition and structure. 
One of the primary conclusions of this dissertation, is that the availability of mineral-rich seedbeds is a primary factor promoting shrub-driven changes in land-cover. Stated differently, heavy accumulations of undecomposed surface organic matter-which are generally widespread in modern tundra environments-greatly constrain opportunities for shrub and tree recruitment. Although large amounts of organic carbon from mammoth-steppe vegetation became incorporated into permafrost during the Pleistocene, as in "yedoma" permafrost deposits currently extant in eastern Siberia and Alaska (Zimov et al., 2009), mineral-rich substrates were almost certainly much more widespread in the mammoth steppe than they are in modern tundra landscapes, due to differences in vegetation composition (e.g., Pleistocene dominance of grasses) and a legacy of intense disturbance by large herbivores. Additionally, the widespread, continuous deposition of windborne loess originating from glaciated areas would also have helped to maintain mineral-rich surface soils; these silt-rich soils would likely have been susceptible to differential frost-heave and the development of extensive patternedground geomorphology (see Chapter 3). In contrast, modern tundra soils are typically characterized by a thick surface horizon of undecomposed, and relatively recalcitrant organic material that is largely composed of moss and woody material. The development of these Holocene organic soils has likely placed constraints on tall shrub and tree recruitment that were not nearly as prevalent during the early Holocene. Additionally, the extent of the Arctic Ocean was smaller and most of the northern Eurasian continental shelf was exposed during the early Holocene; as a result, a much larger geographic area was available for the spread of boreal vegetation - both because of the larger landmass, 
and because continental climate regimes could penetrate farther northward than at present. The widespread occurrence of organic-rich, acidic soils, and the relatively high eustatic sea-level of the present-day indicates that future changes in the distribution of tall shrubs and trees in the circumpolar Arctic region-and especially in northern Eurasia, most of which has remained unglaciated for a long period of time-are likely to occur more slowly, and over smaller geographic areas than during earlier periods of the Holocene. 
Future directions

Central to questions regarding environmental change in the Pan-Arctic, are the strong feedbacks that exist between high-latitude land-cover, and the global climate system. Feedback mechanisms include direct effects on the exchange of radiant energy and latent heat between the land surface and the atmosphere, as well as indirect effects on climate related to the storage and potential mobilization of large pools of carbon stored in permafrost soils. The field-based studies undertaken at the Kharp landscape highlighted the importance of permafrost processes in promoting the expansion of tall alder shrublands in tundra ecotones. One unanticipated outcome of these studies, was the opportunity to investigate the impacts of shrub expansion on the physical and thermal properties of permafrost at a site in which the recent spatio-temporal dynamics of shrub extent were known (see Frost et al., 2012). We anticipate that the temporal soil temperature datasets we acquired in shrublands of varying age will be useful in characterizing the impacts of tall shrub expansion on active-layer temperature, disturbance regime, permafrost stability, and carbon balance in Low Arctic patternedground ecosystems.

\section{References}

Abaimov, A. P., Zyryanova, O. A., Prokushkin, S. G., Koike, T., and Matsuura, Y. 2000. Forest ecosystems of the cryolithic zone of Siberia; regional features, mechanisms of stability and pyrogenic changes. Eurasian Journal of Forest Research, 1, 1-10. 
ACIA, 2005. Arctic Climate Impact Assessment. Cambridge University Press, New York, NY.

Blok, D., Sass-Klaassen, U., Schaepman-Strub, G., Heijmans, M. M. P. D., Sauren, P., and Berendse, F. 2011. What are the main climate drivers for shrub growth in Northeastern Siberian tundra? Biogeosciences, 8, 1169-1179.

Briffa, K. R., Jones, P. D., Schweingruber, F. H., Shiyatov, S. G., and Cook, E. R. 1995. Unusual twentieth-century summer warmth in a 1,000-year temperature record from Siberia. Nature, 376, 156-159.

Devi, N., Hagedorn, F., Moiseev, P., Bugmann, H., Shiyatov, S., Mazepa, V., and Rigling, A. 2008. Expanding forests and changing growth forms of Siberian larch at the Polar Urals treeline during the 20th century. Global Change Biology, 14, 15811591.

Esper, J., and Schweingruber, F.H., 2004. Large-scale treeline changes recoroded in Siberia. Geophysical Research Letters, 31, L06202.

Forbes, B. C., Macias-Fauria, and M., Zetterberg, P. 2010. Russian Arctic warming and "greening" are closely tracked by tundra shrub willows. Global Change Biology, 16, 1542-1554.

Frost, G. V., Epstein, H. E., Walker, D. A., Matyshak, G., and Ermokhina, K. 2012. Linkages between patterned ground, alder shrubland development, and active layer temperature in the northwest Siberian Low Arctic. Proceedings of the Tenth International Conference on Permafrost, 1, 119-124. 
Guthrie, R. D. 2006. New carbon dates link climatic change with human colonization and Pleistocene extinctions. Nature, 441, 207-209.

Kaplan, J. O., and New, M. 2006. Arctic climate change with a $2^{\circ} \mathrm{C}$ global warming: timing, climate patterns and vegetation change. Climatic Change, 79, 213-241.

MacDonald, G., Kremenetski, K., and Beilman, D. 2008. Climate change and the northern Russian treeline zone. Philosophical Transactions of the Royal Society Biological Sciences, 363, 2283-2299.

MacDonald, G. M., Velichko, A. A., Kremenetski, C. V., Borisova, O. K., Goleva, A. A., Andreev, A. A., et al. 2000. Holocene treeline history and climate change across northern Eurasia. Quaternary Research, 53, 302-311.

Payette, S., and Gagnon, R. 1985. Late Holocene deforestation and tree regeneration in the forest-tundra of Quebec. Nature, 313, 570-572.

Shiyatov, S. G., Terent'ev, M. M., and Fomin, V. V., 2005. Spatiotemporal dynamics of forest-tundra communities in the Polar Urals. Russian Journal of Ecology, 36, 6975.

Zimov, N. S., Zimov, S. A., Zimova, A. E., Zimova, G. M., Chuprynin, V. I., and Chapin, F. S. 2009. Carbon storage in permafrost and soils of the mammoth-steppe biome: role in the global carbon budget. Geophysical Research Letters, 36, L02502.

Zimov, S. A., Chuprynin, V. I., Oreshko, A. P., Chapin, F. S. III, Reynolds, J. F., and Chapin, M. C. 1995. Steppe-tundra transition: a herbivore-driven biome shift at the end of the Pleistocene. American Naturalist, 146, 765-794. 